Universidade de São Paulo

Escola de Engenharia de São Carlos

Departamento de Hidráulica e Saneamento

Programa de Pós-Graduação em Ciências da Engenharia Ambiental

\title{
Ecologia trófica de espécies alóctones (Cichla cf. ocellaris e Plagioscion squamosissimus) e nativa (Geophagus brasiliensis) nos reservatórios do rio Tietê
}

Patrícia Monte Stefani

Dissertação apresentada à Escola de Engenharia de São Carlos, da Universidade de São Paulo, como parte dos requisitos para obtenção do título de Mestre em Ciências da Engenharia Ambiental.

ORIENTADORA: Profa. Dra. Odete Rocha

São Carlos - SP 
A vida sem medo liberta as nossas melhores faculdades: o olhar limpo, a alegria inocente, 0 assombro espontâneo. $O$ grau em que conseguimos nos

libertar dos nossos medos, será a medida da nossa entrega generosa e confiante à vida. 


\section{Agradecimentos}

- Aos meus pais Edison e Ruth e as minhas irmãs Adriana e Daniela, por todo apoio, incentivo, confiança, palavras de carinho e paciência. Muito obrigada, eu amo vocês!

- A minha orientadora Profa. Dra. Odete Rocha pela credibilidade, orientação, apoio e amizade durante a elaboração desse trabalho.

- A amiga Fernanda T. Marciano pela amizade, incentivo, "orientação", conselhos e toda ajuda durante o desenvolvimento do trabalho. Muito obrigada!

- Aos amigos do DEBE, Ana Lúcia, Roberta, Denise, Fernanda, Renata, Rosana, Kátia, Magno, Paulo, Zezinho, Rafael, Fábio e Fernando, pela amizade, companhia, ajuda, paciência e pelos momentos de descontração (principalmente na hora do café), que tornaram a nossa rotina de laboratório menos cansativa!

- Aos amigos Clayton, Raphael, Paula e Leandro, que me ajudaram MUITO no laboratório. Muito Obrigada!

- Aos técnicos do DEBE (Airton Soares, José Valdecir e Alcídio), sem os quais este trabalho não poderia se realizar.

- Aos amigos do CRHEA, Caroline, Cláudio, Mariano, Eduardo e Gabriel pela amizade e por todos os momentos alegres que passamos juntos.

- A Capes, pela bolsa de estudos concedida.

- Ao Ministério do Meio Ambiente, que através do projeto PROBIO II Monitoramento e desenvolvimento de tecnologias para o manejo de espécies exóticas em águas doces, colaborou para a realização deste trabalho.

- Aos funcionários e colegas do CRHEA (Claudete, Wellington, Achiles e Mara), por todo apoio.

- Aos funcionários e colegas do DEBE (Edna, Malu e Dora), pela boa recepção e apoio!

- As minhas melhores amigas Luciana Bides ("irmã postiça"), Cristiane Eles e Camila Galvão, pela amizade, convivência, carinho, companhia, apoio e por todos os momentos alegres que vivemos juntas. Obrigada Super's! Amo vocês!

- Aos amigos queridos Alexandre Arruda, Igor Araújo, Fabrício Castro e Eduardo Gentile (Dudinha), que sempre estiverem ao meu lado me incentivando e dizendo palavras de carinho. Adoro vocês! 
- A tia Nice por me acolher em São Carlos, pelo apoio e incentivo em todos os momentos de desânimo.

- Aos meus cunhados Alessandro e Maurício, pela amizade, apoio e ajuda durante o mestrado.

- E a todos que de forma direta ou indireta colaboraram para o bom desenvolvimento deste trabalho, Muito Obrigada! 
A elaboração deste trabalho contou com os recursos financeiros do Projeto PROBIO (MMA/CNPq/BIRD/GEF), convênio 952/02 como produto do subprojeto "Monitoramento e Desenvolvimento de Tecnologias para o Manejo de Espécies Exóticas em águas Doces" 


\section{Lista de Tabelas}

Tabela 1: Características gerais do reservatório de Barra Bonita. .................................. 8

Tabela 2: Características gerais do reservatório de Bariri ............................................ 9

Tabela 3: Características gerais do reservatório de Ibitinga. ....................................... 11

Tabela 4: Características gerais do reservatório de Promissão....................................... 12

Tabela 5: Características gerais do reservatório de Nova Avanhandava. ........................ 13

Tabela 6: Características gerais do reservatório de Três Irmãos...................................... 14

Tabela 7: Abundância numérica, volume (\%) e peso seco (\%) dos itens alimentares consumidos por Geophagus brasiliensis, coletados no reservatório de Barra Bonita, amostrados nos meses de novembro de 2002 e novembro de 2003. (n. i. = não identificado).

Tabela 8: Abundância numérica, volume (\%) e peso seco (\%) dos itens alimentares consumidos por Geophagus brasiliensis, consumidos no reservatório de Bariri, amostrados nos meses de fevereiro, maio, setembro e novembro de 2003. (n. i. = não identificado)

Tabela 9: Abundância numérica, volume (\%) e peso seco (\%) dos itens alimentares consumidos por Geophagus brasiliensis, coletados no reservatório de Ibitinga no mês de dezembro de 2002 .

Tabela 10: Abundância numérica, volume (\%) e peso seco (\%) dos itens alimentares consumidos por P. squamosissimus, coletados no reservatório de Barra Bonita, nos meses de novembro de 2002 e novembro de 2003. (n. i. = não identificado). .......29

Tabela 11: Abundância numérica, volume (\%) e peso seco (\%) dos itens alimentares consumidos por P. squamosissimus no reservatório de Bariri, coletados nos meses de fevereiro, junho, setembro e novembro de 2003. (n. i. = não identificado).......32

Tabela 12: Abundância numérica, volume (\%) e peso seco (\%) dos itens alimentares consumidos por $P$. squamosissimus, coletados no reservatório de Ibitinga, nos meses de dezembro de 2002, dezembro de 2003 e fevereiro de 2004.(n. i. = não identificado).

Tabela 13: Abundância numérica, volume (\%) e peso seco (\%) dos itens alimentares consumidos por $P$. squamosissimus no reservatório de Promissão, nos meses de maio e dezembro de 2003. (n. i. = não identificado).

Tabela 14: Abundância numérica, volume (\%) e peso seco (\%) dos itens alimentares consumidos por $P$. squamosissimus no reservatório de Nova Avanhandava, nos meses de dezembro de 2002 e janeiro de 2004. (n. i. = não identificado) ....

Tabela 15: Abundância numérica, volume (\%) e peso seco (\%) dos itens alimentares consumidos por $P$. squamosissimus no reservatório de Três Irmãos, nos meses de dezembro de 2002 e janeiro de 2004. (n. i. = não identificado).

Tabela 16: Precipitação acumulada no mês $(\mathrm{mm})$; volume total do reservatório $\left(\mathrm{m}^{3}\right)$, vazão defluente $\left(\mathrm{m}^{3} / \mathrm{s}\right)$ e tempo de residência (dias) para o reservatório de Bariri durante os meses de fevereiro, junho, setembro e novembro.

Tabela 17: Abundância numérica, volume (\%) e peso seco (\%) dos itens alimentares consumidos por $C$. ocellaris, coletados no reservatório de Bariri, no mês de novembro de 2003.

Tabela 18: Abundância numérica, volume (\%) e peso seco (\%) dos itens alimentares consumidos por $C$. ocellaris, coletados no reservatório de Ibitinga, nos meses de dezembro de 2002 e fevereiro de 2004. (n. i. = não identificado). 
Tabela 19: Abundância numérica, volume (\%) e peso seco (\%) dos itens alimentares consumidos por $C$. ocellaris, coletados no reservatório de Promissão nos meses de maio e dezembro de 2003. (n. i. = não identificado).

Tabela 20: Abundância numérica, volume (\%) e peso seco (\%) dos itens alimentares consumidos por $C$. ocellaris, coletados no reservatório de Nova Avanhandava, nos meses de dezembro de 2002 e janeiro de 2004. (n. i. = não identificado) ...............63

Tabela 21: Abundância numérica, volume (\%) e peso seco (\%) dos itens alimentares consumidos por $C$. ocellaris, coletados no reservatório de Três Irmãos, nos meses de maio de 2003 e janeiro de 2004. (n. i. = não identificado) 


\section{Lista de Figuras}

Figura 1: Localização dos reservatórios do médio e baixo rio Tietê. (Fonte: modificado de São Paulo (Estado) 1982 - Coordenadoria da indústria e comércio: diretrizes para a política de desenvolvimento e desconcentração industrial).

Figura 2: Reservatório de Barra Bonita. Fonte: AES/TIETÊ AS (2006) ........................... 8

Figura 3: Reservatório de Bariri. Fonte: AES/TIETÊ AS (2006) .................................... 9

Figura 4: Reservatório de Ibitinga. Fonte: AES/TIETÊ AS (2006)................................ 10

Figura 5: Reservatório de Promissão. Fonte: AES/TIETÊ AS (2006)............................ 11

Figura 6: Reservatório de Nova Avanhandava. Fonte: AES/TIETÊ AS (2006).............. 12

Figura 7: Reservatório de Três Irmãos. Fonte: CESP (2006) ...................................... 13

Figura 8: Grau de repleção dos estômagos dos acarás ( $G$. brasiliensis) coletados no reservatório de Barra Bonita, nos meses de novembro de 2002 e 2003. ................. 18

Figura 9: Freqüência de ocorrência (\%) dos itens alimentares encontrados no estômagos de Geophagus brasiliensis coletados no reservatório de Barra Bonita, nos meses de novembro de 2002 e 2003. (n.i. = não identificado).

Figura 10: Grau de repleção dos estômagos dos acarás ( $G$. brasiliensis) coletados no reservatório de Bariri nos meses de fevereiro, junho, setembro e novembro de 2003.

Figura 11: Freqüência de ocorrência (\%) dos itens alimentares encontrados nos estômagos de Geophagus brasiliensis, coletados no reservatório de Bariri, nos meses de fevereiro, junho, setembro e novembro de 2003. (n. i.= não identificado)

Figura 12: Grau de repleção dos estômagos dos acarás (G. brasiliensis), coletados no reservatório de Ibitinga no mês de dezembro de 2002 .

Figura 13: Freqüência de ocorrência (\%) dos itens alimentares encontrados nos estômagos dos exemplares de Geophagus brasiliensis, coletados no reservatório de Ibitinga no mês de dezembro de 2002 .

Figura 14: Grau de repleção dos estômagos das corvinas (P. squamosissimus), coletadas no reservatório de Barra Bonita, em novembro de 2002 e novembro de 2003.

Figura 15: Freqüência de ocorrência (\%) dos itens alimentares encontrados no estômago de P. squamosissimus, coletados no reservatório de Barra Bonita, nos meses de novembro de 2002 e novembro de 2003. (n. i.= não identificado).

Figura 16: Grau de repleção dos estômagos das corvinas (P. squamosissimus), coletadas no reservatório de Bariri, nos meses de fevereiro, junho, setembro e novembro de 2003.

Figura 17: Freqüência de ocorrência (\%) dos itens alimentares encontrados no estômago de $P$. squamosissimus, coletados no reservatório de Bariri, nos meses de fevereiro, junho, setembro e novembro de 2003. (n. i. = não identificado)

Figura 18: Grau de repleção dos estômagos das corvinas (P. squamosissimus) coletados, nos meses de dezembro de 2002, dezembro de 2003 e fevereiro de 2004.

Figura 19: Freqüência de ocorrência (\%) dos itens alimentares encontrados nos estômagos de $P$. squamosissimus, coletados no reservatório de Ibitinga, nos meses de dezembro de 2002, dezembro de 2003 e fevereiro de 2004.

Figura 20: Grau de repleção dos estômagos das corvinas (P. squamosissimus), coletadas no reservatório de Promissão, nos meses de maio e dezembro de $2003 .$.

Figura 21: Freqüência de ocorrência (\%) dos itens alimentares encontrados no estômago de P. squamosissimus, coletados no reservatório de Promissão, nos períodos de maio e dezembro de 2003. 
Figura 22: Grau de repleção dos estômagos das corvinas (P. squamosissimus), coletadas no reservatório de Nova Avanhandava, nos meses de dezembro de 2002 e janeiro de 2004.

Figura 23: Freqüência de ocorrência (\%) dos itens alimentares encontrados no estômago de $P$. squamosissimus no reservatório de Nova Avanhandava, nos meses de dezembro de 2002 e janeiro de 2004.

Figura 24: Grau de repleção dos estômagos das corvinas (P. squamosissimus) coletadas, no reservatório de Três Irmãos, nos meses de maio de 2003 e janeiro de 2004 .... 43

Figura 25: Freqüência de ocorrência (\%) dos itens alimentares encontrados nos estômagos de $P$. squamosissimus, coletadas no reservatório de Três Irmãos, nos períodos de maio de 2003 e janeiro de 2004. (n. i. = não identificado).

Figura 26: Freqüência de ocorrência $(\%)$ dos itens alimentares consumidos pela corvina $(P$. squamosissimus), no reservatório de Bariri, Médio Tietê, no mês de fevereiro de 2003. FE $=$ Campsurinae (Fragmento de Ephemeroptera); $\mathrm{MO}=$ Massa de Ovos; FP = Fragmentos de Peixe; $\mathrm{PX}=$ peixe (não identificado); $\mathrm{MV}=$ Material Vegetal; $\mathrm{Pla}=$ Plagioscion squamosissimus; Chi $=$ Pupa de Chironomidae (Diptera); Phy = Phlyllocycla $\mathrm{sp}$ (Ninfa de Odonata); Lib = Libellulidae (Ninfa de Odonata); Ash = Asheum sp (Larva de Diptera); Goe $=$ Goeldichironomus sp (Larva de Diptera); Sil = Siluriformes; Cic $=$ Cichlidae; $\mathrm{DT}=$

Detritos.

Figura 27: Freqüência de ocorrência (\%) dos itens alimentares consumidos pela corvina $(P$. squamosissimus), no reservatório de Bariri, Médio Tietê, no mês de junho de 2003. FP = Fragmentos de Peixe; FE = Fragmentos de Ephemeroptera; MV = Material Vegetal; Coe = Coelotanypus sp (Larva de Diptera); $\mathrm{Cic}=$ Cichlidae; $\mathrm{Chi}=$ Pupa de Chironomidae (Diptera); Tri $=$ Larva de Trichoptera; FO = Fragmentos de Odonata; Phy $=$ Phlyllocycla sp (Ninfa de Odonata); PX = Peixe; Cer = Ceratopogonidae (Larva de Diptera); $\mathrm{Abl}=$ Ablabesmyia sp (Larva de Diptera); Bru $=$ Brundiniella sp (Larva de Diptera); Cry = Cryptochironomus sp (Larva de Diptera); FI = Fragmentos de inseto.

Figura 28: Freqüência de ocorrência (\%) dos itens alimentares consumidos pela corvina (P. squamosissimus), no reservatório de Bariri, Médio Tietê, no mês de setembro de 2003. $\mathrm{MV}=$ Material vegetal; $\mathrm{FE}=$ Fragmentos de Ephemeroptera; $\mathrm{Chi}=$ Pupa de Chironomidae (Diptera); $\mathrm{MO}=$ Massa de ovos; FP = Fragmentos de peixe; $\mathrm{FI}=$ Fragmentos de inseto; Not $=$ Notodiaptomus sp (Copepoda Calanoida); Phy $=$ Phlyllocycla sp (Ninfa de Odonata); Tri = Larva de Trichoptera; Mac $=$ Macrobrachium sp (Camarão); FCC = Fragmentos de Copepoda Calanoida; $\mathrm{Chal}=$ Larva de Chaoborus sp (Diptera); Chap = Pupa de Chaoborus sp (Diptera); Cer = Larva de Ceratopogonidae (Diptera); $\mathrm{PX}=$ Peixe (não identificado)...

Figura 29: Freqüência de ocorrência (\%) dos itens alimentares consumidos pela corvina (P. squamosissimus), no reservatório de Bariri, Médio Tietê, no mês de novembro de 2003. FP $=$ Fragmentos de Peixe; $\mathrm{MV}=$ Material vegetal; Coe $=$ Larva de Coelotanypus sp (Diptera); Abl = Larva de Ablabesmyia sp (Diptera); PX = peixe; $\mathrm{FE}=$ Fragmentos de Ephemeroptera; Cry $=$ Larva de Cryptochironomus $\mathrm{sp}$ (Diptera); $\mathrm{Cic}=$ Cichlidae; FI = Fragmentos de inseto; Har = Larva de Harnischia sp (Diptera); Phy = Phyllocycla $\mathrm{sp}$ (Ninfa de Odonata); Tri = larva de Trichoptera; $\mathrm{Bru}=$ Larva de Brundiniella $\mathrm{sp}$ (Diptera); Cer = Larva de Ceratopogonidae (Diptera); Chi = Pupa de Chironomidae (Diptera); Chap = Pupa de Chaoborus sp (Diptera); Chal $=$ Larva de Chaoborus sp $($ Diptera $) ; \mathrm{MO}=$ Massa de ovos; DT = Detritos.

Figura 30: "Cluster" dos quatro períodos estudados no reservatório de Bariri de acordo com a dieta alimentar de Plagioscion squamosissimus. $(\mathrm{cf}=0,97)$.

Figura 31: Itens alimentares consumidos por Plagioscion squamosissimus no reservatório de Bariri, pelas diferentes classes de tamanho. $\mathrm{FP}=$ Fragmentos de peixe, $\mathrm{PX}=$ peixe, $\mathrm{Pla}=$ 
Plagioscion squamosissimus, $\mathrm{Sil}=$ Siluriformes, $\mathrm{Cic}=$ Cichlidae, $\mathrm{FE}=$ Campsurinae (Fragmentos de Ephemeroptera), MO = massa de ovos, Phy = Phyllocycla sp (ninfa de Odonata), Lib = Libellulidae (ninfa de Odonata), FO = fragmentos de Odonata, Tri = larva de Trichoptera, $\mathrm{FI}=$ fragmentos de inseto, $\mathrm{Chi}=$ pupa de Chironomidae (Díptera), $\mathrm{Goe}=$ Goeldichironomus sp (larva de Diptera), Coe = Coelotanypus sp (larva de Diptera), Cer = Ceratopogonidae (larva de Diptera), $\mathrm{Abl}=$ Ablabesmyia $\mathrm{sp}$ (larva de Diptera), Bru $=$ Brundiniella sp (larva de Diptera), Cry = Cryptochironomus sp (larva de Diptera), Har = Harnischia sp (larva de Díptera), Ash = Asheum sp (larva de Diptera), Chap = pupa de Chaoborus sp (Diptera), Chal = larva de Chaoborus sp (Diptera), FCC $=$ fragmentos de Copepoda Calanoida, Not $=$ Notodiaptomus sp $($ Copepoda Calanoida $), \mathrm{Mac}=$ Machobrachium $\mathrm{sp}$ (Crustacea), $\mathrm{MV}=$ material vegetal, DT $=$ detritos.

Figura 32: Grau de repleção dos estômagos dos tucunarés (C. ocellaris), coletados no reservatório de Bariri no mês de novembro de 2003.

Figura 33: Freqüência de ocorrência (\%) dos itens alimentares encontrados nos estômagos de $C$. ocellaris, coletados no reservatório de Bariri, em novembro de 2003.

Figura 34: Grau de repleção dos estômagos dos tucunarés (C. ocellaris), coletados no reservatório de Ibitinga nos meses de dezembro de 2002 e fevereiro de 2004.......59

Figura 35: Freqüência de ocorrência (\%) dos itens alimentares encontrados nos estômagos de C. ocellaris, coletados no reservatório de Ibitinga, nos meses de dezembro de 2002 e fevereiro de 2004. (n. i. = não identificado).

Figura 36: Grau de repleção dos estômagos dos tucunarés ( $C$. ocellaris) coletados no reservatório de Promissão, nos meses de maio e dezembro de 2003.

Figura 37: Freqüência de ocorrência (\%) dos itens alimentares encontrados nos estômagos de $C$. ocellaris, coletados no reservatório de Promissão, nos meses de maio e dezembro de 2003. (n. i. = não identificado).

Figura 38: Grau de repleção dos estômagos dos tucunarés (C. ocellaris), coletados no reservatório de Nova Avanhandava, nos meses de maio e dezembro de 2003......66 62

Figura 39: Freqüência de ocorrência (\%) dos itens alimentares encontrados nos estômagos de $C$. ocellaris, coletados no reservatório de Nova Avanhandava, nos meses de dezembro de 2002 e janeiro de 2004.

Figura 40: Grau de repleção dos estômagos dos tucunarés (C. ocellaris), coletados no reservatório de Três Irmãos, nos meses de maio de 2003 e janeiro de 2004

Figura 41: Freqüência de ocorrência (\%) dos itens alimentares encontrados nos estômagos dos tucunarés ( $C$. ocellaris), coletados no reservatório de Três Irmãos, nos meses de maio e dezembro de 2003. (n. i. = não identificado). 


\section{Resumo}

STEFANI, PATRICIA, M. (2006). Ecologia trófica de espécies alóctones (Cichla $c f$. ocellaris e Plagioscion squamosissimus) e nativa (Geophagus brasiliensis) nos reservatórios do rio Tietê. São Carlos, 2006. 114 f., Dissertação (mestrado) - Escola de Engenharia de São Carlos, Universidade de São Paulo.

A introdução de espécies nos ecossistemas pode levar a conseqüências difíceis de serem controladas, sendo que a competição por recursos alimentares talvez seja o principal meio pelo qual uma espécie introduzida possa afetar as espécies nativas, podendo ocasionar a extinção. Neste sentido, os estudos de alimentação tornam-se importantes ao fornecerem subsídios para compreender o funcionamento trófico de um ecossistema. Considerando estes aspectos, o objetivo da pesquisa foi conhecer a ecologia trófica das espécies introduzidas (Plagioscion squamosissimus e Cichla cf. ocellaris) e da espécie nativa (Geophagus brasiliensis), avaliando as possíveis interações entre elas. Para o estudo da dieta das espécies escolhidas, foram utilizados os exemplares capturados durante o desenvolvimento do projeto PROBIO 2. As coletas foram realizadas nos seis reservatórios do Médio e Baixo rio Tietê, no período de novembro de 2002 a fevereiro de 2004. Foram realizadas análises quantitativas (freqüência de ocorrência, método volumétrico e método gravimétrico) dos itens encontrados, caracterizando a preferência alimentar das espécies. Neste trabalho o acará (Geophagus brasiliensis), apresentou um hábito alimentar onívoro, consumindo principalmente larvas de Diptera, insetos aquáticos e microcrustáceos. A espécie (Cichla cf. ocellaris) apresentou um hábito alimentar piscívoro, consumindo principalmente peixes e crustáceos. A corvina ( $P$. squamossisimus) foi considerada piscívora, apresentando um amplo espectro alimentar, consumindo principalmente peixes, insetos aquáticos e crustáceos. A ampla distribuição da espécie $P$. squamosissimus nos seis reservatórios do médio e baixo rio Tietê e a plasticidade alimentar evidenciada pela análise de conteúdo estomacal sugerem que a corvina exerce uma forte pressão sobre as espécies nativas, cuja dinâmica populacional pode ser alterada.

Palavras-chaves: espécies introduzidas, ecologia trófica, alimentação de peixes 


\begin{abstract}
STEFANI, PATRICIA, M. (2006). The trophic ecology of allochthonous species (Cichla cf. ocellaris e Plagioscion squamosissimus) is native (Geophagus brasiliensis) from the Tietê River reservoirs. São Carlos, 2006. 114 f., Dissertation (master) - São Carlos Engineering School, University of São Paulo.

The species introduction into the ecosystems may lead to difficult consequences hard to be controlled and the competition for food resources being the main factor by which introduced species can affect the native species, even causing their extinction. In this sense, the feeding studies are important by supplying subsidies to understand the trophic functioning of an ecosystem. Considering these aspects, the objective of this research was to know the trophic ecology of the introduced species Plagioscion squamosissimus and Cichla cf. ocellaris and of the native species (Geophagus brasiliensis), evaluating the possible interactions between them. For the diet study of the chosen species, were used the samples collected during the development of the project PROBIO 2. Sampling was carried out in six reservoirs of the Middle and Low Tietê River, between November 2002 and February 2004. Qualitative analysis was done (occurrence frequency, volumetric method e gravimetric method) on the found items, characterizing the species feeding preference. In this work, the acará (Geophagus brasiliensis) presented an omnivorous feeding habit, mainly consuming Dipteral worms, aquatic insects and micro crustaceans. The species (Cichla cf. ocellaris) presented a piscivorous feeding habit, mainly consuming fishes and crustaceans. The curvina $(P$. squamossisimus) was considered piscivorous, presenting an ample feeding spectrum, mainly consuming fishes, aquatic insects and crustaceans. The ample distribution of the specie P. squamosissimus in the six reservoirs of the Middle and Low Tietê River and the plasticity revealed by the stomach content analysis, suggests that the curvina exercises a strong pressure over the native species, in which population dynamics can be changed.
\end{abstract}

Key words: introduced species, trophic ecology, fish feeding. 


\section{Sumário}

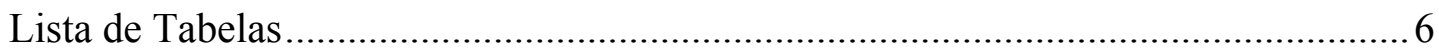

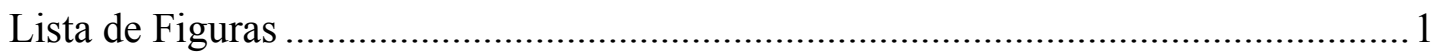

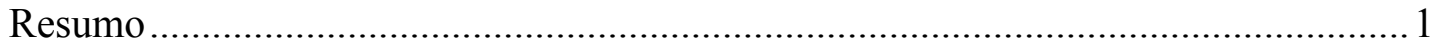

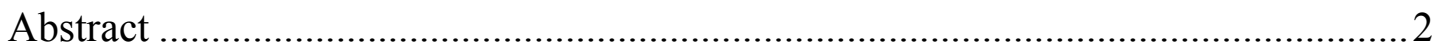

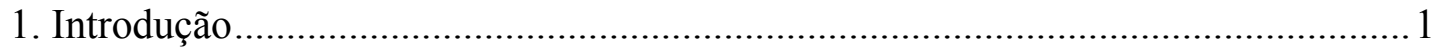

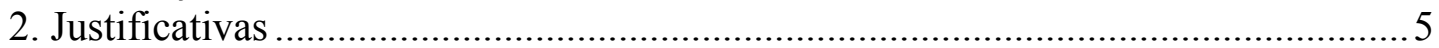

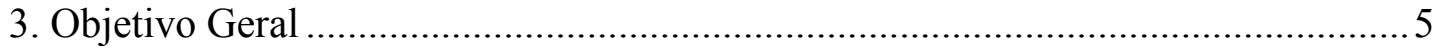

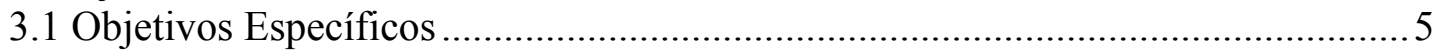

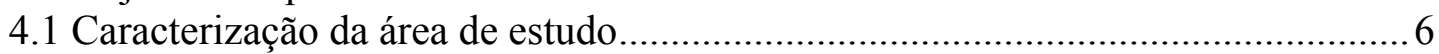

4.1.1 Reservatório de Barra Bonita ...................................................................... 7

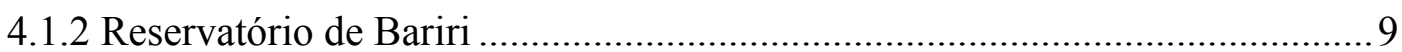

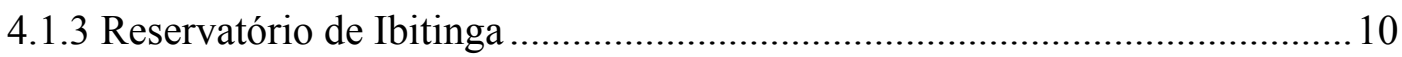

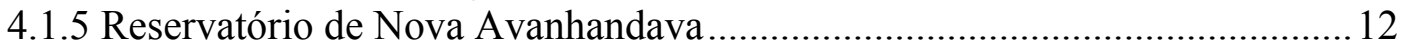

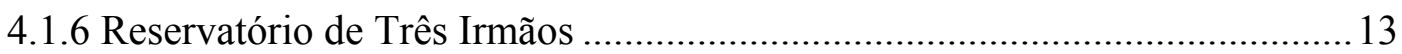

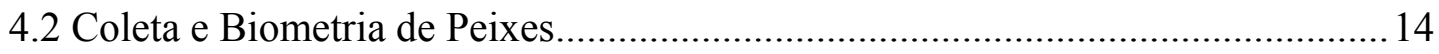

4.3 Extração dos Estômagos e Análise dos Conteúdos Estomacais........................... 15

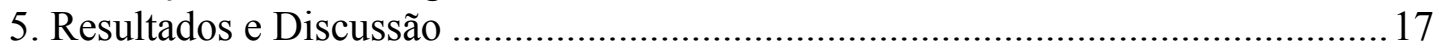

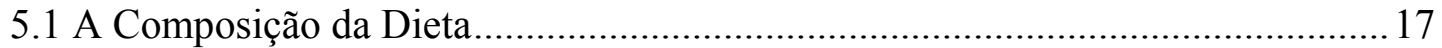

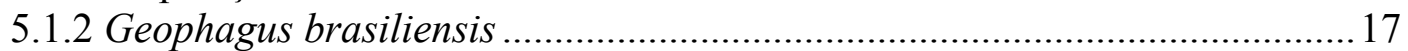

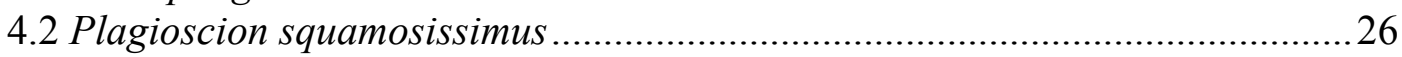

4.2.1 Variação Temporal na dieta de Plagioscion squamosissimus no Reservatório de

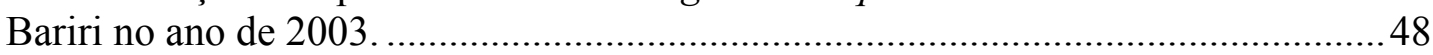

4.2.2 Variação Ontogenética na alimentação de Plagioscion squamosissimus no

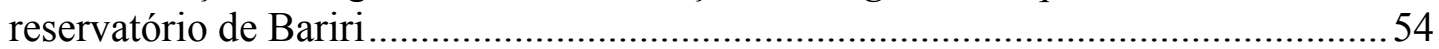

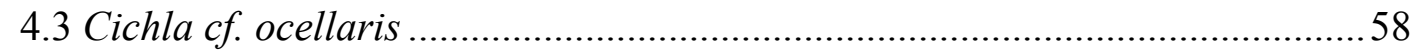

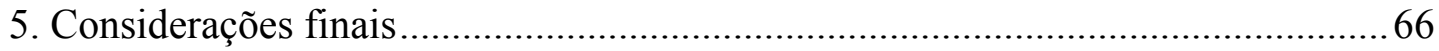

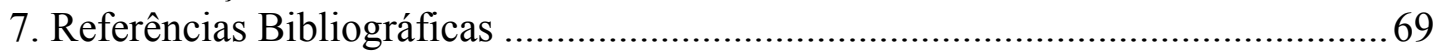

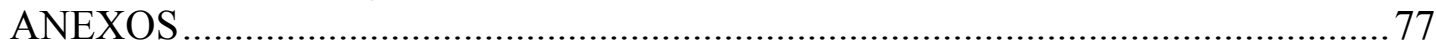

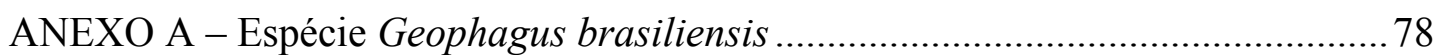

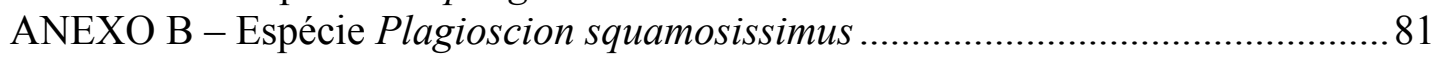

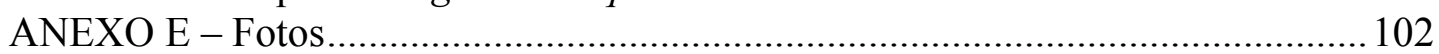




\section{Introdução}

A colonização do ambiente natural pelo homem, em praticamente todos os casos, leva à introdução de organismos animais e vegetais, seja de forma intencional ou acidental. As introduções biológicas têm sido consideradas uma ameaça à biodiversidade global (ESPINDOLA et al., 2003), uma vez que representam a inserção de um elemento totalmente novo na fauna de uma região (AGOSTINHO et al., 1994).

Em ambos os casos, freqüentemente, o ato da introdução é seguido da extinção total ou parcial de espécies nativas, modificações relevantes nas cadeias tróficas e no balanço populacional das comunidades e alterações nos processos funcionais dos ecossistemas (ESPÍNDOLA et al., 2003; ROCHA et al. 2005).

As águas doces são ambientes particularmente sujeitos às invasões biológicas, porque a dispersão é facilitada pelo próprio fluxo da água (ESPINDOLA et al., 2003). Dentre os vertebrados, o grupo de peixes tem se destacado com relação à introdução de espécies exóticas, com graves conseqüências em diferentes partes do mundo (ZARET \& PAINE, 1973).

Introduções de peixes ocorrem desde a Idade Média (AGOSTINHO et al., 1994). As primeiras introduções foram realizadas por chineses e romanos há mais de 4000 anos (AGOSTINHO \& JULIO Jr, 1996). Essa atividade foi mais intensa entre 1950 e 1985 (WELCOMME, 1988). A região Neotropical (América do Sul e Central), que contém a maior diversidade de peixes do planeta, sofreu um maior número de introduções exóticas $(25,3 \%$ do total), a maioria delas realizada com o objetivo de fornecer alternativas à piscicultura (WELCOMME, 1988).

A carpa comum (Cyprinus carpio), pioneira nas introduções, teve o auge de dispersão mundial e cultivo entre 1910 e 1940, sendo substituída pelas tilápias (Oreochromis niloticus e Tilapia rendalli) nas décadas de 50 a 70 (WELCOMME, 1988).

No Brasil, a introdução de espécies teve início com a carpa, no final do século XIX, e com a truta arco-íris (Salmo gairdneri) no início do século XX (WELCOMME, 1988). A maioria das introduções ocorreu entre as décadas de 1960 e 1970, com declínio a partir de 1980 (WELCOMME, 1988). AGOSTINHO et al. (1994) e AGOSTINHO et al. (1996) confirmam que à maioria das introduções de espécies alóctones foram realizadas após a década de 60, alcançando o máximo a partir de 1970, impulsionadas pela construção de reservatórios. $\mathrm{Na}$ maioria dos casos as introduções 
foram realizadas pelas próprias empresas do setor elétrico, visando incrementar a pesca como uma forma de compensação a diminuição desta no rio a jusante em conseqüência do barramento (SMITH et al., 2005), e também para favorecer os usos múltiplos do reservatório com desenvolvimento do turismo, além de utilizar recursos e habitats disponíveis, pela utilização de formas forrageiras, ou ainda como forma de controlar o desenvolvimento indesejável de outros organismos (AGOSTINHO et al., 1994).

Nos reservatórios do Médio e Baixo Rio Tietê (SMITH et al., 2005), o primeiro registro de introdução de espécie alóctone se refere à espécie amazônica Astronotus ocellatus (apaiari) introduzida em 1938, na região Nordeste, e em seguida no Sudeste

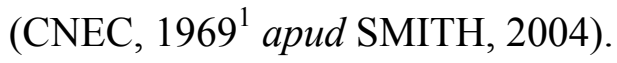

Existe registro da introdução da corvina, Plagioscion squamosissimus, trazida em 1966 para o Estado de São Paulo pela Companhia Energética de São Paulo (CESP), inicialmente no rio Pardo e em seguida invadindo o rio Grande, o rio Paraná, os reservatórios de Ilha Solteira e Jupiá e posteriormente colonizando o rio Tietê (BRAGA, 1998; AGOSTINHO \& JÚLIO Jr, 1999). Em seguida, vieram os tucunarés (Cichla ocellaris e Cichla monoculus), a sardinha (Triportheus signatus), o trairão (Hoplias lacerdae), o tambaqui (Colossoma macropomum), e diversas outras (SMITH et al., 2005).

De acordo com WELCOMME (1988) a principal via de introdução e dispersão de espécies exóticas é a aqüicultura. Esse mesmo autor estimou que 41\% das 273 espécies que atravessaram fronteiras alcançaram os novos ambientes por esta via, sendo importadas para fins experimentais (sobrevivência e crescimento) ou para atividade econômica. $\mathrm{Na}$ piscicultura intensiva as espécies podem alcançar os corpos de água naturais por meio de: a) escapes pela água efluente dos tanques; b) acidentes por rompimento ou transbordamento dos tanques; c) soltura deliberada de indivíduos remanescentes nos tanques durante seu esvaziamento e d) descartes resultantes das atividades de manejo dos tanques (AGOSTINHO et al., 1994).

Os pesque-pagues e a piscicultura em tanques-rede são modalidades de piscicultura que apresentam grande potencial para a dispersão e a instalação de espécies alienígenas nos cursos de água naturais (AGOSTINHO et al., 1994).

\footnotetext{
${ }^{1}$ CONSÓRCIO NACIONAL DE ENGENHEIROS CONSULTORES (CNEC). O barramento dos rios e a fauna ictiológica, SP, 122 p. 1969.
} 
A estocagem direta de espécies exóticas ou alóctones em cursos d' água ou reservatórios também constitui um importante mecanismo de dispersão de peixes para novas áreas. Este procedimento foi empregado pelos órgãos de fomento à pesca e pelo setor elétrico brasileiro. Entre as espécies introduzidas dessa forma, e registradas em ambientes naturais da bacia do rio Paraná, destacam-se os tucunarés (pesca esportiva e controle de piranhas e tilápias), tilápias (pesca e forragem), o "black-bass" (pesca esportiva), a sardinha (forragem) e a corvina (pesca) (AGOSTINHO et al., 1994).

A aquariofilia é também considerada como uma das responsáveis pela introdução de espécies (WELCOMME, 1988). Esse autor estima em 16\% a participação desta atividade no número total de espécies introduzidas no planeta.

Uma outra fonte de introduções é o uso de iscas vivas na pesca esportiva, não apenas pelo escape dos anzóis, mas principalmente pela soltura deliberada das iscas remanescentes após a pesca (AGOSTINHO et al., 1994).

A introdução de espécies em um ecossistema pode acarretar conseqüências difíceis de serem avaliadas (BRAGA, 1998). As espécies introduzidas possuem maior tolerância às condições ambientais, sendo consideradas espécies rústicas e de rápido crescimento, tendo vantagens competitivas em relação às espécies nativas (ESPINDOLA et al., 2003). Alguns organismos introduzidos hibridizam-se com espécies nativas proximamente relacionadas competem por alimento ou por locais de reprodução, ou introduzem doenças (patógenos e parasitas) (ROCHA et al., 2005).

Além disso, as introduções de peixes podem resultar, dependendo do tipo de espécies escolhidas, na redução dos estoques das espécies nativas ou mesmo suas extinções locais, em decorrência das alterações no habitat hospedeiro, pressões de competição, predação, nanismo e degradação genética do estoque hospedeiro (AGOSTINHO et al., 1994).

A competição por recursos alimentares é, talvez, o principal meio pelo qual uma espécie de peixe introduzida afeta as espécies nativas (AGOSTINHO et al., 1994). Sendo assim, os estudos sobre alimentação de peixes são muito importantes por fornecerem subsídios para compreender o funcionamento trófico de um ecossistema, ou seja, o conjunto de relações do tipo predação e competição entre os organismos (RIBEIRO-FILHO, 1999).

A partir do conhecimento da dieta dos peixes de uma comunidade e da abundância específica dos itens consumidos as diferentes categorias tróficas podem ser identificadas, e o grau de importância dos diferentes níveis tróficos no funcionamento 
do sistema determinado, sendo possível entender melhor algumas inter-relações entre os componentes da comunidade (AGOSTINHO et al., 1997). Estudos de ecologia trófica têm revelado uma considerável versatilidade alimentar para a maioria dos teleósteos (ABELHA et al., 2001). A maioria dos peixes pode mudar de um alimento para outro tão logo ocorram alterações na abundância relativa do recurso alimentar em uso (HAHN et al., 1997; AGOSTINHO e JULIO JR., 1999; WOOTON, 1999), inserindo a perspectiva de que a dieta reflete a disponibilidade de alimento no ambiente (WOOTON, 1999).

Alterações na dieta de peixes podem ser regidas por modificações espaciais e sazonais do hábitat, se levado em conta que locais e períodos distintos dispõem de diferentes condições abióticas e de ofertas de alimento (ABELHA et al., 2001).

O estudo da dieta através da análise do conteúdo estomacal apresenta muitos problemas, entre eles o reconhecimento dos organismos que foram ingeridos e sua quantificação (HYNES, 1950). Estes problemas se devem à grande diversidade de itens consumidos pela maior parte das espécies de peixes, além da fragmentação e dos diferentes estágios de digestão dos mesmos.

Além disso, as relações alimentares entre as espécies de peixes variam grandemente de um lugar para outro. Isto ocorre pela falta de espécies especialistas, o que dificulta na identificação dos itens alimentares consumidos e também devido à grande diversidade das condições ambientais (UIEDA, 1995).

Em estudos de ecologia trófica, além das informações sobre a dieta, devem ser levadas em consideração também às características do ambiente e as informações sobre o comportamento de forrageamento das espécies (UIEDA, 1995).

Desta forma, o estudo sobre os hábitos alimentares das espécies introduzidas (Plagioscion squamosissimus e Cichla cf. monoculus) e da espécie nativa (Geophagus brasiliensis) permite conhecer exatamente qual o recurso está sendo utilizado pelas diferentes espécies de peixes e, portanto a intensidade real de competição entre as mesmas. Esses estudos são de suma importância para uma avaliação do estado atual da comunidade e para a elaboração de planos de manejo, uma vez que estes ambientes são muito vulneráveis às invasões biológicas. 


\section{Justificativas}

A escolha da espécie nativa Geophagus brasiliensis, para esse trabalho baseouse na sua ampla distribuição e abundância nos reservatórios do Médio e Baixo rio Tietê.

As espécis introduzidas Plagioscion squamosissimus e Cichla cf. monoculus foram escolhias para esse estudo por serem dentre as espécies introduzidas, as que se encontram melhor estabelecidas nos reservatórios do Médio e Baixo rio Tietê e por serem espécies alvo do projeto PROBIO 2 (Projeto monitoramento e desenvolvimento de tecnologias para o manejo de espécies exóticas em águas doces, financiado pelo MMA/CNPq/BIRD/GEF), ao qual este trabalho esteve vinculado.

\section{Objetivo Geral}

Conhecer a ecologia trófica das espécies alóctones Plagioscion squamosissimus (Corvina) e Cichla cf. ocellaris (Tucunaré), introduzidas na bacia do rio Tietê, e da espécie nativa Geophagus brasiliensis (Acará), visando inferir sobre as possíveis interações biológicas entre estas.

\subsection{Objetivos Específicos}

a) Identificar até o menor nível taxonômico possível os itens alimentares consumidos pelas espécies de peixes selecionadas.

b) Examinar os itens alimentares ingeridos pelas espécies selecionadas, determinando sua importância relativa para estas, no ambiente natural.

c) Determinar a existência de mudanças sazonais no hábito alimentar da espécie Plagioscion squamosissimus, em função das mudanças ambientais, no reservatório de Bariri.

d) Caracterizar as mudanças ontológicas no hábito alimentar da espécie Plagioscion squamosissimus, no reservatório de Bariri. 


\section{Material e Métodos}

\subsection{Caracterização da área de estudo}

O rio Tietê atravessa praticamente todo o território paulista, desde a Serra do Mar até o rio Paraná. Seu comprimento total é de 1,15 mil km e o grande desnível de seu curso tem sido aproveitado para a construção de várias barragens destinadas à produção de energia elétrica. É considerado, atualmente, um rio navegável nos trechos de Barra Bonita (443 km) e de Nova Avanhandava e no trecho da barragem de Jupiá, no rio Paraná $(40 \mathrm{~km})$. O rio Tietê é dividido em quatro trechos: Alto Tietê, Médio Tietê Superior, Médio Tietê Inferior e Baixo Tietê (SMITH et al., 2002) (Figura 1).

A Bacia do Tietê Médio Superior tem uma área de drenagem de $7.070 \mathrm{~km}^{2}$, englobando 15 municípios, os rios Piracicaba e Tietê e o primeiro reservatório do sistema: Barra Bonita (SMITH et al., 2002; ESPINDOLA et al., 2003).

A Bacia do Tietê Médio Inferior tem uma área de drenagem de $23.700 \mathrm{~km}^{2}$, com 65 municípios e três reservatórios: Ibitinga, Bariri e Promissão. A Bacia do Baixo Tietê Inferior tem uma área de drenagem de $13.655 \mathrm{Km}^{2}$, com 32 municípios e inclui os dois últimos reservatórios do sistema: Nova Avanhandava e Três Irmãos (SMITH et al., 2002; ESPINDOLA et al., 2003). Esses reservatórios foram construídos para atender à crescente demanda energética da região, que possui a maior densidade demográfica do país, 2.300 indústrias e uma parcela acrescida para suprir a irrigação, a criação de gado e outros usos como navegação, recreação e suprimento de água (BARBOSA et al., 1999).

Em geral, toda a área de estudo é caracterizada pela ausência de vegetação nativa e mata ciliar, sendo os recursos hídricos destinados à geração de energia elétrica, embora incluam outros usos, como o abastecimento público, recepção de efluentes domésticos e industriais, irrigação, a navegação e lazer (ESPINDOLA et al., 2003). 

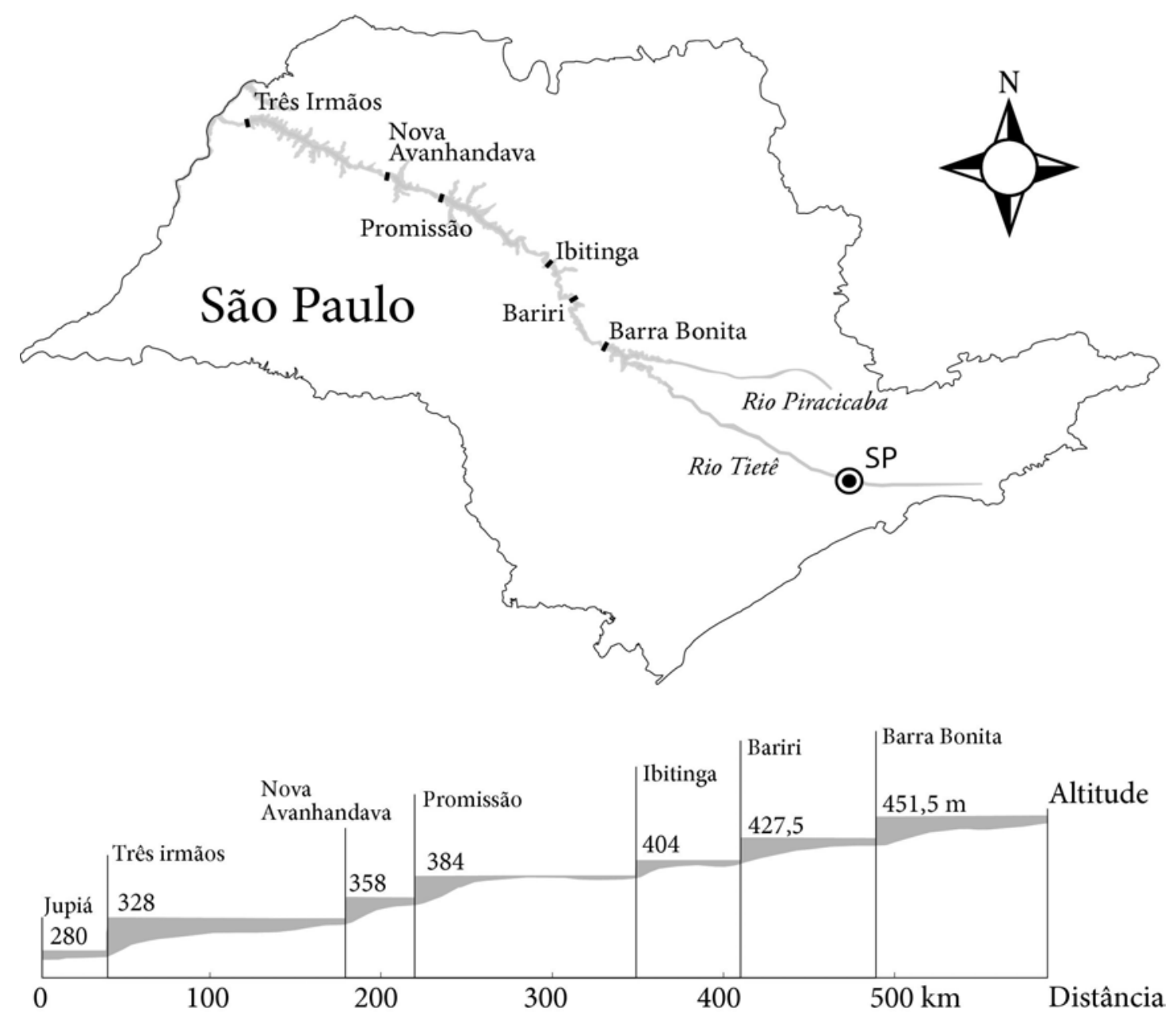

Figura 1: Localização dos reservatórios do médio e baixo rio Tietê. (Fonte: modificado de São Paulo (Estado) 1982 - Coordenadoria da indústria e comércio: diretrizes para a política de desenvolvimento e desconcentração industrial).

\subsubsection{Reservatório de Barra Bonita}

O reservatório de Barra Bonita (Figura 2) representa o primeiro grande aproveitamento hidrelétrico da CESP, formado em 1963, a partir do represamento realizado à jusante do encontro dos rios Piracicaba e Tietê e seus rios tributários (CESP, 1998; AES/TIETÊ AS, 2006). O reservatório localiza-se entre os municípios de Barra Bonita (margem direita) e Igaraçu (margem esquerda), entre as coordenadas $22^{\circ} 90^{\prime} \mathrm{S}$ e $48^{\circ} 34^{\prime} \mathrm{W}$, a $430 \mathrm{~m}$ de altitude. Por ser o primeiro grande represamento de águas, reflete o processo de toda a área de captação, a qual conta com uma população de 23 milhões de habitantes em áreas urbanizadas, incluindo a região metropolitana de São Paulo e as cidades de Campinas e Sorocaba. 


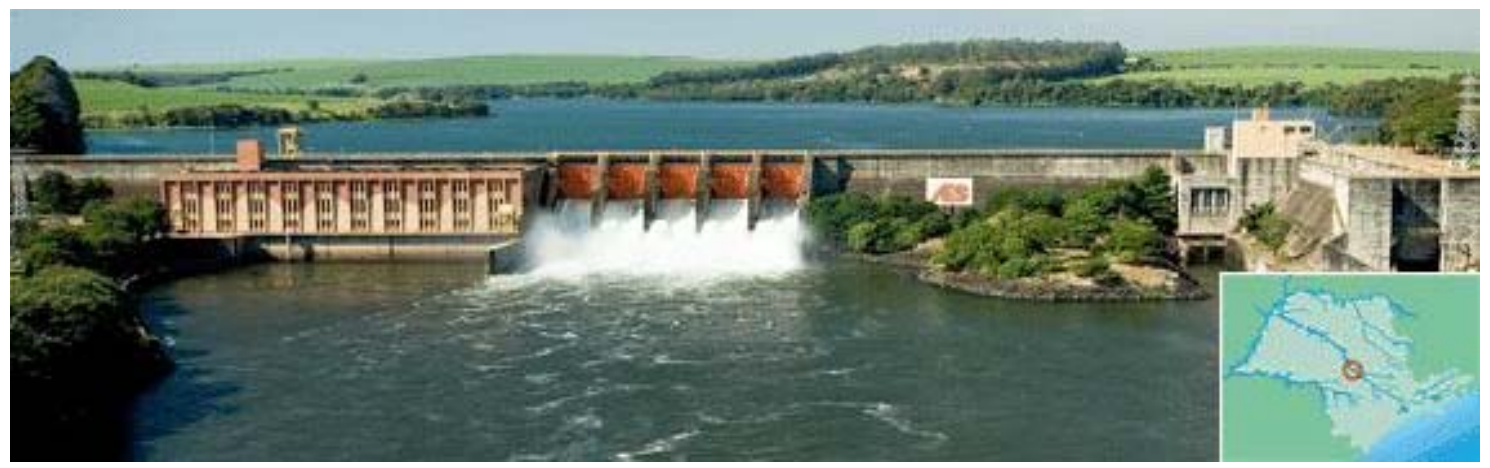

Figura 2: Reservatório de Barra Bonita. Fonte: AES/TIETÊ AS (2006)

A sua barragem possui 480 metros de comprimento e foi concluída em 1964. A área de inundação do reservatório é de 31.000 ha e o tempo de residência da água é de 37 a 137 dias (Tabela 1).

Tabela 1: Características gerais do reservatório de Barra Bonita.

\begin{tabular}{cc}
\hline \multicolumn{2}{c}{ Características } \\
\hline Área alagada $(\mathrm{ha})$ & 31.000 \\
Área de drenagem $\left(\mathrm{km}^{2}\right)$ & 32.330 \\
Vazão média anual $\left(\mathrm{m}^{3} / \mathrm{s}\right)$ & 402 \\
Tempo de residência $($ dias $)$ & 90.3 \\
Volume total $\left(10^{6} \mathrm{~m}^{3}\right)$ & 3.135 \\
Volume útil $\left(10^{6} \mathrm{~m}^{3}\right)$ & 2.566 \\
Perímetro $(\mathrm{km})$ & 525 \\
Profundidade média $(\mathrm{m})$ & 10.2 \\
Profundidade máxima (m) & 30.2 \\
Ano do enchimento & 1964 \\
\hline Fonte: CESP (1998), CETESB (2001), AES/TIETÊ AS (2006)
\end{tabular}

Nas áreas urbanas da bacia em que o reservatório está inserido, se concentram mais de 400.000 habitantes e na zona rural cultiva-se principalmente cana-de-açúcar, café, citrus, hortaliças e frutas, além de existirem algumas áreas de reflorestamento. De acordo com a CETESB (2001), existem aproximadamente 1.020 indústrias nesta bacia, destacando-se as indústrias têxteis, alimentícias, de papel e papelão, abatedouros, engenhos e usinas de açúcar e álcool.

Na região ocorre também à extração de areia para a construção civil e para fins industriais, argila, brita e calcário. A maior parte das extrações de areia é feita diretamente no leito dos cursos d' água, através da dragagem direta, e em menor escala, 
nas planícies aluviais (PEREIRA, 2003). A água do reservatório é utilizada para a geração de energia elétrica, navegação e turismo.

\subsubsection{Reservatório de Bariri}

A represa de Bariri (Figura 3) foi formada pelo barramento do trecho médio do rio Tietê, em 1965, sendo este o segundo reservatório do sistema em cascata. Está localizada entre as coordenadas $22^{\circ} 06^{\prime} \mathrm{S}$ e $48^{\circ} 45^{\prime} \mathrm{W}$ e a uma altitude de $420 \mathrm{~m}$ (CESP, 1998).

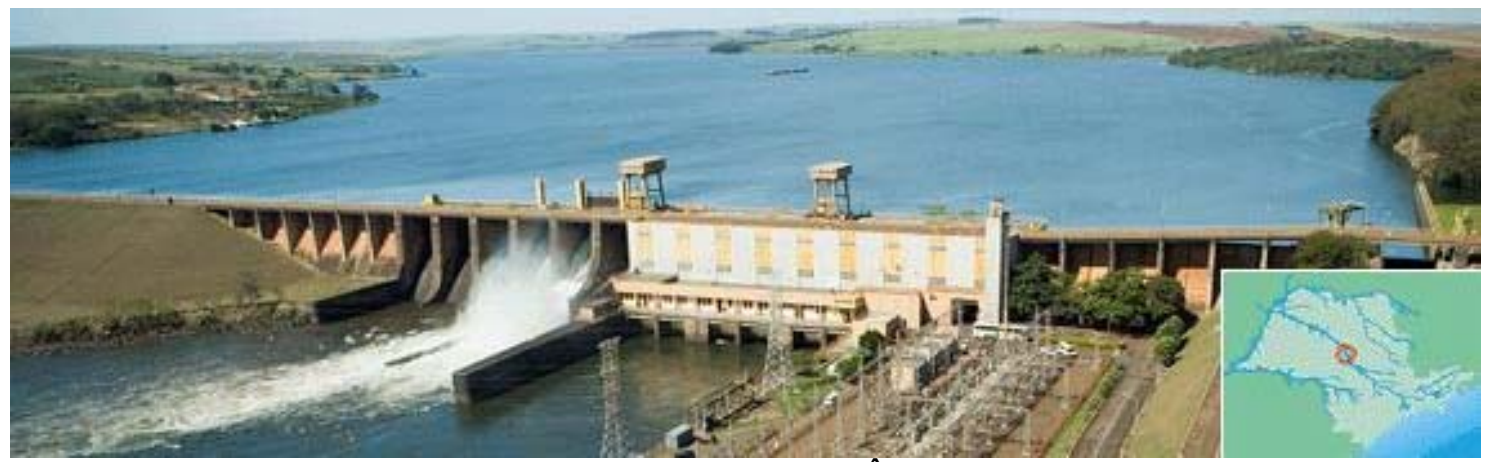

Figura 3: Reservatório de Bariri. Fonte: AES/TIETÊ AS (2006)

O reservatório apresenta uma área de drenagem $35.439 \mathrm{~km}^{2}$ de área de drenagem que estão integrados à bacia do Paraná e em seguida à Bacia do Prata. O tempo de residência da água é de 7 a 24 dias, a vazão média anual é aproximadamente de 443 $\mathrm{m}^{3} / \mathrm{s}$ e a profundidade média do lago é 6,8 metros (Tabela 2). A represa está localizada na região centro-oeste do Estado de São Paulo, entre os municípios de Bariri e Boracéia. Sua barragem de 856,25m foi construída em 1969 (FRACÁCIO, 2001).

Tabela 2: Características gerais do reservatório de Bariri

\begin{tabular}{cc}
\hline \multicolumn{2}{c}{ Características } \\
\hline Área alagada $(\mathrm{ha})$ & 5.546 \\
Área de drenagem $\left(\mathrm{km}^{2}\right)$ & 35.439 \\
Vazão média anual $\left(\mathrm{m}^{3} / \mathrm{s}\right)$ & 443 \\
Tempo de residência $($ dias $)$ & $7 \mathrm{a} 24$ \\
Volume total $\left(10^{6} \mathrm{~m}^{3}\right)$ & 542 \\
Volume útil $\left(10^{6} \mathrm{~m}^{3}\right)$ & 60 \\
Perímetro $(\mathrm{km})$ & 193 \\
Profundidade média $(\mathrm{m})$ & 8,6 \\
Profundidade máxima $(\mathrm{m})$ & - \\
Ano do enchimento & 1969 \\
\hline
\end{tabular}

Fonte: CESP (1998), AES/TIETÊ AS (2006) 
Esse reservatório está localizado a jusante da Usina de Barra Bonita e a montante da barragem de Ibitinga, tendo como afluentes principais os rios Lençóis, Jaú, Bauru e Ribeirão Grande (CESP, 1998).

A água chega ao reservatório principalmente pela vazão turbinada da barragem de Barra Bonita que, nos períodos quentes, exporta água com baixas concentrações de oxigênio dissolvido e elevados valores de material orgânico, influenciando no estado trófico do reservatório a jusante (CESP, 1998).

A cobertura vegetal encontrada na área é composta de cerrados, cerradões, várzeas, capoeira e matas, e os solos são destinados às atividades urbanas, industriais e agropecuárias, com grandes áreas de pastagem e de monocultura da cana-de-açúcar, café, milho e citrus (PEREIRA, 2003). A água do reservatório é utilizada para a geração de energia elétrica, irrigação, transporte hidroviário e turismo.

\subsubsection{Reservatório de Ibitinga}

O reservatório de Ibitinga (Figura 4) é o terceiro reservatório da série e está localizado a jusante da barragem de Bariri e a montante do reservatório de Promissão, entre as coordenadas $21^{\circ} 45^{\prime} \mathrm{S}$ de latitude e $48^{\circ} 59^{\prime} \mathrm{W}$ de longitude.

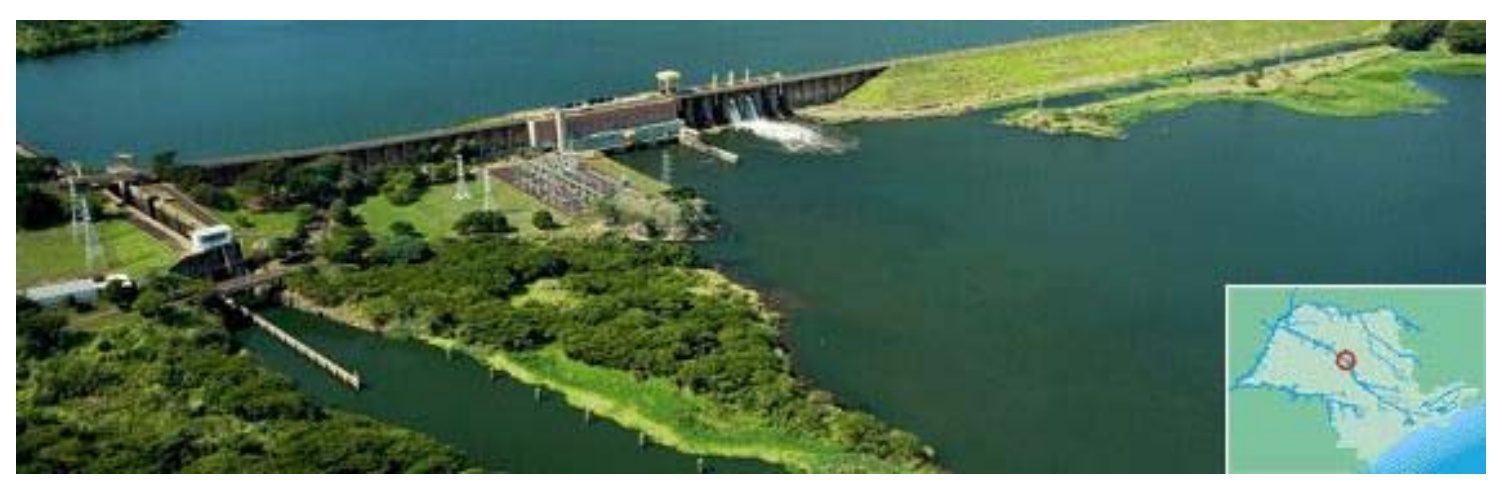

Figura 4: Reservatório de Ibitinga. Fonte: AES/TIETÊ AS (2006).

Esse reservatório possui uma área alagada de 12.216 ha e uma área de drenagem de $43.500 \mathrm{~km}^{2}$ (Tabela 3), tendo como afluentes principais os rios Jacaré-Pepira e Jacaré-Guaçu (CESP, 1998). 
Tabela 3: Características gerais do reservatório de Ibitinga.

\begin{tabular}{cc}
\hline \multicolumn{2}{c}{ Características } \\
\hline Área alagada $(\mathrm{ha})$ & 12.216 \\
Área de drenagem $\left(\mathrm{km}^{2}\right)$ & 43.500 \\
Vazão média anual $\left(\mathrm{m}^{3} / \mathrm{s}\right)$ & 525 \\
Tempo de residência $($ dias $)$ & $12 \mathrm{a} 43$ \\
Volume total $\left(10^{6} \mathrm{~m}^{3}\right)$ & 981 \\
Volume útil $\left(10^{6} \mathrm{~m}^{3}\right)$ & 56 \\
Perímetro $(\mathrm{km})$ & - \\
Profundidade média $(\mathrm{m})$ & 8,6 \\
Profundidade máxima $(\mathrm{m})$ & - \\
Ano do enchimento & 1969 \\
\hline
\end{tabular}

Fonte: CESP (1998), AES/TIETÊ AS (2006)

Sua área de entorno é caracterizada pelo predomínio de pastagens, com poucas áreas de capoeira e reflorestamento e intensas zonas de cultivos de cana-de-açúcar e citricultura. As atividades industriais principais são as usinas de açúcar e álcool, engenhos, curtumes, indústrias alimentícias e metal (CETESB, 2001).

\subsubsection{Reservatório de Promissão}

O reservatório de Promissão (Figura 5) é o quarto reservatório do sistema em cascata do Médio e Baixo rio Tietê. Construído em 1974, está localizado entre as coordenadas $21^{\circ} 17^{\prime} \mathrm{S}$ de latitude e $49^{\circ}$ e $47^{\prime} \mathrm{W}$ de longitude (CESP, 1998).

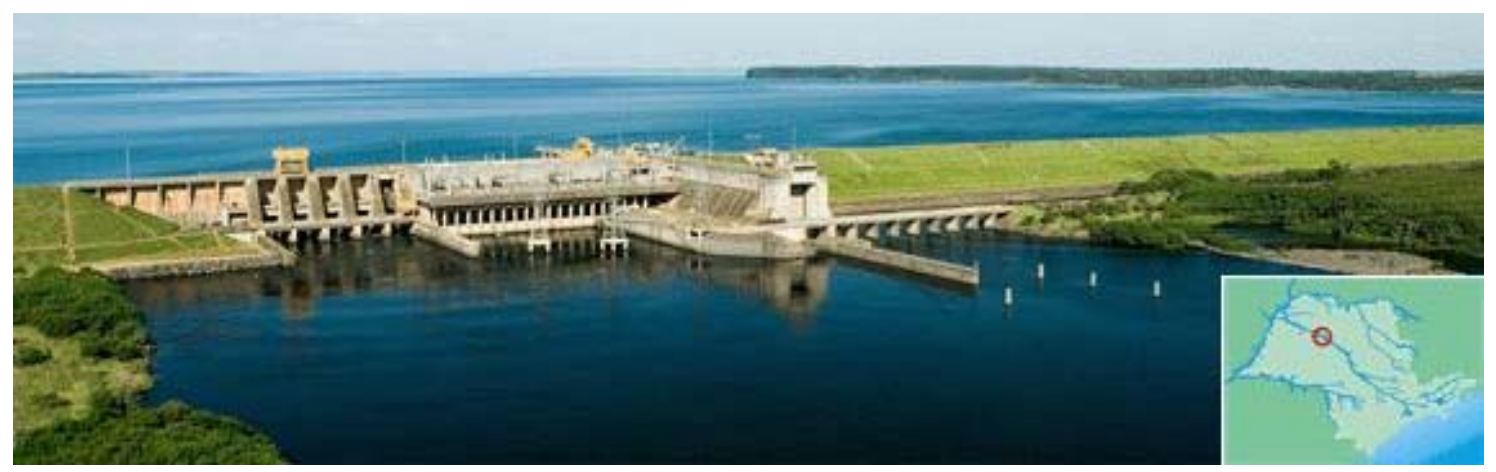

Figura 5: Reservatório de Promissão. Fonte: AES/TIETÊ AS (2006)

A área alagada é de 58.548 ha e a área de drenagem é de $57.610 \mathrm{~km}^{2}$ (Tabela 4), estando a uma altitude de 380 metros (CETESB, 2001). 
Tabela 4: Características gerais do reservatório de Promissão.

\begin{tabular}{cc}
\hline \multicolumn{2}{c}{ Características } \\
\hline Área alagada (ha) & 58.548 \\
Área de drenagem $\left(\mathrm{km}^{2}\right)$ & 57.610 \\
Vazão média anual $\left(\mathrm{m}^{3} / \mathrm{s}\right)$ & 640 \\
Tempo de residência $($ dias $)$ & $124 \mathrm{a} 458$ \\
Volume total $\left(10^{6} \mathrm{~m}^{3}\right)$ & 7.418 \\
Volume útil $\left(10^{6} \mathrm{~m}^{3}\right)$ & 2.128 \\
Perímetro $(\mathrm{km})$ & 1.423 \\
Profundidade média $(\mathrm{m})$ & 12 \\
Profundidade máxima $(\mathrm{m})$ & - \\
Ano do enchimento & 1975 \\
\hline Fonte: CESP (1998), CETESB (2001), AES/TIETÊ AS $(2006)$
\end{tabular}

A represa recebe a contribuição de vários rios tributários, como os rios Dourado, Cervo Grande, Batalha e Ribeirão dos Porcos, tendo suas características limnológicas influenciadas localmente por eles (FRACÁCIO, 2001).

Os principais usos do solo no entorno da bacia estão associados à urbanização, às indústrias e à agropecuária. As principais atividades industriais com potencial poluidor são as usinas de açúcar e álcool, os engenhos, os curtumes e as indústrias alimentícias (PEREIRA, 2003).

\subsubsection{Reservatório de Nova Avanhandava}

O reservatório de Nova Avanhandava (Figura 6) é o quinto reservatório da série e está inserido no sistema do Baixo Tietê.

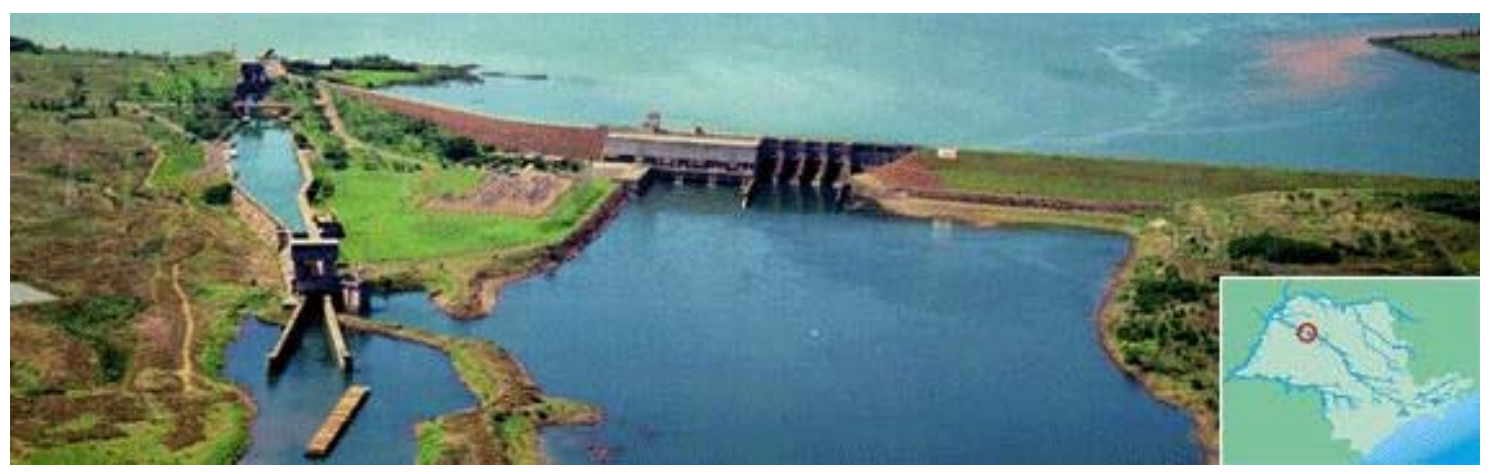

Figura 6: Reservatório de Nova Avanhandava. Fonte: AES/TIETÊ AS (2006) 
Possui uma área alagada de 21.700 ha e uma área de drenagem de $62.300 \mathrm{~km}^{2}$ (Tabela 5). A barragem possui 2.038 metros de comprimento e foi construída em 1985 (CESP, 1998; CETESB, 2001; AES/TIETÊ AS, 2006). Os afluentes principais são: Rio dos Patos, Ribeirão dos Ferreiros, Ribeirão Bonito e Ribeirão Lajeado (CESP, 1998).

Tabela 5: Características gerais do reservatório de Nova Avanhandava.

\begin{tabular}{cc}
\hline \multicolumn{2}{c}{ Características } \\
\hline Área alagada (ha) & 21.700 \\
Área de drenagem $\left(\mathrm{km}^{2}\right)$ & 62.300 \\
Vazão média anual $\left(\mathrm{m}^{3} / \mathrm{s}\right)$ & 688 \\
Tempo de residência $($ dias $)$ & $32 \mathrm{a} 119$ \\
Volume total $\left(10^{6} \mathrm{~m}^{3}\right)$ & 2.720 \\
Volume útil $\left(10^{6} \mathrm{~m}^{3}\right)$ & 380 \\
Perímetro $(\mathrm{km})$ & 298 \\
Profundidade média $(\mathrm{m})$ & - \\
Profundidade máxima $(\mathrm{m})$ & - \\
Ano do enchimento & 1985 \\
\hline Fonte: CESP (1998), CETESB (2001), AES/TIETÊ AS $(2006)$
\end{tabular}

\subsubsection{Reservatório de Três Irmãos}

O reservatório de Três Irmãos (Figura 7) é o maior e último reservatório do Sistema Tietê. Está localizado à oeste do Estado de São Paulo, aproximadamente a 28 $\mathrm{km}$ da foz do rio Tietê no rio Paraná (FRACÁCIO, 2001). Localiza-se próximo à cidade de Pereira Barreto, entre as coordenadas $21^{\circ} 45^{\prime} \mathrm{S}$ de latitude e $49^{\circ} 47^{\prime} \mathrm{W}$ de longitude.

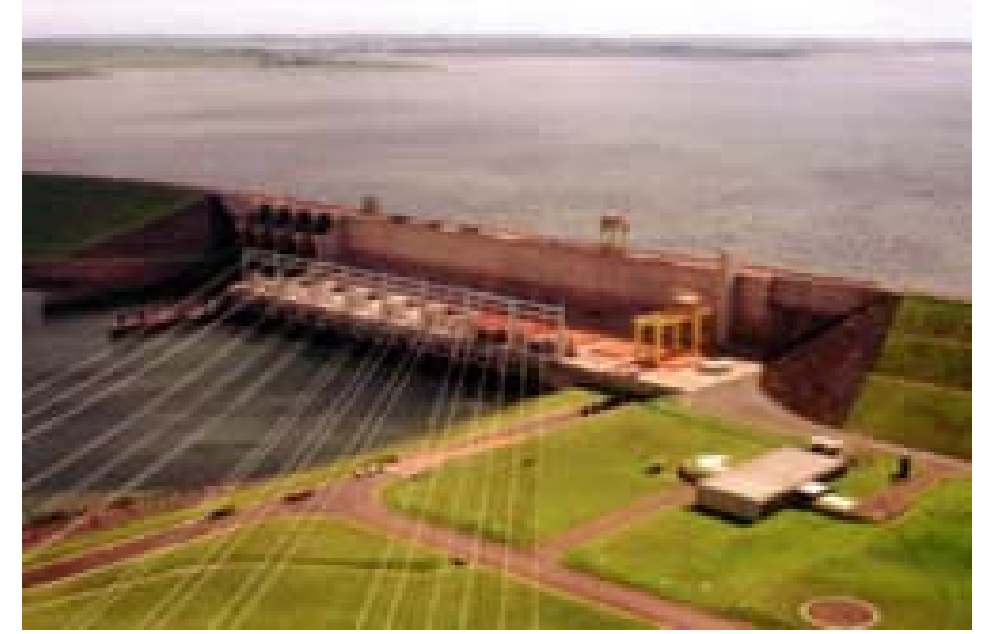

Figura 7: Reservatório de Três Irmãos. Fonte: CESP (2006) 
A área alagada é de 81.700 ha e sua área de drenagem de $70.600 \mathrm{~km}^{2}$. A barragem mede 3.710 metros de comprimento e foi concluída em 1991 (PEREIRA, 2003) (Tabela 6).

Tabela 6: Características gerais do reservatório de Três Irmãos.

\begin{tabular}{cc}
\hline \multicolumn{2}{c}{ Características } \\
\hline Área alagada $(\mathrm{ha})$ & 81.700 \\
Área de drenagem $\left(\mathrm{km}^{2}\right)$ & 70.600 \\
Vazão média anual $\left(\mathrm{m}^{3} / \mathrm{s}\right)$ & 733 \\
Tempo de residência $($ dias $)$ & $166 \mathrm{a} 615$ \\
Volume total $\left(10^{6} \mathrm{~m}^{3}\right)$ & 13.800 \\
Volume útil $\left(10^{6} \mathrm{~m}^{3}\right)$ & 3.449 \\
Perímetro $(\mathrm{km})$ & - \\
Profundidade média $(\mathrm{m})$ & - \\
Profundidade máxima $(\mathrm{m})$ & - \\
Ano do enchimento & 1991 \\
\hline
\end{tabular}

Fonte: CESP (1998), CESP (2006).

Da série de represas do rio Tietê, esse reservatório é o único que ainda se encontra sob o gerenciamento da Companhia Energética de Estado de São Paulo. A usina possui um sistema de duas eclusas, sendo cada uma com 142 metros de comprimento e com uma altura de 24 metros (CESP, 1998; CESP, 2006).

Essas duas eclusas possibilitam a ligação do rio Tietê ao rio Paraná (no reservatório de Jupiá). Além da ligação das duas eclusas, existe também uma ligação com o reservatório de Ilha Solteira, por meio de um canal artificial, denominado canal de Pereira Barreto, que tem um comprimento de 9,6 $\mathrm{km}$ de uma profundidade de 4 metros (CESP, 2006).

\subsection{Coleta e Biometria de Peixes}

As coletas foram realizadas no período de novembro de 2002 a fevereiro de 2004, com redes de espera (malhadeiras), utilizando-se as malhagens de 3, 4, 6, 8, 10 e $11 \mathrm{~cm}$ entre nós opostos. As coletas dos peixes foram realizadas em três estações de coleta, de maneira a melhor caracterizar o sistema e suas variáveis nos três compartimentos ou porções: rio (estação 1-início), transição (estação 2-meio) e lacustre (estação 3-barragem), nos seis reservatórios do médio e baixo rio Tietê. 
Foram colocadas três baterias de redes, localizadas uma em cada estação de coleta. As redes foram colocadas no período da tarde, entre as 16 e 18 horas, e retiradas na manhã seguinte, permanecendo 12 horas no local.

Ainda em campo, foram feitos os registros das espécies coletadas com a sua respectiva abundância, para em seguida fixar cada indivíduo em formol 10\%, colocando-os em sacos plásticos contendo as informações sobre a época de coleta e o ponto em que foi coletado. Todo material fixado foi transportado até o laboratório do DEBE (Departamento de Ecologia e Biologia Evolutiva, USFCar), onde foram submetidos à biometria (comprimentos padrão, comprimento total e peso corporal).

Os exemplares foram identificados em laboratório com auxílio de chaves de identificação (BRITSKI et al.,1984) e confirmados por especialistas do Museu de Zoologia da USP.

Posteriormente à realização da identificação e biometria, as espécies foram separadas em classe de tamanho, pelo método de STURGES (1926):

$$
\mathbf{h}=\mathbf{R} / \mathbf{K}
$$

onde:

$\mathrm{h}=$ amplitude de classes de tamanho;

$\mathrm{R}=$ amplitude total dos dados, ou seja, diferença entre o maior valor e o menor valor de comprimento padrão;

$\mathrm{K}=1+3,222 \cdot \log \mathrm{n}$

Sendo n o tamanho da amostra.

\subsection{Extração dos Estômagos e Análise dos Conteúdos Estomacais}

Para o presente estudo foi realizado em cada exemplar, uma incisão ventral longitudinal na cavidade celomática, a partir da abertura uro-genital em direção à cabeça, para a retirada do estômago, cortando a região de junção deste com o intestino.

Com o estômago aberto foi determinado visualmente o grau de repleção, que representa o estado de enchimento dos estômagos segundo o critério estabelecido por HERRÁN (1988), conforme a escala: 
- grau 0 = estômago completamente vazio;

- grau 1 = 1/4 do estômago com conteúdo;

- grau $2=1 / 2$ do estômago com conteúdo;

- grau $3=3 / 4$ do estômago com conteúdo;

- grau 4 = estômago completamente cheio.

Após estimado o grau de repleção, as paredes dos estômagos foram lavadas com formol 4\% para a retirada total do conteúdo. Os itens alimentares retirados do estômago foram analisados em microscópio estereoscópico da marca Zeiss, modelo Stemi SV 6, para a identificação até o menor nível taxonômico possível, utilizando-se chaves de identificação: MCCAFFERTY (1981) e PENNAK (1989). Além disso, para a identificação contou-se com o auxílio dos doutorandos MsC. José Valdecir de Lucca e MsC. Alexandre K. de Oliveira, Dr. Paulo Z. Pamplin e do Dr. Cláudio Froehlich da Faculdade de Filosofia, Ciências e Letras de Ribeirão Preto (USP).

Após a identificação dos itens alimentares (análise qualitativa), foram realizadas análises quantitativas dos itens encontrados, através da freqüência de ocorrência, da determinação do volume (método volumétrico) e peso seco de cada item encontrado (método gravimétrico), caracterizando a preferência alimentar da espécie.

A freqüência de ocorrência foi obtida registrando-se o número de peixes em que cada item ocorreu, obtendo-se a porcentagem em relação ao número total de estômagos com alimento (HAHN, 1991).

Para a determinação do volume foram utilizadas provetas de 10 e $30 \mathrm{ml}$, e foi seguido o seguinte procedimento: em um volume de água conhecido, adicionou-se cada item alimentar isoladamente, registrando-se o volume deslocado provocado pelo item (FONTELES-FILHO, 1989). Por meio deste método registrou-se o volume de cada item, calculando-se posteriormente a contribuição relativa de cada item alimentar em relação ao total de itens presentes no conteúdo estomacal.

A contribuição relativa de cada item alimentar foi também determinada em termos de biomassa, pelo método gravimétrico. Para isso foi determinado o peso seco dos diferentes itens alimentares. Os materiais foram acondicionados em cadinhos confeccionados com papel alumínio e secos em estufa a $60{ }^{\circ} \mathrm{C}$, por um período de 72 horas. Determinou-se em seguida o peso seco de cada item alimentar, posteriormente calculando-se as contribuições relativas de cada item, as quais foram expressas em porcentagem. 
Os principais itens alimentares consumidos pelas espécies Plagioscion squamosissimus, Cichla cf. ocellaris e Geophagus brasiliensis foram fotografados (Anexo D) utilizando-se um sistema de aquisição de imagens do microscópio Zeiss, modelo Axioskop 2 plus, uma câmera digital NIKON (Coolpix 4300) acoplada a lupa e uma câmera digital NIKON (Coolpix 885) do próprio departamento (DEBE).

\section{Resultados e Discussão}

\subsection{A Composição da Dieta}

$\mathrm{Na}$ interpretação de dados das análises do conteúdo estomacal é importante lembrar que taxas desiguais de digestão podem influenciar os resultados (STRAUSS, 1979). Organismos com corpos macios são digeridos mais rapidamente do que organismos com partes resistentes (mandíbulas e carapaças) e assim sua importância pode ser subestimada (VOROS et al., 1997).

No presente trabalho, durante a análise do conteúdo estomacal das espécies $(P$. squamosissimus, G. brasiliensis e Cichla cf. ocellaris), foram frequentemente encontrados fragmentos de insetos aquáticos, principalmente de Odonata e Ephemeroptera, os quais são provavelmente as partes mais quitinizadas e mais difíceis de serem digeridas. Larvas de Trichoptera foram encontradas dentro do casulo, que é constituído por grãos de areia e construído pelo próprio animal.

Em relação à presença de escamas de peixes no estômago, como o tecido animal é rapidamente digerido, sobrariam as escamas. Assim, elas seriam apenas uma evidência da piscivoria (ZAVALA-CAMIN, 1996). As escamas foram encontradas no conteúdo estomacal da corvina (P. squamosissimus) e do acará (Geophagus brasiliensis).

\subsubsection{Geophagus brasiliensis}

Foram analisados 74 estômagos do acará (Geophagus brasiliensis) coletados no reservatório de Barra Bonita, nos meses de novembro de 2002 e novembro de 2003. Dos 74 estômagos estudados, 32 estavam vazios, 13 parcialmente cheios (3/4 com conteúdo) e 7 totalmente cheios de alimento (Figura 8). 


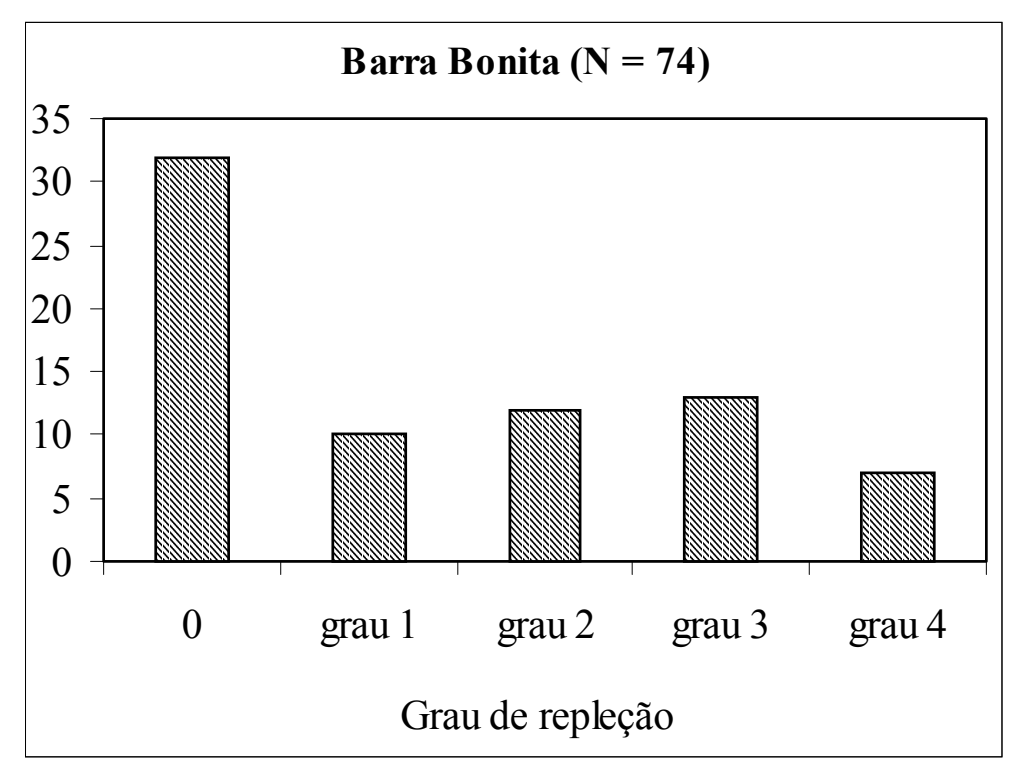

Figura 8: Grau de repleção dos estômagos dos acarás (G. brasiliensis) coletados no reservatório de Barra Bonita, nos meses de novembro de 2002 e 2003.

Os principais itens consumidos pelo acará (G. brasiliensis) nesse reservatório foram Harnischia sp (larva de Diptera) (28,5\%), fragmentos de inseto (28,5\%), Copepoda Cyclopoida (21,4\%), detritos (19\%), Aedokritus sp (larva de Diptera) $(16,6 \%)$ e Copepoda Calanoida (14,2\%) Os itens larva de Chironomidae, Cladocera, Chydoridae (Cladocera), escamas, Tanytarsus sp (larva de Diptera), Daphnia sp (Cladocera) e Hirudinea representaram 4,7\% da frequência.

Os itens peixe (não identificado), Procladius sp (larva de Diptera), Coelotanypus sp (larva de Diptera), Ostracoda, material vegetal, Hymenoptera, Bosminidae (Cladocera) e Daphnia gessneri (Cladocera), foram menos freqüentes nos estômagos analisados, contribuindo com 2,3\% da freqüência de ocorrência (Figura 9).

Os itens alimentares mais importantes em relação ao volume foram os fragmentos de inseto $(44,4 \%)$, detritos $(22,2 \%)$, material vegetal $(22,2 \%)$, peixe (não identificado) $(11,1 \%)$ e escama $(11,1 \%)$. Os demais itens não tiveram o volume medido devido ao reduzido tamanho dos itens e da pequena quantidade encontrada no conteúdo estomacal. 


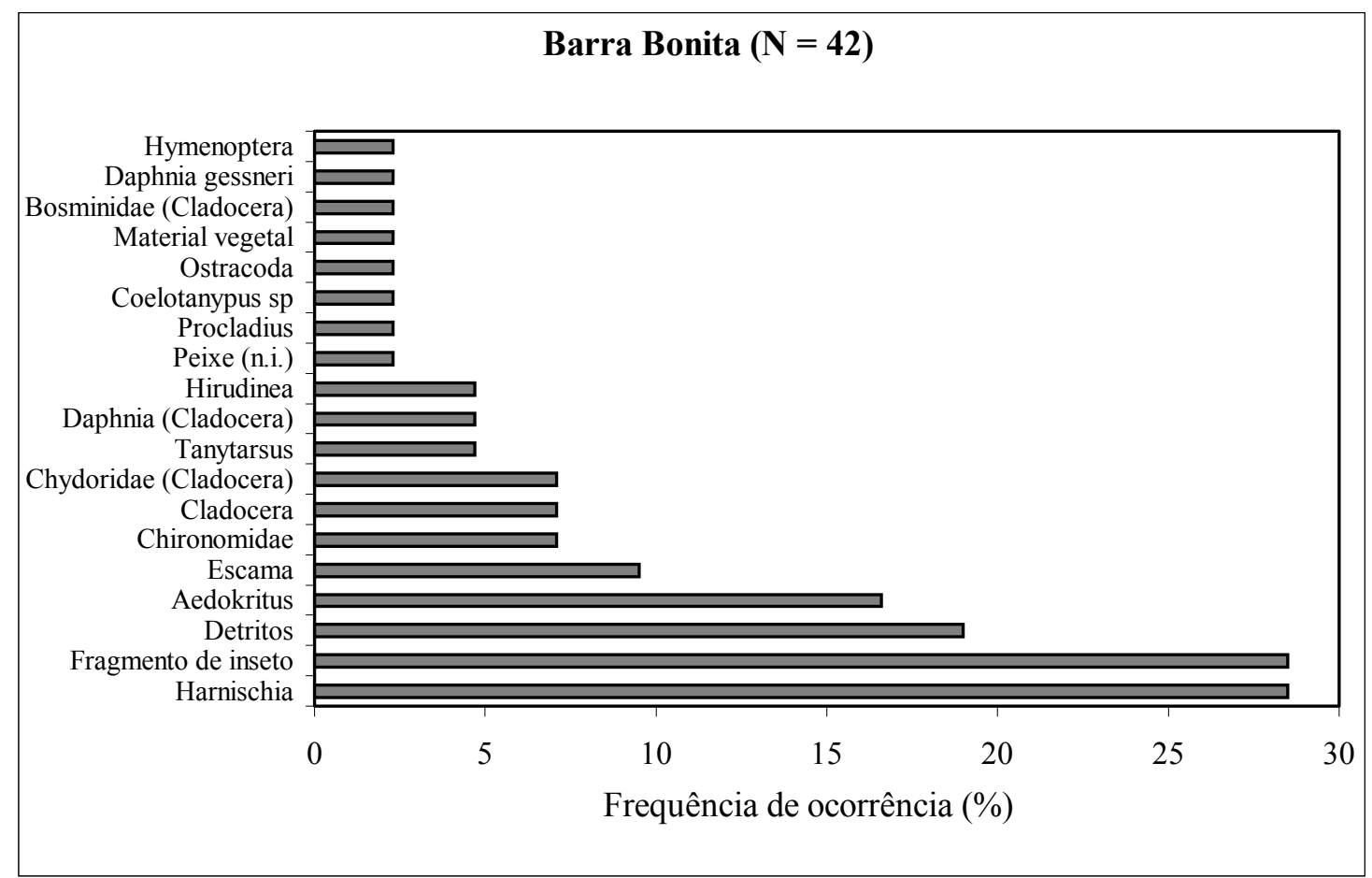

Figura 9: Freqüência de ocorrência (\%) dos itens alimentares encontrados no estômagos de Geophagus brasiliensis coletados no reservatório de Barra Bonita, nos meses de novembro de 2002 e 2003. (n.i. = não identificado).

Em relação ao peso seco, os itens mais importantes foram escamas (89\%), fragmentos de inseto $(6,2 \%)$, detritos $(4,6 \%)$, peixes (não identificado) $(0,4 \%)$ e Hirudinea $(0,6 \%)$. Os itens Hymenoptera e material vegetal ocorreram com frequência muito baixa: $0,1 \%$ e $0,07 \%$, respectivamente. Para os demais itens não foi possível aferir o peso.

Copepoda Calanoida foi numericamente, o item alimentar mais abundante, sendo registrados 55 indivíduos nos estômagos analisados seguido do item larva de Diptera com 49 indivíduos. (Tabela 7). 
Tabela 7: Abundância numérica, volume (\%) e peso seco (\%) dos itens alimentares consumidos por Geophagus brasiliensis, coletados no reservatório de Barra Bonita, amostrados nos meses de novembro de 2002 e novembro de 2003. (n. i. = não identificado).

\begin{tabular}{lccc}
\hline \multicolumn{1}{c}{ Itens Alimentares } & $\begin{array}{c}\text { Abundância } \\
\text { Larva de Diptera }\end{array}$ & $\begin{array}{c}\text { Volumétrico } \\
\text { V (\%) }\end{array}$ & $\begin{array}{c}\text { Gravimétrico } \\
\mathbf{P ~ ( \% )}\end{array}$ \\
\hline Aedokritus sp & $\mathbf{4 9}$ & & \\
Coelotanypus sp & 13 & 0 & 0 \\
Harnischia sp & 1 & 0 & 0 \\
Procladius sp & 30 & 0 & 0 \\
Tanytarsus sp & 1 & 0 & 0 \\
Chironomidae & 1 & 0 & 0 \\
Cladocera & 3 & 0 & 0 \\
Cladocera (n. i.) & $\mathbf{1 0}$ & & 0 \\
Daphnia sp & 3 & 0 & 0 \\
Daphnia gessneri & 3 & 0 & 0 \\
Bosminidae & 1 & 0 & 0 \\
Chydoridae & 1 & 0 & 0 \\
Copepoda & 2 & 0 & 0 \\
Calanoida & $\mathbf{5 5}$ & & $\mathbf{8 9 , 4}$ \\
Cyclopoida & 33 & 0 & 0,4 \\
Peixe & 20 & 0 & 89 \\
Peixe (n. i.) & $\mathbf{1}$ & $\mathbf{1 1 , 1}$ & \\
Escama & 1 & 11,1 & 0 \\
Outros & - & - & 0,6 \\
Ostracoda & & & 0,1 \\
Hirudinea & 2 & 0 & 0,2 \\
Hymenoptera & 4 & 0 & 4,6 \\
Fragmentos de inseto & 1 & 0 & \\
Material vegetal & - & 44 & 07 \\
Detritos & - & 22,2 & \\
\hline
\end{tabular}

O reservatório de Bariri foi estudado no período chuvoso (fevereiro e novembro de 2003) e no período seco (junho e setembro de 2003). Foram analisados no total 120 estômagos de G. brasiliensis. Destes, 59 estômagos foram encontrados vazios e apenas 8 estavam completamente cheios de alimento (Figura 10). 


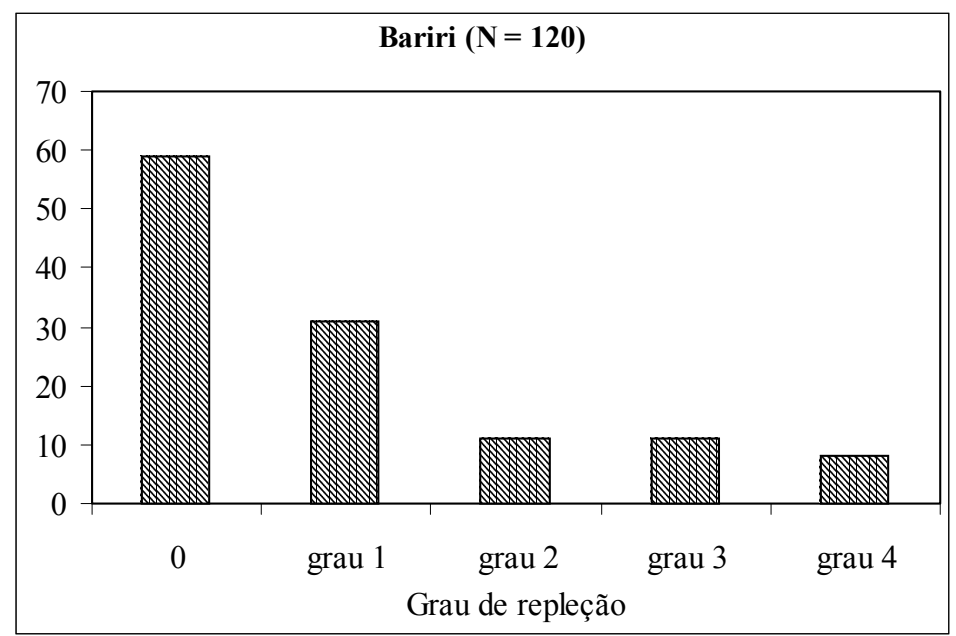

Figura 10: Grau de repleção dos estômagos dos acarás (G. brasiliensis) coletados no reservatório de Bariri nos meses de fevereiro, junho, setembro e novembro de 2003.

$\mathrm{O}$ item alimentar mais importante em relação à freqüência de ocorrência foi detritos (57\%), seguido dos itens material vegetal (16,3\%), Chironomidae (larva de Diptera) (14,7\%), fragmentos de inseto e Hirudinea com 9,8\% (Figura 11).

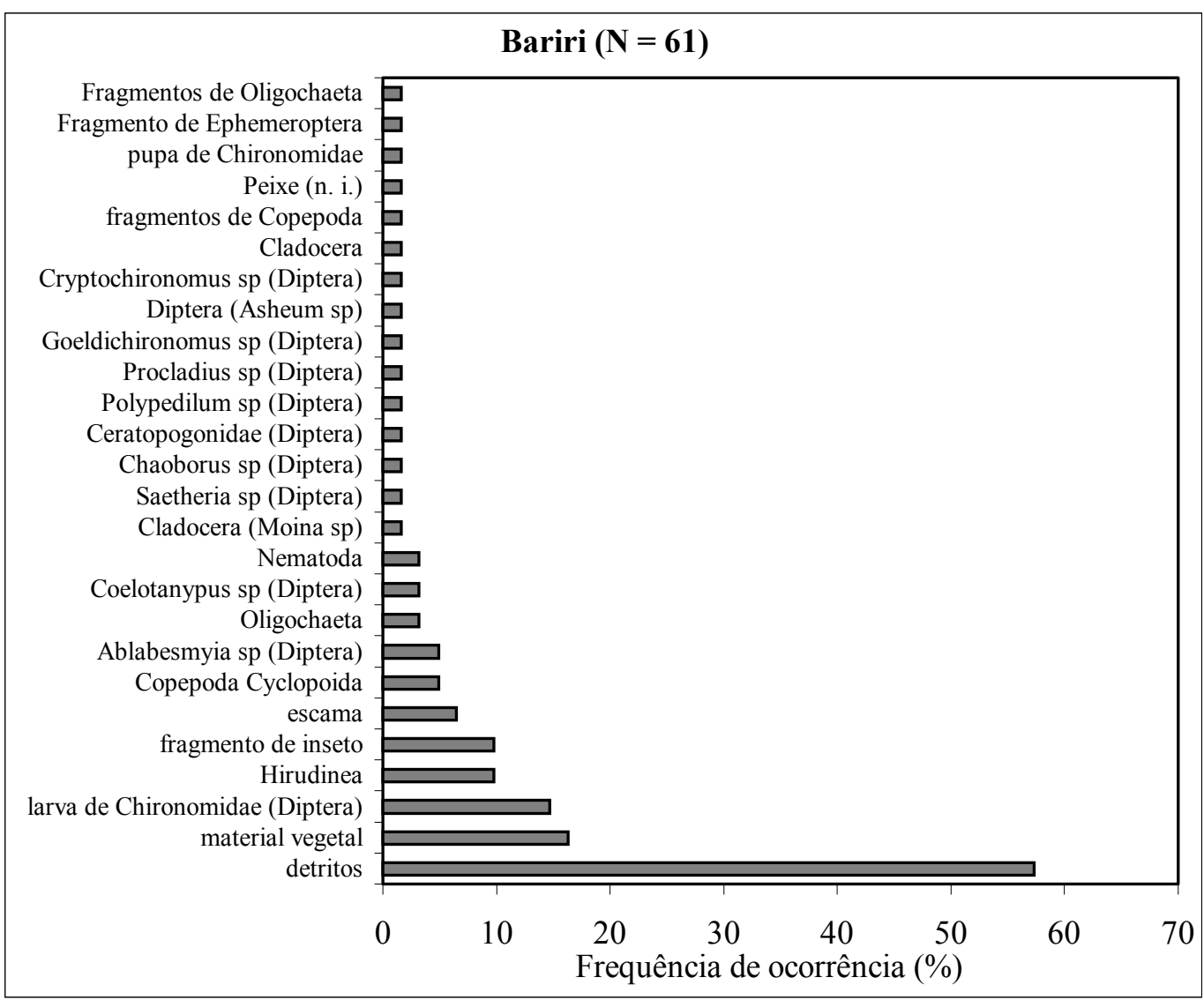

Figura 11: Freqüência de ocorrência (\%) dos itens alimentares encontrados nos estômagos de Geophagus brasiliensis, coletados no reservatório de Bariri, nos meses de fevereiro, junho, setembro e novembro de 2003. (n. i.= não identificado) 
O item numericamente mais abundante foi larva de Diptera com 55 indivíduos. Em relação ao volume e biomassa o item detrito representou $31,2 \%$ do volume e $62,8 \%$ do peso, respectivamente (Tabela 8).

Tabela 8: Abundância numérica, volume (\%) e peso seco (\%) dos itens alimentares consumidos por Geophagus brasiliensis, consumidos no reservatório de Bariri, amostrados nos meses de fevereiro, maio, setembro e novembro de 2003. (n. i. = não identificado).

\begin{tabular}{|c|c|c|c|}
\hline Itens Alimentares & $\begin{array}{c}\text { Abundância } \\
\mathbf{N}\end{array}$ & $\begin{array}{c}\text { Volumétrico } \\
\text { V (\%) }\end{array}$ & $\begin{array}{c}\text { Gravimétrico } \\
\mathbf{P}(\mathbf{\%})\end{array}$ \\
\hline Larva de Díptera & 55 & - & - \\
\hline Ablabesmyia sp & 6 & 0 & 0 \\
\hline Asheum sp & 1 & 0 & 0 \\
\hline Coelotanypus sp & 2 & 0 & 0 \\
\hline Cryptochironomus sp & 1 & 0 & 0 \\
\hline Goeldichironomus sp & 35 & 0 & 0 \\
\hline Polypedilum sp & 1 & 0 & 0 \\
\hline Procladius sp & 1 & 0 & 0 \\
\hline Chironomidae & 5 & 0 & 0 \\
\hline Saetheria sp & 1 & 0 & 0 \\
\hline Chaoborus sp & 1 & 0 & 0 \\
\hline Ceratopogonidae & 1 & 0 & 0 \\
\hline Pupa de Diptera & 3 & - & - \\
\hline pupa de Chironomidae & 3 & 0 & 0 \\
\hline Peixe & 3 & 12,5 & 11 \\
\hline Peixe (n.i.) & 1 & 12,5 & 2,5 \\
\hline Escama & 2 & 0 & 8,5 \\
\hline Copepoda & 5 & - & - \\
\hline Cyclopoida & 5 & 0 & 0 \\
\hline fragmentos de Copepoda & - & 0 & 0 \\
\hline Cladocera & 2 & - & - \\
\hline Cladocera (n. i.) & 1 & 0 & 0 \\
\hline Moina $\mathrm{sp}$ & 1 & 0 & 0 \\
\hline Oligochaeta & 11 & 6,2 & 2,8 \\
\hline Oligochaeta (n. i.) & 11 & 6,2 & 0 \\
\hline Fragmentos de Oligochaeta & - & 0 & 2,8 \\
\hline \multicolumn{4}{|l|}{ Outros } \\
\hline Fragmentos de Ephemeroptera & - & 6,2 & 8,5 \\
\hline fragmentos de inseto & - & 0 & 0,5 \\
\hline Hirudínea & 12 & 0 & 1 \\
\hline Nematoda & 12 & 0 & 0 \\
\hline Detritos & - & 31,2 & 62,8 \\
\hline Material vegetal & - & 44 & 1 \\
\hline
\end{tabular}


O acará no reservatório de Ibitinga foi coletado no mês de dezembro de 2002. Foram analisados no total 17 estômagos. Destes, 13 estavam completamente vazios e 4 estômagos estavam com $1 / 4$ preenchido com alimentos (Figura 12).

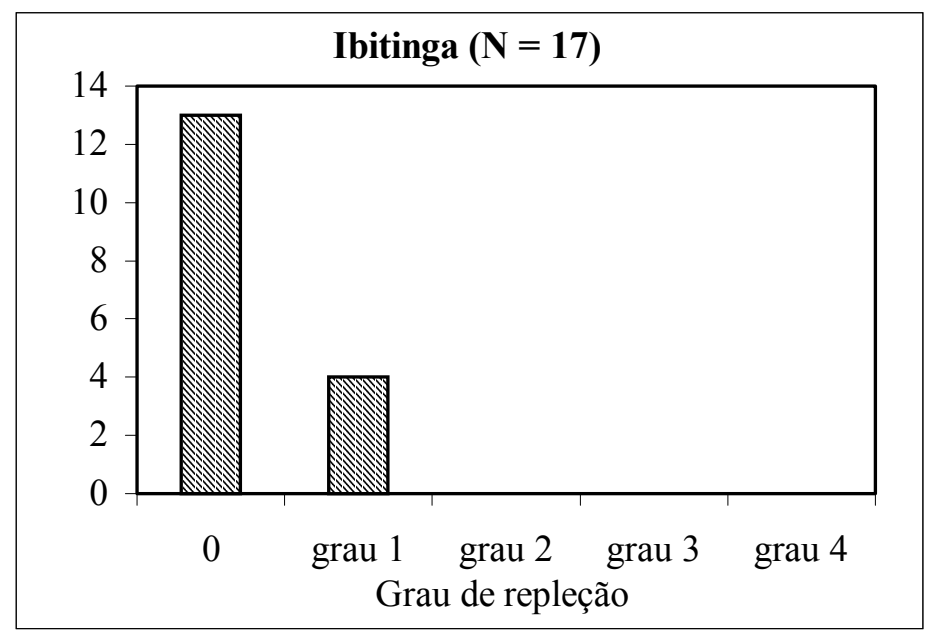

Figura 12: Grau de repleção dos estômagos dos acarás (G. brasiliensis), coletados no reservatório de Ibitinga no mês de dezembro de 2002.

O item alimentar com maior freqüência de ocorrência nos estômagos analisados foi fragmentos de inseto (50\%), seguido dos itens Ablabesmyia sp e Aedokritus sp (Larva de Diptera) e material vegetal com 25\% de freqüência (Figura 13).

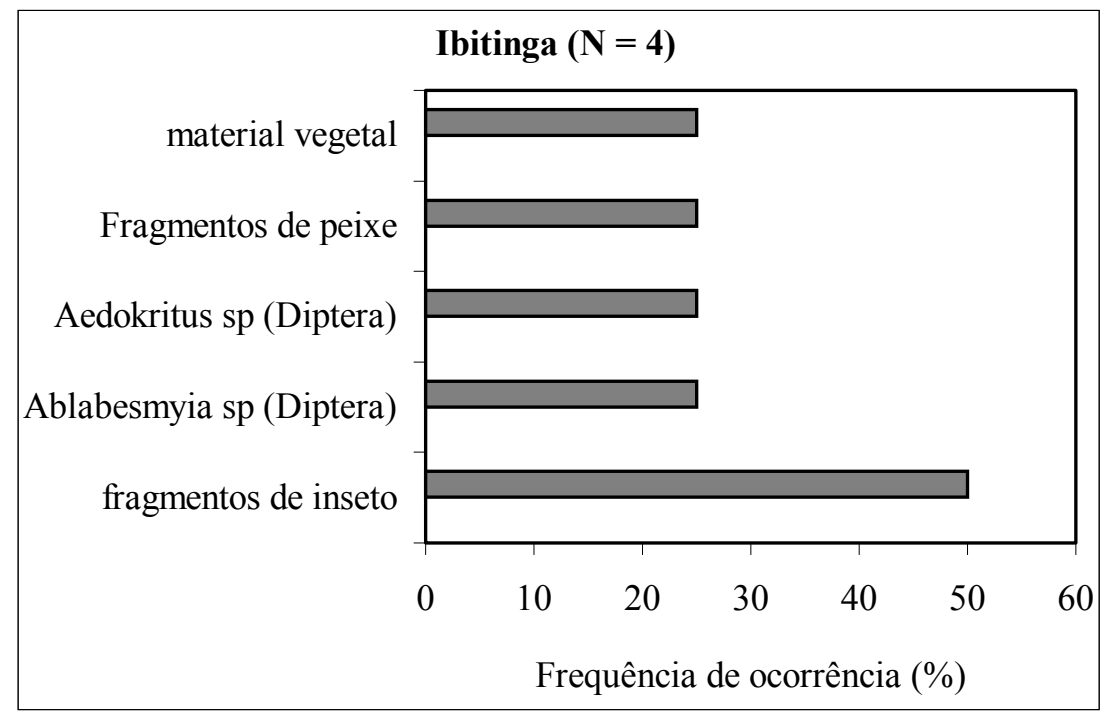

Figura 13: Freqüência de ocorrência (\%) dos itens alimentares encontrados nos estômagos dos exemplares de Geophagus brasiliensis, coletados no reservatório de Ibitinga no mês de dezembro de 2002. 
Não foi possível medir o volume dos itens consumidos pelo G. brasiliensis, por causa do tamanho e da pequena quantidade encontrada dentro dos estômagos. Em relação à biomassa o item fragmentos de inseto foi o mais significativo (com 50\%), seguido dos itens fragmentos de peixe (40\%) e material vegetal (10\%) (Tabela 9).

$\mathrm{O}$ item mais consumido foi larva de Diptera, tendo sido registrados dois indivíduos. Para os itens fragmentos de inseto, fragmentos de peixe e material vegetal, não foi possível registrar a abundância numérica (Tabela 9).

Tabela 9: Abundância numérica, volume (\%) e peso seco (\%) dos itens alimentares consumidos por Geophagus brasiliensis, coletados no reservatório de Ibitinga no mês de dezembro de 2002.

\begin{tabular}{lccc}
\hline \multicolumn{1}{c}{ Itens Alimentares } & $\begin{array}{c}\text { Abundância } \\
\text { N }\end{array}$ & $\begin{array}{c}\text { Volumétrico } \\
\text { V (\%) }\end{array}$ & $\begin{array}{c}\text { Gravimétrico } \\
\mathbf{P ~ ( \% )}\end{array}$ \\
\hline Larva de Díptera & $\mathbf{2}$ & - & - \\
Ablabesmyia sp & 1 & 0 & 0 \\
Aedokritus sp & 1 & 0 & 0 \\
Outros & & & 50 \\
fragmentos de inseto & - & 0 & 40 \\
fragmentos de peixe & - & 0 & 10 \\
material vegetal & - & 0 & \\
\hline
\end{tabular}

Neste trabalho foram analisados 221 estômagos do acará (Geophagus brasiliensis), capturados nos reservatórios de Barra Bonita, Bariri e Ibitinga.

No reservatório de Nova Avanhandava não foram coletados indivíduos da espécie G. brasiliensis. Em Três Irmãos apenas um indivíduo de acará foi coletado, sendo durante a análise do conteúdo estomacal verificou-se que o estômago estava totalmente vazio.

$\mathrm{O}$ estudo da dieta permitiu caracterizar o acará como uma espécie de hábito alimentar onívoro, nas represas do médio Tietê, consumindo principalmente microcrustáceos (Copepoda Calanoida, Copepoda Cyclopoida e Cladocera), larvas de Diptera (Chaoboridae e Chironomidae), fragmentos de insetos, detritos (grãos de areia) e material vegetal.

No reservatório de Barra Bonita, Geophagus brasiliensis consumiu principalmente larvas de quironomídeos (Harnischia sp, Aedokritus sp, Tanytarsus sp, Procladius sp, Coelotanypus sp) e fragmentos de outros insetos, e com menor frequência microcrustáceos e detritos. 
SURIANI (2006), estudando os macroinvertebrados bentônicos nas represas de Barra Bonita, Bariri e Ibitinga, localizadas no Médio Tietê, verificou que os Chironomidae foram organismos muito abundantes.

No reservatório de Bariri, o acará consumiu 26 itens alimentares, sendo detritos e larvas de Diptera os itens mais freqüentes.

Segundo HUTCHINSON (1993) a ordem Diptera é a mais diversa entre as ordens de insetos na água doce, com destaque para a família Chironomidae, pois seus representantes são geralmente os mais abundantes entre os macroinvertebrados bentônicos de ambientes lacustres e fluviais, provavelmente em função da sua elevada capacidade adaptativa a diferentes substratos e de sua plasticidade (STRIXINO \& TRIVINHO-STRIXINO, 1998). Desta forma, provavelmente, o elevado consumo deste item poderia ser interpretado como decorrente da sua maior disponibilidade no ambiente.

Segundo ROCHE et al. (2005), a ingestão acidental de partículas, como detritos, argila e areia, junto com os itens alimentares, podem ocorrer especialmente no caso dos bentívoros. Isso explica o fato do item detritos ser encontrado com freqüência no conteúdo estomacal dos indivíduos analisados.

No reservatório de Ibitinga, o item mais freqüentemente encontrado nos estômagos foi fragmentos de inseto, seguido de larvas de Diptera, fragmentos de peixe e material vegetal.

UIEDA (1995), por meio de observações subaquáticas no rio da Fazenda, Ubatuba-SP, verificou que G. brasiliensis se alimenta catando itens sobre o substrato (areia/lodo), selecionando o alimento na boca e eliminando uma nuvem de areia pelos opérculos. A análise da dieta permitiu à autora concluir que, nesta localidade, $G$. brasiliensis era onívoro, embora predominantemente insetívora, consumindo insetos aquáticos (formas jovens de Diptera e Ephemeroptera), ácaros aquáticos, crustáceos, escamas e material vegetal.

ARCIFA et al. (1988) reportaram essa espécie se alimentando principalmente de insetos aquáticos, seguidos de detritos e microcrustáceos.

BARRELLA et al., (1994) comparando a comunidade de peixes do Rio Manso (MT) e do rio Jacaré Pepira (SP) caracterizaram o hábito alimentar de G. brasiliensis como onívoro.

HAHN et al. (1997) classificaram G. brasiliensis como bentívoro, ingerindo principalmente detritos e quironomídeos, no reservatório do Segredo. 
De acordo com AGOSTINHO et al. (1997) esta espécie foi classificada como bentívora na represa de Foz do Areia, alimentando-se principalmente de microcrustáceos, nematóides, peixes, coleópteros aquáticos e detritos, enquanto na represa de Segredo, alimentou-se de frutas/sementes, detrito/sedimento e peixes.

MESCHIATTI \& ARCIFA (2002) classificaram o acará (G. brasiliensis) como insetívoro, consumindo com maior frequência insetos aquáticos, seguidos de larvas de peixe, no lago de Monte Alegre, um pequeno reservatório eutrofizado.

SMITH et al. (2003), verificou sementes, algas filamentosas, rotíferos e copépodos dentre os itens alimentares consumidos por G. brasiliensis, nos reservatórios do rio Tietê.

PEREIRA et al., (2004) estudando o hábito alimentar de nove espécies de peixes no reservatório de Três Irmãos, caracterizou o acará (G. brasiliensis) como insetívoro.

G. brasiliensis na lagoa Almécega (Vale do Rio Doce-MG) alimentou-se principalmente de copépodos, cladóceros, sementes e grãos de areia. Na lagoa Verde (Vale do Rio Doce- MG) os itens mais consumidos foram cladóceros, copépodos e areia (ASSUMPÇÃO et al., 2005).

Nos reservatórios estudados, G. brasiliensis consumiu vários itens alimentares de diversos níveis tróficos, sendo assim considerada uma espécie onívora, de acordo com o trabalho desenvolvido por ASSUMPÇÃO et al. (2005).

\subsection{Plagioscion squamosissimus}

O reservatório de Barra Bonita foi estudado no período chuvoso e as coletas foram realizadas em novembro de 2002 e novembro de 2003. Foram analisados 117 estômagos, sendo que desses 79 continham alimento, 38 estavam vazios e 18 estômagos totalmente cheios (Figura 14). 


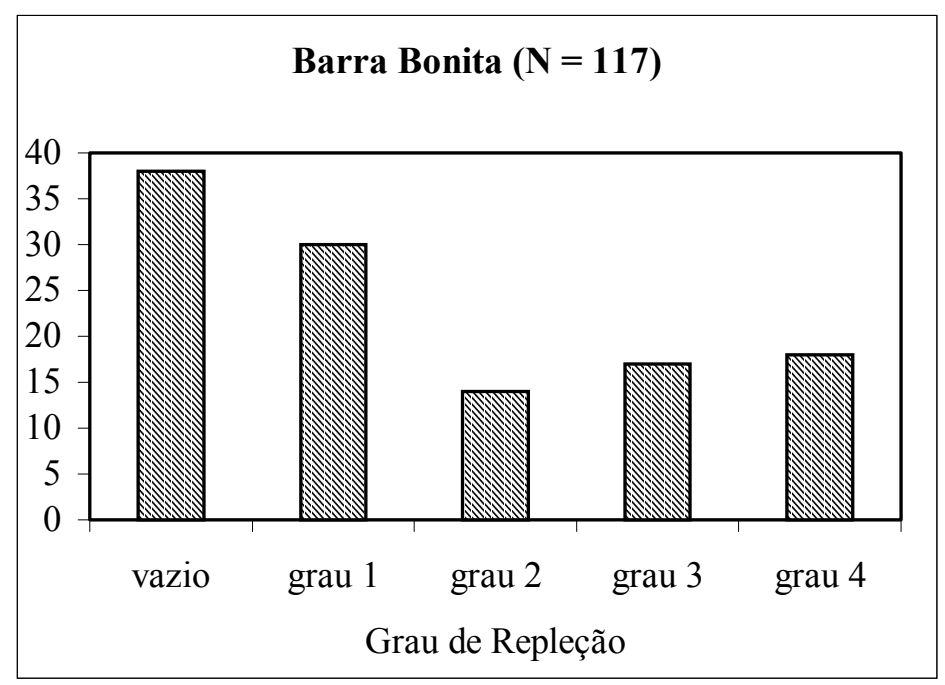

Figura 14: Grau de repleção dos estômagos das corvinas (P. squamosissimus), coletadas no reservatório de Barra Bonita, em novembro de 2002 e novembro de 2003.

Neste reservatório a corvina ( $P$. squamosissimus) apresentou uma dieta alimentar baseada principalmente em peixes. Os itens alimentares encontrados com maior freqüência foram fragmentos de peixes $(63,2 \%)$ e peixes inteiros $(21,5 \%)$ que não puderam ser identificados devido ao alto grau de digestão.

Pequenos peixes não identificados da família Cichlidae $(3,8 \%)$ e da família Characidae (1,2\%), indivíduos da própria espécie Plagioscion squamosissimus $(1,2 \%)$ e um indivíduo da espécie Astyanax altiparanae (1,2\%), foram consumidos com menor freqüência.

No entanto, os itens fragmentos de peixe, peixe (n.i.), Plagioscion squamosissimus (corvina), Cichlidae, Characidae e Astyanax altiparanae (lambari), somados representaram $92 \%$ da freqüência de ocorrência.

Também foram ingeridos Phyllocycla sp (ninfas de Odonata) (7,8\%), material vegetal (3,8\%), larvas de Diptera (Chironomidae: 2,5\% e Cryptochironomus sp: 2,5\%), fragmentos de insetos (1,2\%) e Notodiaptomus sp (Copepoda Calanoida) (1,2\%) (Figura $15)$. 


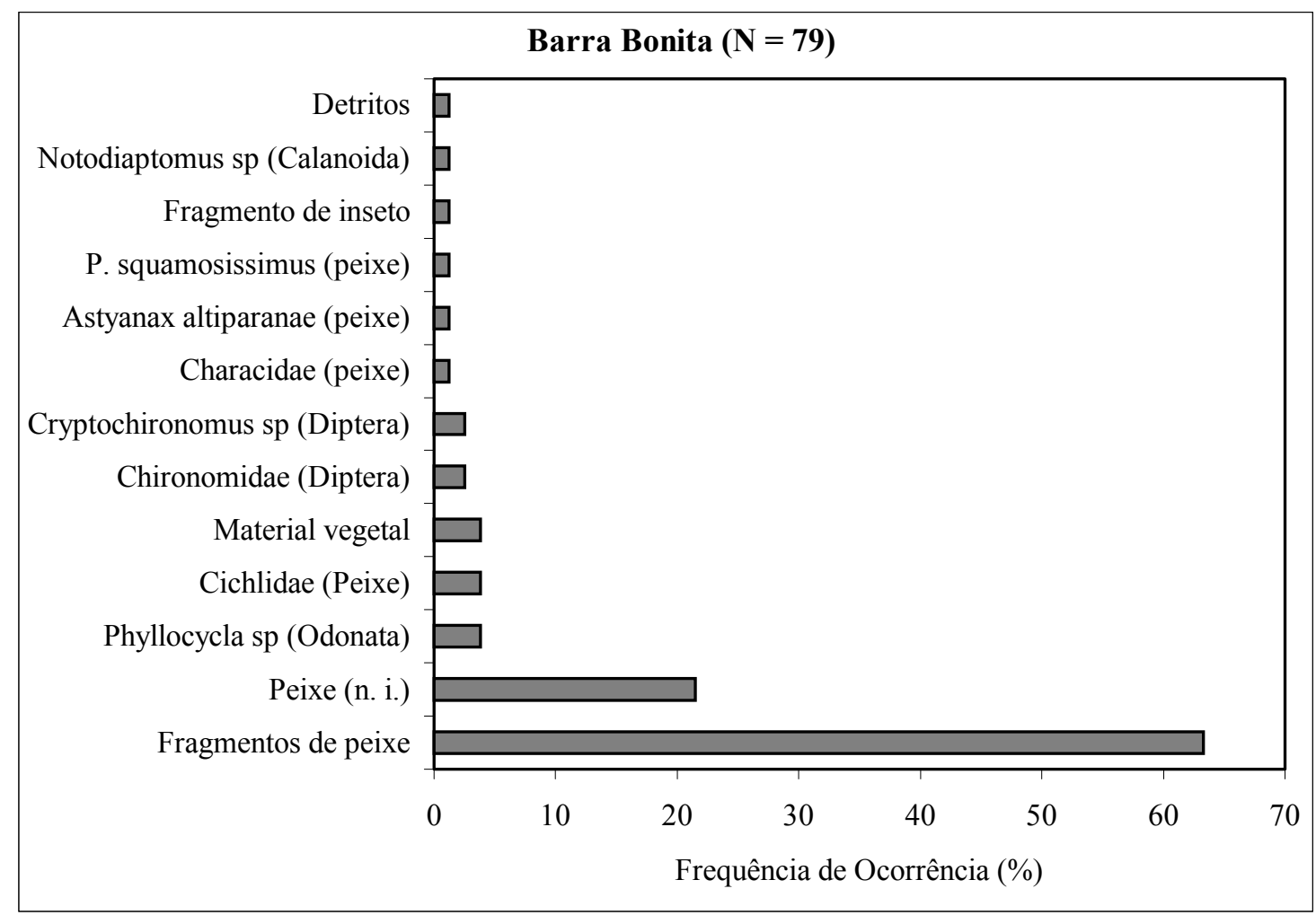

Figura 15: Freqüência de ocorrência (\%) dos itens alimentares encontrados no estômago de P. squamosissimus, coletados no reservatório de Barra Bonita, nos meses de novembro de 2002 e novembro de 2003. (n. i.= não identificado)

O item alimentar mais consumido pela corvina foi Cichlidae (peixe) tendo sido registrados 72 indivíduos, seguido dos itens peixe (não identificado e $P$. squamosissimus) com 64 indivíduos e 34 indivíduos, respectivamente. Os itens menos abundantes foram indivíduos da família (Characidae e Astyanax altiparanae) sendo encontrados somente um indivíduo nos estômagos analisados.

No entanto, a somatória dos itens peixe (não identificado), fragmentos de peixe, Cichlidae, Plagioscion squamosissimus (corvina), Astyanax altiparane (lambari) e Characidae, representam 172 indivíduos consumidos pela espécie $P$. squamosissimus.

Os itens alimentares fragmentos de peixes e peixes (não identificado) contribuíram com $37 \%$ e $26 \%$, respectivamente, do volume total dos itens ingeridos por P. squamosissimus. Alguns itens como detritos $(0,2 \%)$ e Characidae (peixe) $(0,1 \%)$ corresponderam a um volume muito pequeno.

Os itens alimentares: fragmentos de insetos, material vegetal, Notodiaptomus $\mathrm{sp}$ (Copepoda Calanoida), Chironomidae e Cryptochironomus sp (larva de Diptera), apresentaram um volume inferior a $0,1 \%$, devido ao tamanho e à pequena quantidade encontrada no estômago. 
Em relação à biomassa os itens alimentares mais importantes foram: fragmentos de peixes (30,5\%), peixe (não identificado) (29\%), P. squamosissimus (peixe) (11,8\%), Astyanax altiparanae (lambari) (17\%), Cichlidae (peixe) (9,8\%), Phyllocycla sp (ninfa de Odonata) $(1,1 \%)$ e Characidae (peixe) (0,7\%). Os itens Cryptochironomus sp e Chironomidae (larva de Diptera) e Notodiaptomus sp (Copepoda Calanoida) não tiveram a biomassa determinada devido à pequena quantidade de material (Tabela 10).

Tabela 10: Abundância numérica, volume (\%) e peso seco (\%) dos itens alimentares consumidos por $P$. squamosissimus, coletados no reservatório de Barra Bonita, nos meses de novembro de 2002 e novembro de 2003. (n. i. = não identificado).

\begin{tabular}{lccc}
\hline \multicolumn{1}{c}{ Itens Alimentares } & Abundância & Volumétrico & Gravimétrico \\
& $\mathbf{N}$ & $\mathbf{V ~ ( \% )}$ & $\mathbf{P ~ ( \% )}$ \\
\hline Peixe & $\mathbf{1 7 2}$ & $\mathbf{9 9}$ & $\mathbf{9 8 , 8}$ \\
fragmentos de peixe & - & 37 & 30,5 \\
peixe (n.i.) & 64 & 26 & 29 \\
Cichlidae & 72 & 16,3 & 17 \\
Astyanax altiparanae (lambari) & 1 & 12,5 & 11,8 \\
Plagioscion squamosissimus (corvina) & 34 & 7,1 & 9,8 \\
Characidae & 1 & 0,1 & 0,7 \\
Odonata & $\mathbf{3}$ & $\mathbf{0 , 8}$ & $\mathbf{1 , 1}$ \\
Phyllocycla sp & 3 & 0,8 & 1,1 \\
Larva de Diptera & $\mathbf{6}$ & - & $\mathbf{0 , 1}$ \\
Chironomidae & 4 & 0 & 0,1 \\
Cryptochironomus sp & 2 & 0 & 0 \\
Outros & & & \\
fragmentos de inseto & - & 0 & 0,01 \\
material vegetal & - & 0 & 0,1 \\
Detritos & - & 0,2 & 0,07 \\
Notodiaptomus sp (Copepoda Calanoida) & 2 & 0 & 0 \\
\hline
\end{tabular}

No reservatório de Bariri foram analisados 258 estômagos de $P$. squamosissimus, nos meses de fevereiro, junho, setembro e novembro de 2003. Dos 258 estômagos analisados, 74 estavam vazios e 59 estavam parcialmente cheios (grau 3) (Figura 16). 


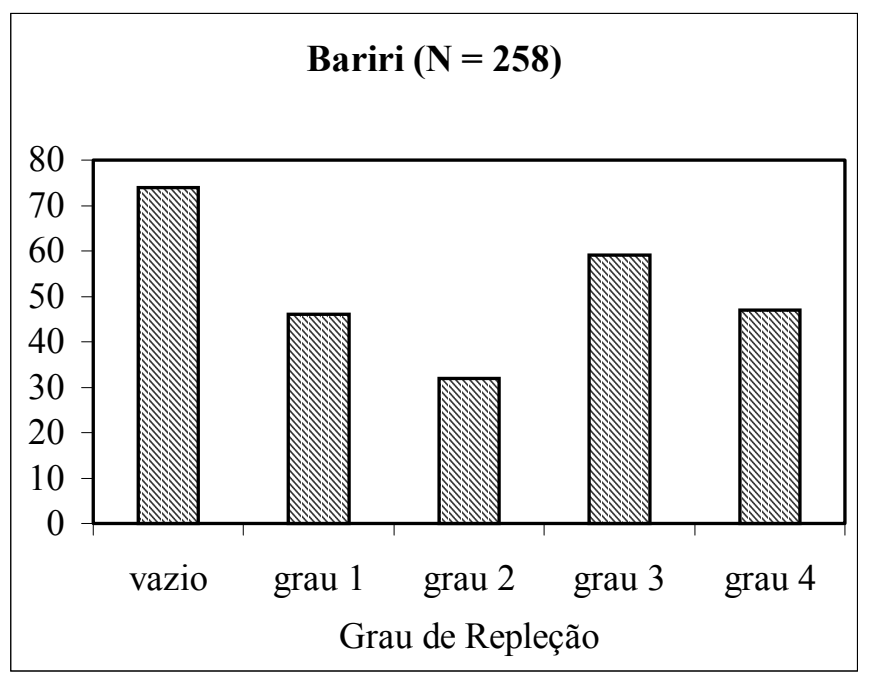

Figura 16: Grau de repleção dos estômagos das corvinas (P. squamosissimus), coletadas no reservatório de Bariri, nos meses de fevereiro, junho, setembro e novembro de 2003.

Diversos itens alimentares foram utilizados por $P$. squamosissimus nesse reservatório nos meses amostrados. $\mathrm{O}$ item alimentar fragmentos de Ephemeroptera apresentou maior freqüência de ocorrência (36,4\%), seguido dos itens fragmentos de peixe $(33,6 \%)$, massa de ovos de Ephemeroptera (14,6\%), material vegetal $(12,5 \%)$, peixe (não identificado) (10,3\%), pupa de Chironomidae (Diptera) $(7,6 \%)$, fragmentos de inseto (5,4\%), Coelotanypus sp (larva de Diptera) (4,3\%), Phyllocycla sp (ninfa de Odonata) (3,8\%), Ablabesmyia sp e Cryptochironomus sp (larva de Diptera) (2,1\%).

Os itens Plagioscion squamosissimus (peixe), Ceratopogonidae e Chaoborus sp (larva de Diptera) e pupa de Chaoborus sp (Diptera) apresentaram freqüência igual a 1,6\%. Larva de Trichoptera, Notodiaptomus sp (Copepoda Calanoida) e larva de Chironomidae (larva de Diptera) representaram 1,0\% da freqüência.

Os itens Siluriformes (peixe), fragmentos de Odonata, Macrobrachium sp (camarão de água doce), Asheum sp, Brundiniella sp e Harnischia sp (larva de Diptera), fragmentos de Copepoda Calanoida e detritos representaram $0,5 \%$ da freqüencia (Figura 17). 


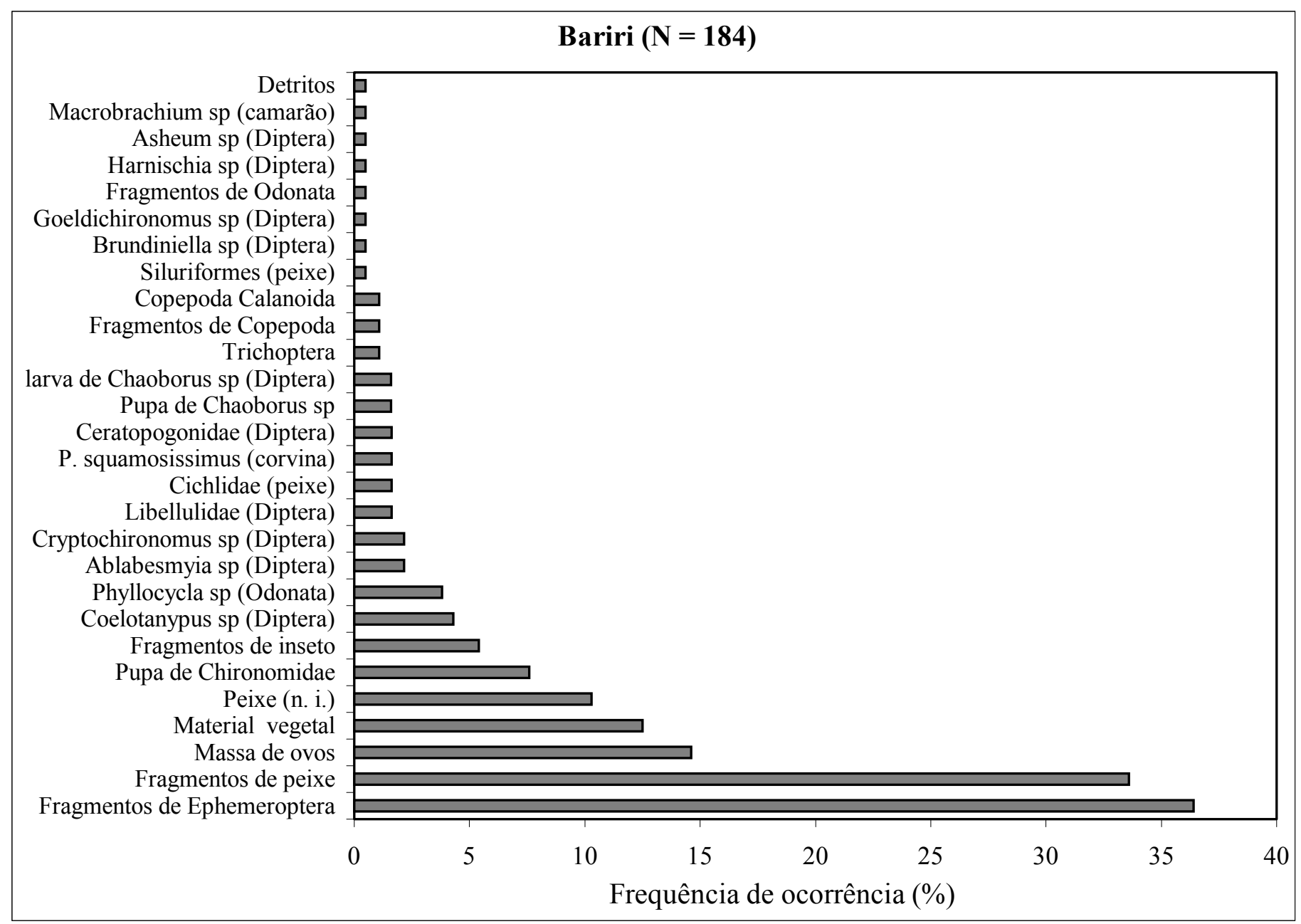

Figura 17: Freqüência de ocorrência (\%) dos itens alimentares encontrados no estômago de $P$. squamosissimus, coletados no reservatório de Bariri, nos meses de fevereiro, junho, setembro e novembro de 2003. (n. i. = não identificado). 
Em relação ao volume (\%) o item fragmentos de peixe foi o mais importante, representando $33,5 \%$ do volume total, seguido dos itens peixe (não identificado) (19,5\%), Plagioscion squamosissimus (peixe) (16,6\%), Campsurinae (fragmentos de Ephemeroptera) (13,5\%), massa de ovos de Ephemeroptera $(9,1 \%)$ e fragmentos de insetos $(2,7 \%)$.

Para os itens Ceratopogonidae, Coelotanypus sp, Ablabesmyia sp, Brundiniella sp, Cryptochironomus sp, Harnischia sp, Asheum sp, Goeldichironomus sp e Chaoborus sp (larva de Diptera), pupa de Chaoborus sp (Diptera), fragmentos de Copepoda Calanoida, Notodiaptomus sp (Copepoda Calanoida) e detritos, não foi possível aferir o volume, devido ao pequeno tamanho dos itens ingeridos pela espécie.

$\mathrm{O}$ item mais importante em relação à biomassa foi fragmentos de peixe $(40,4 \%)$, seguido dos itens Plagioscion squamosissimus (peixe) (16,2\%), massa de ovos de Ephemeroptera (14,3\%), peixe (não identificado) (14,3\%), Campsurinae (fragmentos de Ephemeroptera) (9,5\%), Phyllocycla sp (ninfa de Odonata) (1,1\%), Macrobrachium $\mathrm{sp}$ (camarão de água doce) (1\%), larvas de Trichoptera (1\%), Cichlidae (peixe) $(0,8 \%)$, fragmentos de inseto $(0,8 \%)$, Libellulidae (ninfa de Odonata) $(0,3 \%)$, material vegetal $(0,2 \%)$, Siluriformes (peixe) $(0,1 \%)$, fragmentos de Odonata $(0,06 \%)$ e detritos $(0,03 \%)$.

Em relação à abundância os itens alimentares peixe (não identificado), fragmentos de peixe, Plagioscion squamosissimus (corvina), Cichlidae e Siluriformes, foram, juntos, os mais representativos, tendo sido registrados 129 indivíduos (Tabela $11)$.

Tabela 11: Abundância numérica, volume (\%) e peso seco (\%) dos itens alimentares consumidos por P. squamosissimus no reservatório de Bariri, coletados nos meses de fevereiro, junho, setembro e novembro de 2003. (n. i. = não identificado).

\begin{tabular}{lccc}
\hline \multicolumn{1}{c}{ Itens Alimentares } & Abundância & Volumétrico & Gravimétrico \\
& $\mathbf{N}$ & $\mathbf{V ~ ( \% )}$ & $\mathbf{P ~ ( \% )}$ \\
\hline Peixe & $\mathbf{1 2 9}$ & $\mathbf{7 0 , 8}$ & $\mathbf{7 1 , 8}$ \\
fragmentos de peixe & - & 33,5 & 40,4 \\
peixe (n.i.) & 68 & 19,5 & 14,3 \\
Plagioscion squamosissimus (corvina) & 32 & 16,6 & 16,2 \\
Cichlidae & 26 & 1 & 0,8 \\
Siluriformes & 3 & 0,2 & 0,1 \\
Ephemeroptera & - & $\mathbf{2 2 , 6}$ & $\mathbf{2 3 , 8}$ \\
Campsurinae (fragmentos de & - & 13,5 & 9,5 \\
Ehemeroptera) & - & 9,1 & 14,3 \\
Massa de ovos de Ephemeroptera & $\mathbf{8}$ & $\mathbf{1 , 0 8}$ & $\mathbf{1 , 4 6}$ \\
Odonata & &
\end{tabular}


Phyllocycla sp

$\begin{array}{ccc}5 & 1 & 1,1 \\ 3 & 0,6 & 0,3 \\ - & 0,2 & 0,06\end{array}$

fragmentos de Odonata

37

Larva de Diptera

Ablabesmyia sp

Asheum sp

Brundiniella sp

Ceratopogonidae

Chaoborus sp

Coelotanypus sp

Cryptochironomus sp

Goeldichironomus sp

Harnischia sp

\section{Pupa de Diptera}

pupa de Chaoborus sp

pupa de Chironomidae

1

34

1

33

Outros

larva de Trichoptera

16

fragmentos de inseto

Copepoda

fragmentos de Copepoda

Notodiaptomus sp (Calanoida)

Outros

Machobrachium sp (Camarão)

Material vegetal

Detritos

$-$

3

$\begin{array}{lll}3 & 0 & 0\end{array}$

3

0

0

$1 \quad 0,7 \quad 1$

$\begin{array}{lll}- & - & 0,2\end{array}$

$\begin{array}{lll}- & 0,1 & 0,03\end{array}$

O reservatório de Ibitinga foi estudado em dezembro de 2002, dezembro de 2003 e fevereiro de 2004. Foram analisados 199 estômagos, sendo que destes 21 estômagos estavam completamente cheios, 38 estavam apenas com $1 / 4$ do estômago com conteúdo e 79 estavam vazios (Figura 18). 


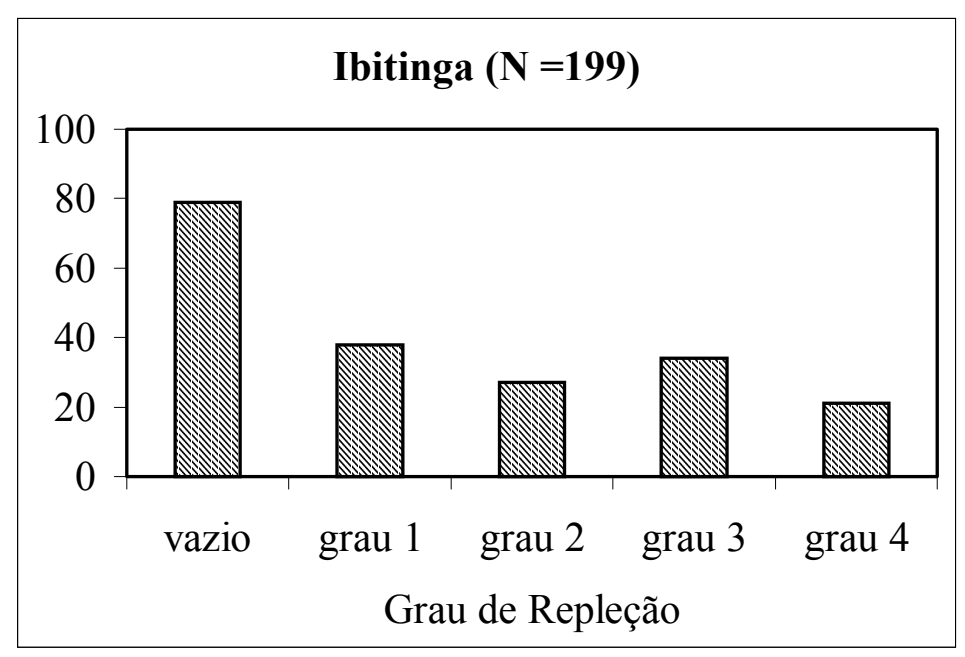

Figura 18: Grau de repleção dos estômagos das corvinas (P. squamosissimus) coletados, nos meses de dezembro de 2002, dezembro de 2003 e fevereiro de 2004.

Nesse reservatório, Plagioscion squamosissimus apresentou uma dieta alimentar baseada principalmente em peixes e insetos aquáticos. O item alimentar Phyllocycla sp (ninfa de Odonata) $(35,8 \%)$ foi o conteúdo com maior freqüência de ocorrência, seguido dos itens fragmentos de peixe (18,3\%), fragmentos de inseto $(15,8 \%)$, Libellulidae (ninfa de Odonata) (7,5\%), larvas de Trichoptera (6,6\%), peixe (não identificado) (5,8\%), Campsurinae (ninfas de Ephemeroptera) (5,8\%), fragmentos de Odonata (5,8\%), larva de Chaoborus sp (Diptera) (5\%), material vegetal (4,1\%), escama (2,5\%) e pupa de Chironomidae (Diptera) (1,6\%).

Os itens Copepoda Calanoida, Copepoda Cyclopoida, Gastropoda (Mollusca), Hyallela sp (Amphipoda), Oscillatoria sp (Cyanophyceae) e Pseudoanabaena sp (Cyanophyceae) apresentaram a mesma frequência de ocorrência (0,8\%) (Figura 19). 


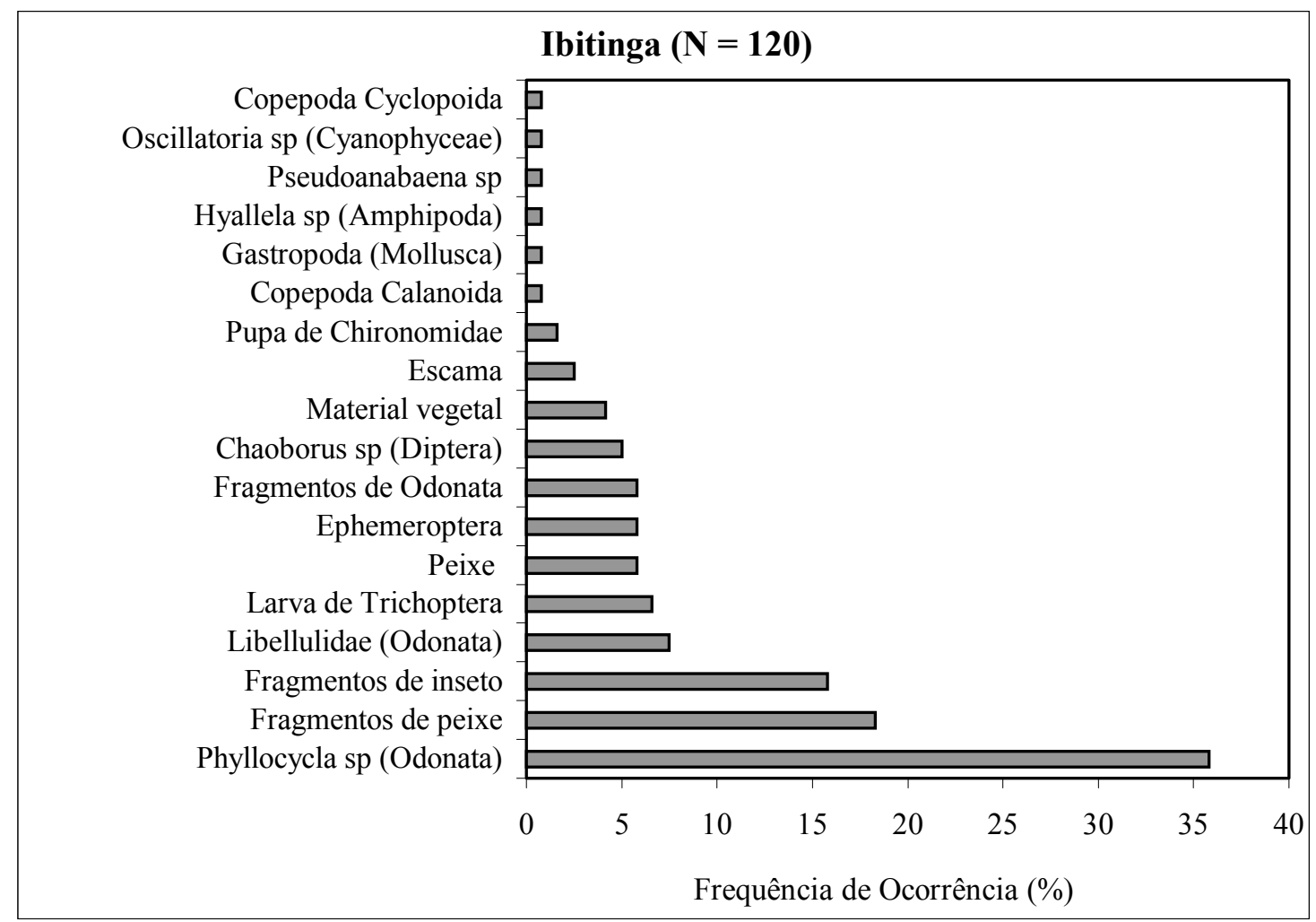

Figura 19: Freqüência de ocorrência (\%) dos itens alimentares encontrados nos estômagos de $P$. squamosissimus, coletados no reservatório de Ibitinga, nos meses de dezembro de 2002, dezembro de 2003 e fevereiro de 2004.

O item alimentar Phyllocycla sp (ninfa de Odonata) foi o mais importante em relação ao volume de todos os itens ingeridos por $P$. squamosissimus, representando $38,4 \%$, seguido dos itens fragmentos de peixe (33,5\%), Libellulidae (ninfa de Odonata) e fragmentos de insetos $(5,3 \%)$.

Alguns itens como Copepoda Calanoida, Copepoda Cyclopoida, Hyallela sp (Amphipoda), larva de Chaoborus sp (Diptera), pupa de Chironomidae (Diptera) e Gastropoda (Mollusca) não tiveram o volume determinado devido ao tamanho dos indivíduos e a pequena quantidade encontrada no conteúdo estomacal .

Em relação ao peso, o item fragmentos de peixe contribuiu com $58,5 \%$ do peso de todos os itens consumidos. Os itens alimentares como, Copepoda Calanoida, Copepoda Cyclopoida, Amphipoda (Hyallela sp), larva de Diptera (Chaoborus sp), pupa de Chironomidae (Diptera) e Gastropoda (Mollusca), não apresentaram valores significativos (Tabela 12).

Os itens alimentares Phyllocycla sp (ninfa de Odonata), Libellulidae (ninfa de Odonata) e fragmentos de Odonata, somados foram os mais representativos em termos de abundância numérica, com 93 indivíduos consumidos. 
Tabela 12: Abundância numérica, volume (\%) e peso seco (\%) dos itens alimentares consumidos por $P$. squamosissimus, coletados no reservatório de Ibitinga, nos meses de dezembro de 2002, dezembro de 2003 e fevereiro de 2004.(n. i. = não identificado).

\begin{tabular}{lccc}
\hline \multicolumn{1}{c}{ Itens Alimentares } & $\begin{array}{c}\text { Abundância } \\
\text { N }\end{array}$ & $\begin{array}{c}\text { Volumétrico } \\
\text { V (\%) }\end{array}$ & $\begin{array}{c}\text { Gravimétrico } \\
\mathbf{P ~ ( \% )}\end{array}$ \\
\hline Peixe & $\mathbf{1 2}$ & $\mathbf{3 5 , 9}$ & $\mathbf{8 7}$ \\
fragmentos de peixe & - & 33,5 & 58,5 \\
Peixe (n.i.) & 12 & 1,8 & 1,0 \\
Escama & - & 0,6 & 27,5 \\
Odonata & $\mathbf{9 3}$ & $\mathbf{5 1 , 4}$ & $\mathbf{6 , 7}$ \\
Phyllocycla sp & 78 & 38,4 & 2,3 \\
Libellulidae & 15 & 9,8 & 1,3 \\
fragmento de Odonata & - & 3,2 & 3,1 \\
Larva de Diptera & $\mathbf{8}$ & - & $\mathbf{0 , 6}$ \\
Chaoborus sp & 8 & 0 & 0,6 \\
Pupa de Diptera & $\mathbf{2}$ & - & - \\
pupa de Chironomidae & 2 & 0 & 0 \\
Copepoda & $\mathbf{3}$ & - & - \\
Calanoida & 2 & 0 & 0 \\
Cyclopoida & 1 & 0 & 0 \\
Cyanophyceae & $\mathbf{2}$ & $\mathbf{1 , 2}$ & $\mathbf{0 , 3 3}$ \\
Oscillatoria sp & 1 & 1,0 & 0,3 \\
Pseudoanabaena sp & 1 & 0,2 & 0,03 \\
Outros & & & \\
Larva de Trichoptera & 18 & 1,4 & 2,0 \\
Gastropoda (Mollusca) & 1 & 0 & 0,02 \\
Ninfa de Ephemeroptera & - & 2,6 & 1,3 \\
Material vegetal & - & 1,6 & 0,3 \\
Fragmentos de inseto & - & 5,3 & 2,3 \\
Hyallela sp (Amphipoda) & 1 & 0,2 & 0 \\
\hline
\end{tabular}

O reservatório de Promissão foi estudado nos meses de maio de 2003 e dezembro de 2003. No total, 134 estômagos foram analisados, sendo que 36 estômagos estavam cheios de conteúdo e 44 estavam completamente vazios (Figura 20). 


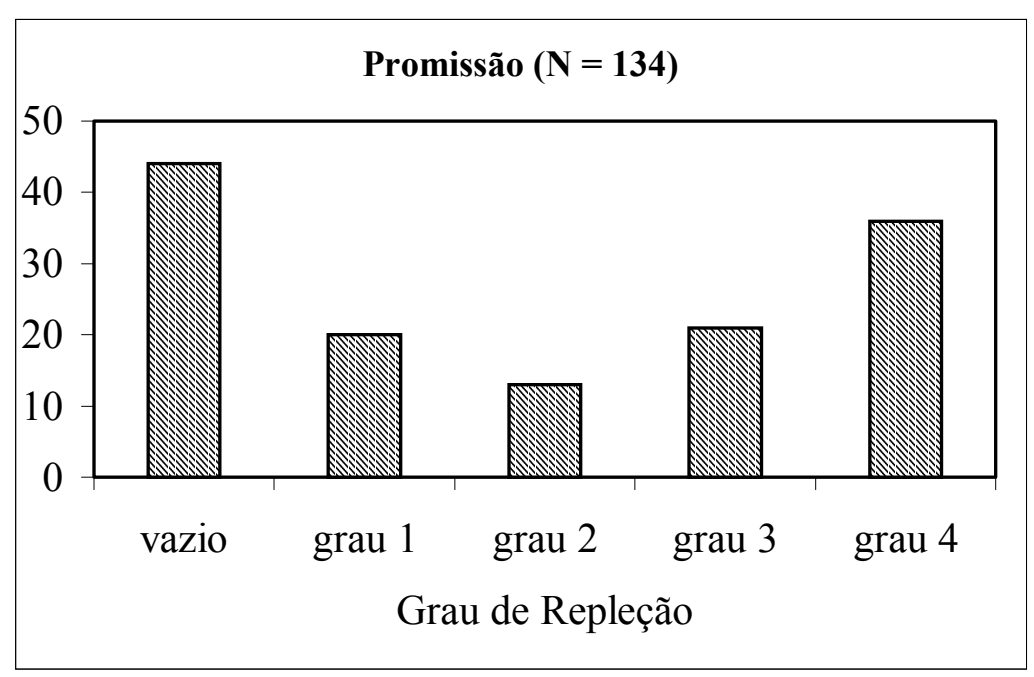

Figura 20: Grau de repleção dos estômagos das corvinas (P. squamosissimus), coletadas no reservatório de Promissão, nos meses de maio e dezembro de 2003.

Nesse reservatório pode-se observar que a corvina ( $P$. squamosissimus) apresentou uma mudança nos itens alimentares ingeridos, utilizando o camarão de água doce como um dos principais itens consumidos.

O camarão (Macrobrachium sp) foi o item mais freqüente representando 56,9\%, seguido dos itens Phyllocycla sp (ninfa de Odonata) (23,2\%), Libellulidae (ninfa de Odonata) (11,6\%), Campsurinae (fragmentos de Ephemeroptera) (9,3\%), Notonectidae (Hemiptera) $(6,9 \%)$, fragmentos de peixe $(5,8 \%)$, fragmentos de Odonata $(4,6 \%)$, fragmentos de inseto (3,4\%), Macrobrachium sp (pós larva de camarão) $(3,4 \%)$, peixe (não identificado) (3,4\%), larva de Chironomidae (Diptera) (2,3\%), pupa de Chironomidae (Diptera) (2,3\%), Notodiaptomus sp (Copepoda Calanoida) (2,3\%), massa de ovos de Ephemeroptera (2,3\%) e larva de Trichoptera (2,3\%). Os demais itens alimentares contribuíram com $1,1 \%$ da frequência de ocorrência (Figura 21). 


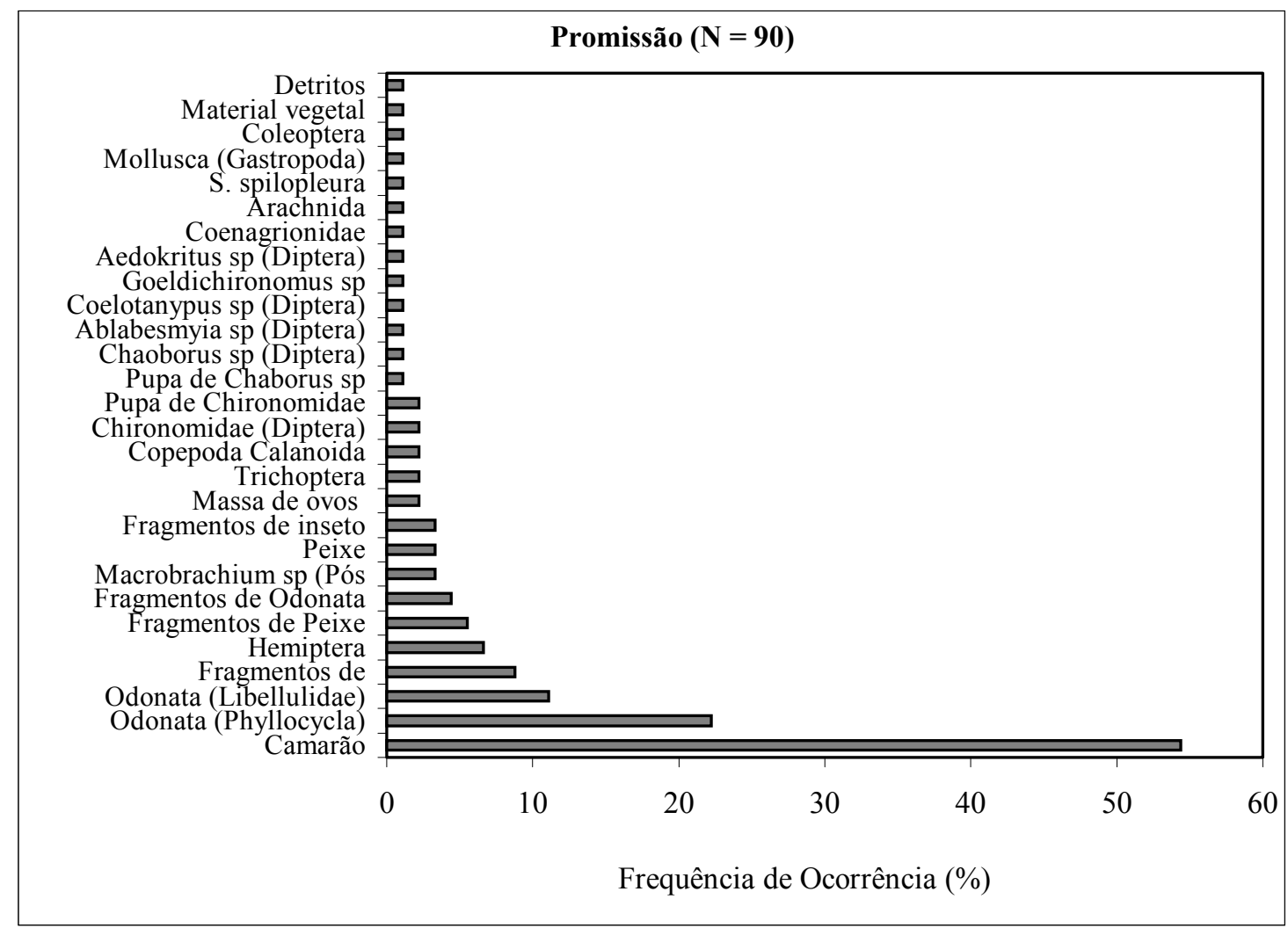

Figura 21: Freqüência de ocorrência (\%) dos itens alimentares encontrados no estômago de $P$. squamosissimus, coletados no reservatório de Promissão, nos períodos de maio e dezembro de 2003.

$\mathrm{O}$ alimento mais ingerido pela corvina ( $P$. squamosissimus) foi o camarão (Macrobrachium sp), sendo consumidos 206 indivíduos (Tabela 13).

Em relação ao volume, o item camarão (Macrobrachium $\mathrm{sp}$ ) foi o mais importante de todos os itens ingeridos por P. squamosissimus, representando 51,8\%, seguido dos itens Phyllocycla sp (ninfa de Odonata) (19,2\%), Libellulidae (ninfa de Odonata) (6,2\%), fragmentos de peixe e Serrasalmus spilopleura (peixe) com 5,8\%.

Alguns itens como as seis espécies de larva de Diptera (Chironomidae, Chaoborus sp, Ablabesmyia sp, Coelotanypus sp, Goeldichironomus sp e Aedokritus sp), pupa de Chironomidae e Chaoborus sp (Diptera), Melanoides tuberculata (Mollusca), Copepoda Calanoida não puderam ter o volume determinado devido ao tamanho dos indivíduos e a pequena quantidade encontrada no conteúdo estomacal.

Em relação à biomassa, o item Macrobrachium sp (camarão) contribuiu com $65 \%$ do peso de todos os itens consumidos. Os itens alimentares como as seis espécies de larva de Diptera (Chironomidae, Chaoborus sp, Ablabesmyia sp, Coelotanypus sp, 
Goeldichironomus sp e Aedokritus sp), pupa de Chironomidae e Chaoborus sp (Diptera) e Copepoda Calanoida não apresentaram valores significativos (Tabela 13).

Tabela 13: Abundância numérica, volume (\%) e peso seco (\%) dos itens alimentares consumidos por $P$. squamosissimus no reservatório de Promissão, nos meses de maio e dezembro de 2003. (n. i. = não identificado).

\begin{tabular}{|c|c|c|c|}
\hline Itens Alimentares & $\begin{array}{c}\text { Abundância } \\
\mathbf{N}\end{array}$ & $\begin{array}{c}\text { Volumétrico } \\
\text { V (\%) }\end{array}$ & $\begin{array}{c}\text { Gravimétrico } \\
\mathbf{P}(\mathbf{( \% )}\end{array}$ \\
\hline Peixe & 2 & 12,3 & 8,4 \\
\hline fragmentos de peixe & - & 5,8 & 0,8 \\
\hline peixe (n. i.) & 1 & 0,7 & 0,3 \\
\hline Serrasalmus spilopleura (pirambeba) & 1 & 5,8 & 6,8 \\
\hline Crustacea (camarão de água doce) & 206 & 55,7 & 68,4 \\
\hline Macrobrachium sp & 156 & 51,8 & 65 \\
\hline Macrobrachium sp (Pós-larva) & 50 & 3,9 & 3,4 \\
\hline Odonata & 60 & 28 & 19,6 \\
\hline Phyllocycla sp & 37 & 19,2 & 16,3 \\
\hline Libellulidae & 19 & 6,2 & 2,8 \\
\hline Coenagrionidae & 4 & 0,5 & 0,2 \\
\hline Fragmentos de Odonata & - & 2,1 & 0,3 \\
\hline Ephemeroptera & - & 1,6 & 2,4 \\
\hline Campsurinae & - & 1,1 & 2 \\
\hline Massa de ovos & - & 0,5 & 0,4 \\
\hline Larva de Díptera & 14 & - & - \\
\hline Ablabesmyia sp & 1 & 0 & 0 \\
\hline Aedokritus sp & 1 & 0 & 0 \\
\hline Chaoborus sp & 2 & 0 & 0 \\
\hline Chironomidae & 2 & 0 & 0 \\
\hline Coelotanypus sp & 1 & 0 & 0 \\
\hline Goeldichironomus sp & 7 & 0 & 0 \\
\hline Pupa de Díptera & 3 & - & - \\
\hline Chabororus sp & 1 & 0 & 0 \\
\hline Chironomidae & 2 & 0 & 0 \\
\hline \multicolumn{4}{|l|}{ Outros } \\
\hline Larva de Trichoptera & 12 & 0,5 & 0,8 \\
\hline Notonectidae (Hemíptera) & 13 & 0,4 & 0,2 \\
\hline Aracnida & 1 & 0,1 & 0,2 \\
\hline Coleóptera & 1 & 0,1 & 0 \\
\hline Fragmentos de inseto & - & 0 & 0,1 \\
\hline Melanoides tuberculata (Mollusca) & 1 & 0 & 0,8 \\
\hline Material Vegetal & - & 0,4 & 0 \\
\hline Detritos & - & 0,1 & 0,1 \\
\hline Copepoda Calanoida & 2 & 0 & 0 \\
\hline
\end{tabular}


O reservatório de Nova Avanhandava foi estudado nos períodos de dezembro de 2002 e janeiro de 2004. 150 estômagos foram analisados, destes 35 estavam vazios e 33 estavam somente com 1/4 (grau 1) de conteúdo alimentar, 32 estômagos estavam completamente cheios (grau 4) (Figura 22).

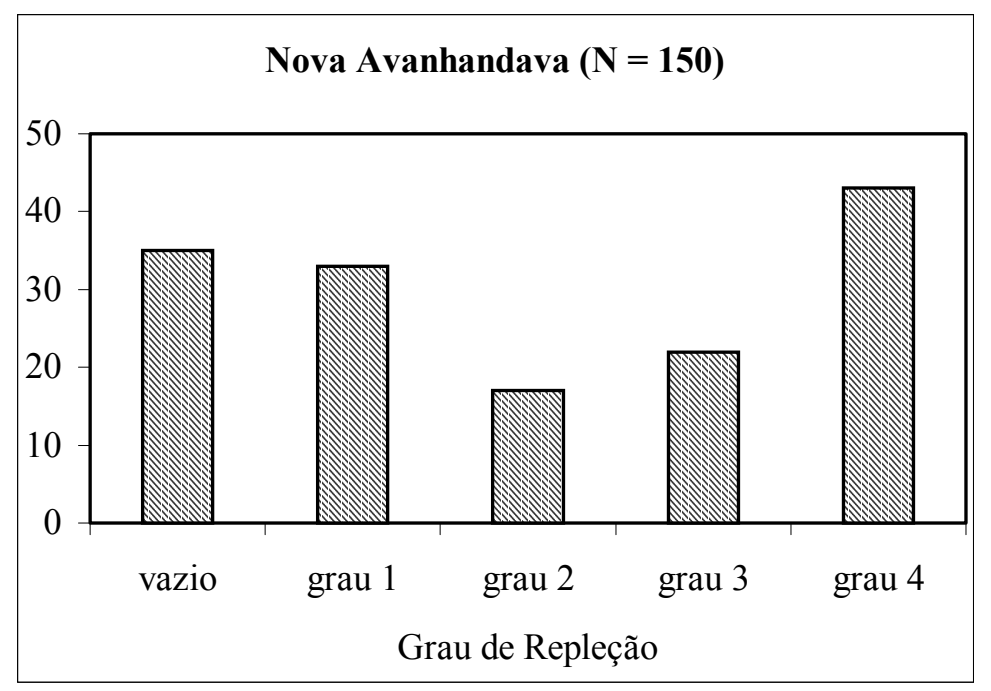

Figura 22: Grau de repleção dos estômagos das corvinas (P. squamosissimus), coletadas no reservatório de Nova Avanhandava, nos meses de dezembro de 2002 e janeiro de 2004.

O item alimentar com maior freqüência de ocorrência encontrada nos estômagos foi Macrobrachium sp (pós larva de camarão) (32,1\%), seguido dos itens Macrobrachium sp (camarão) (29,5\%), Campsurinae (fragmentos de Ephemeroptera) $(22,6 \%)$, Phyllocycla sp (ninfa de Odonata) (19,1\%), fragmentos de peixe $(9,5 \%)$ e Libellulidae (ninfa de Odonata) (8,6\%) (Figura 23). 


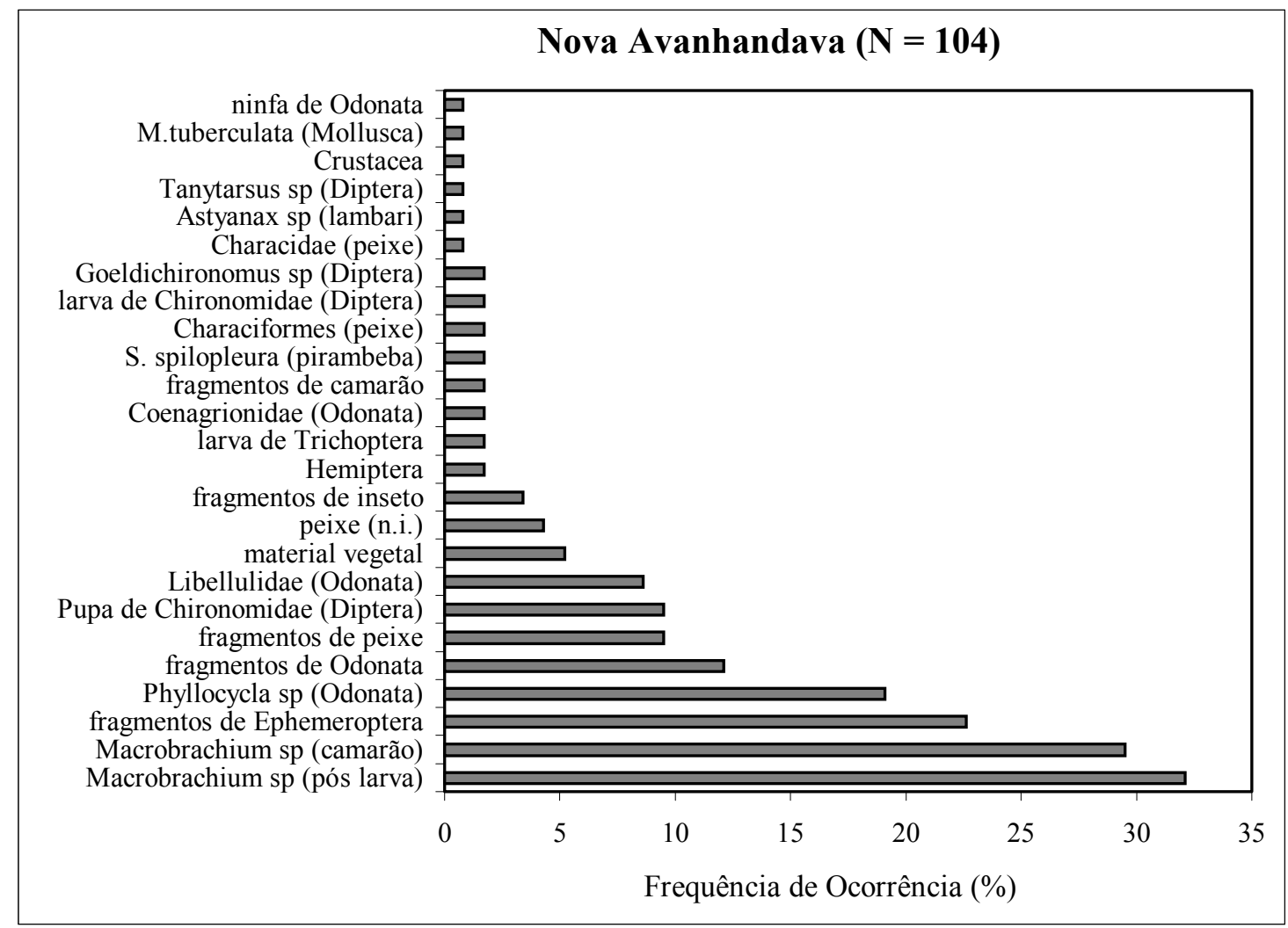

Figura 23: Freqüência de ocorrência (\%) dos itens alimentares encontrados no estômago de $P$. squamosissimus no reservatório de Nova Avanhandava, nos meses de dezembro de 2002 e janeiro de 2004.

Os itens alimentares mais encontrados nos estômagos das corvinas analisadas foram 246 indivíduos da espécie Macrobrachium sp (camarão e pós larva de camarão) e 41 indivíduos de Odonata (Coenagrionidae, Libellulidae, Phyllocycla sp, fragmentos de Odonata e ninfa de Odonata).

O item Macrobrachium sp (camarão) foi o mais significativo em relação ao volume e a biomassa, representando $53 \%$ do volume total e $61,1 \%$ da biomassa (Tabela 14). 
Tabela 14: Abundância numérica, volume (\%) e peso seco (\%) dos itens alimentares consumidos por $P$. squamosissimus no reservatório de Nova Avanhandava, nos meses de dezembro de 2002 e janeiro de 2004. (n. i. = não identificado)

\begin{tabular}{|c|c|c|c|}
\hline Itens Alimentares & $\begin{array}{c}\text { Abundância } \\
\mathbf{N}\end{array}$ & $\begin{array}{c}\text { Volumétrico } \\
\text { V (\%) }\end{array}$ & $\begin{array}{c}\text { Gravimétrico } \\
\mathbf{P}(\mathbf{\%})\end{array}$ \\
\hline Peixe & 10 & 13,7 & 19,6 \\
\hline Fragmentos de peixe & - & 2,6 & 2 \\
\hline Peixe (n.i.) & 4 & 6,1 & 1,8 \\
\hline Serrasalmus spilopleura (pirambeba) & 2 & 2,2 & 2,7 \\
\hline Characiformes & 2 & 2,2 & 3,1 \\
\hline Characidae & 1 & 0,4 & 4,3 \\
\hline Astyanax sp (lambari) & 1 & 0,2 & 5,7 \\
\hline Crustacea (camarão de água doce) & 246 & $\mathbf{5 8 , 9}$ & 63,6 \\
\hline Macrobrachium sp (Pós-larva) & 117 & 5,7 & 2,5 \\
\hline Macrobrachium $\mathrm{sp}$ & 129 & 53 & 61,1 \\
\hline Fragmentos de camarão & - & 0,2 & 0,08 \\
\hline Odonata & 41 & 21,3 & 14,7 \\
\hline Coenagrionidae & 2 & 0,1 & 0,03 \\
\hline Libellulidae & 11 & 4,8 & 2,7 \\
\hline Phyllocycla sp & 27 & 10,3 & 5,4 \\
\hline Fragmentos de Odonata & - & 6,1 & 6,6 \\
\hline Ninfa de Odonata (n. i.) & 1 & 0 & 0 \\
\hline Larva de Díptera & 5 & - & - \\
\hline Chironomidae & 3 & 0 & 0 \\
\hline Goeldichironomus sp & 1 & 0 & 0 \\
\hline Tanytarsus sp & 1 & 0 & 0 \\
\hline Pupa de Diptera & 14 & 0,9 & $\mathbf{0 , 8}$ \\
\hline Chironomidae & 14 & 0,9 & 0,8 \\
\hline \multicolumn{4}{|l|}{ Outros } \\
\hline Larva de Trichoptera & 2 & 0 & 0,2 \\
\hline Fragmentos de inseto & - & 0,3 & 0,08 \\
\hline Notonectidae (Hemiptera) & 1 & 0,1 & 0,01 \\
\hline Campsurinae & - & 1 & 0,6 \\
\hline Crustacea & 1 & 0 & 0 \\
\hline Melanoides tuberculata (Mollusca) & 1 & 0 & 0,2 \\
\hline Material vegetal & - & 3,3 & 0,08 \\
\hline
\end{tabular}

No reservatório de Três Irmãos foram analisados 156 estômagos da corvina $(P$. squamosissimus), nos períodos de maio de 2003 e janeiro de 2004. Durante a análise do conteúdo estomacal foram encontrados 39 estômagos vazios e 53 estômagos completamente cheios (Figura 24). 


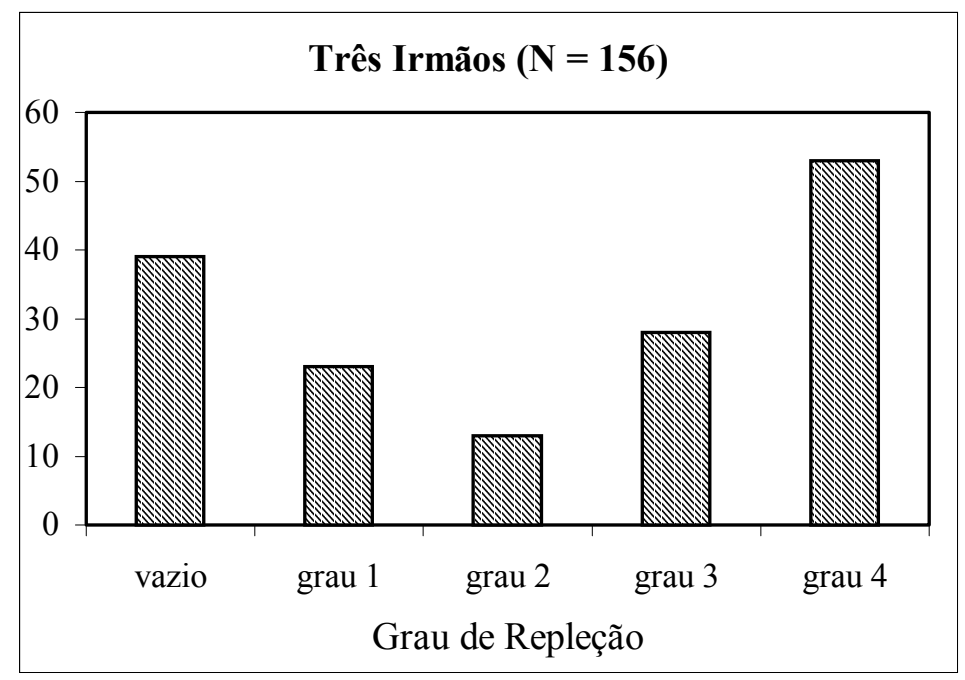

Figura 24: Grau de repleção dos estômagos das corvinas (P. squamosissimus) coletadas, no reservatório de Três Irmãos, nos meses de maio de 2003 e janeiro de 2004.

Os itens alimentares com maior freqüência de ocorrência nos estômagos foram pós larva de camarão (Macrobrachium sp) (76,9\%) e camarão (Macrobrachium sp), (50,4\%). (Figura 25).

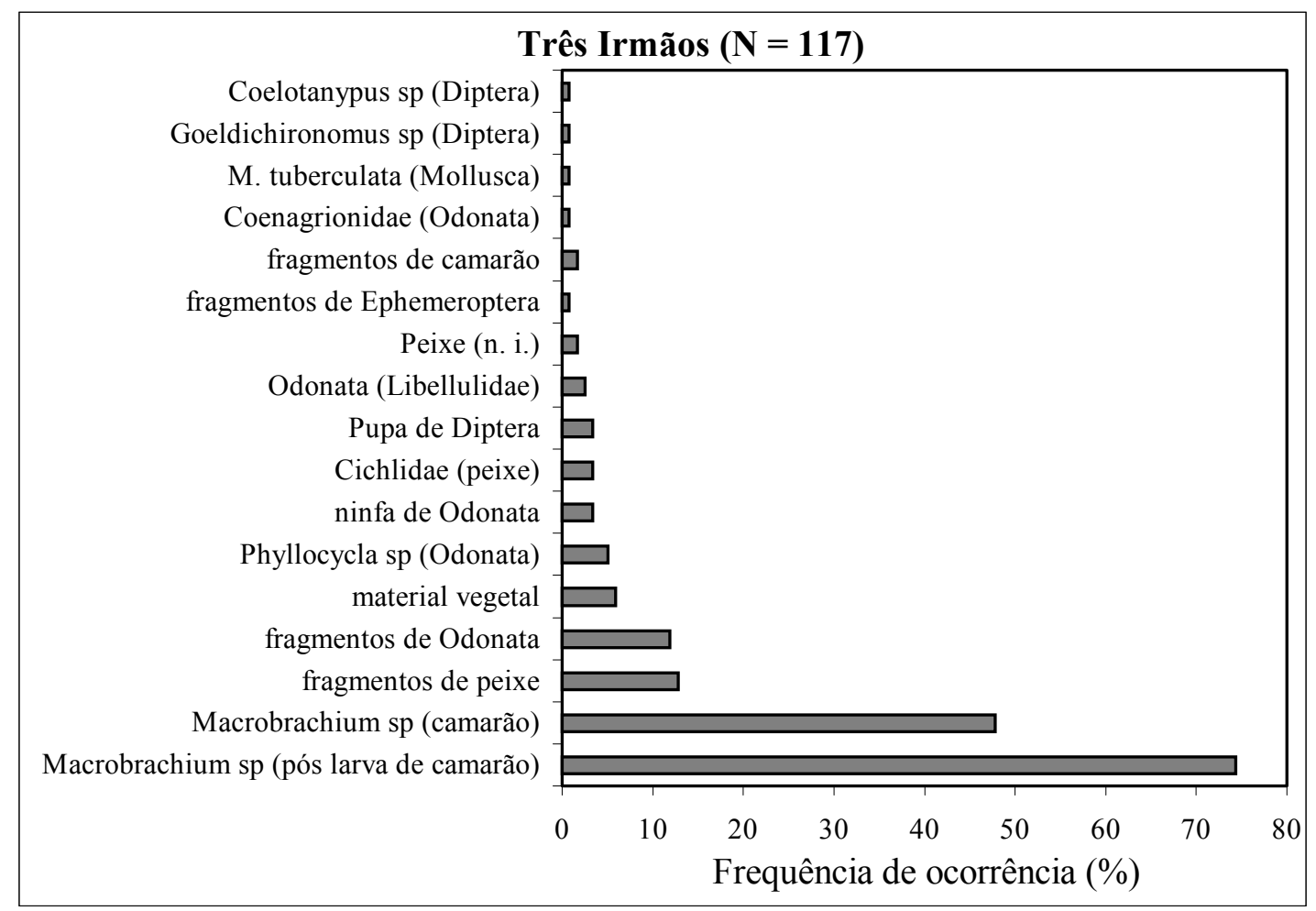

Figura 25: Freqüência de ocorrência (\%) dos itens alimentares encontrados nos estômagos de $P$. squamosissimus, coletadas no reservatório de Três Irmãos, nos períodos de maio de 2003 e janeiro de 2004. (n. i. = não identificado). 
Dentre os itens consumidos, aquele numericamente mais abundante foi o camarão (Macrobrachium sp) com 476 indivíduos (Tabela 15). Em relação ao volume os itens pós larva de camarão (Macrobrachium sp) e camarão (Macrobrachium sp) foram os mais importantes com $37,3 \%$ e $30,5 \%$, respectivamente.

Para a biomassa os itens mais importantes foram camarão (Macrobrachium $\mathrm{sp}$ ) $(32,3 \%)$, peixe (sem identificação) $(13,7 \%)$ e pós larva de camarão (Macrobrachium sp) $(13,2 \%)$ (Tabela 15).

Tabela 15: Abundância numérica, volume (\%) e peso seco (\%) dos itens alimentares consumidos por $P$. squamosissimus no reservatório de Três Irmãos, nos meses de dezembro de 2002 e janeiro de 2004. (n. i. = não identificado).

\begin{tabular}{lccc}
\hline \multicolumn{1}{c}{ Itens Alimentares } & $\begin{array}{c}\text { Abundância } \\
\mathbf{N}\end{array}$ & $\begin{array}{c}\text { Volumétrico } \\
\mathbf{V}(\mathbf{\%})\end{array}$ & $\begin{array}{c}\text { Gravimétrico } \\
\mathbf{P ~ ( \% )}\end{array}$ \\
\hline Peixe & $\mathbf{2}$ & $\mathbf{2 3 , 1}$ & $\mathbf{4 4 , 4}$ \\
Fragmentos de peixe & - & 11,2 & 30 \\
peixe (n.i.) & 1 & 11,8 & 13,7 \\
Cichlidae & 1 & 0,1 & 0,75 \\
Crustacea (camarão de água doce) & $\mathbf{4 7 6}$ & $\mathbf{6 8 , 3}$ & $\mathbf{4 5 , 5}$ \\
Macrobrachium sp (Pós-larva) & 376 & 37,3 & 13,2 \\
Macrobrachium sp & 100 & 30,5 & 32,3 \\
Fragmentos de camarão & - & 0,5 & 0,02 \\
Odonata & $\mathbf{2 5}$ & 7 & $\mathbf{6 , 7 3}$ \\
Coenagrionidae & 1 & 0,1 & 0 \\
Fragmentos de Odonata & - & 0,5 & 3,3 \\
ninfa de Odonata (n. i.) & 9 & 1,2 & 0,03 \\
Libellulidae & 4 & 0,5 & 0,1 \\
Phyllocycla sp & 11 & 4,7 & 3,3 \\
Larva de Díptera & $\mathbf{2}$ & - & - \\
Coelotanypus sp & 1 & 0 & 0 \\
Goeldichironomus sp & 1 & 0 & 0 \\
Pupa de Diptera & & & \\
Pupa de Diptera (n. i.) & 1 & 1 & 0,3 \\
Outros & & & \\
Campsurinae (fragmentos de & & & \\
Ephemeroptera) & - & 0 & 0,03 \\
Melanoides tuberculata (Mollusca) & 1 & 0 & 0 \\
Material vegetal & - & 1,0 & \\
\hline
\end{tabular}

Os resultados obtidos com a análise de conteúdos estomacais permitiram caracterizar a corvina ( $P$. squamosissimus) como uma espécie piscívora generalista, consumindo principalmente peixes (não identificados), pequenos peixes inteiros das ordens Perciformes (família Cichlidae) e Characiformes, e em menor proporção 
indivíduos da ordem Siluriformes, indivíduos das espécies Astyanax sp Serrasalmus spilopleura (Characiformes, Characidae) e Plagioscion squamosissimus (Perciformes, Scianidae).

O trabalho realizado por MARCIANO (2005) indicou que os Characiformes predominaram (em abundância) entre os peixes coletados, seguidos da ordem Perciformes. Outros autores também mostram o domínio dos Characiformes nos reservatórios do Médio e Baixo rio Tietê, como AMARAL \& PETRERE Jr. (1994) no reservatório de Promissão, CASTRO (1994) no reservatório de Barra Bonita e BARRELLA \& PETRERE Jr. (2003) e SMITH (2004) nos reservatórios de Barra Bonita, Ibitinga, Promissão e Três Irmãos.

Os insetos aquáticos também foram bastante consumidos, sendo representados por ninfas de Odonata das famílias Gomphidae (Phyllocycla sp), Libellulidae e Coenagrionidae, ninfas de Ephemeroptera (Campsurinae), larvas de Trichoptera e larvas de Diptera (Chaoboridae e Chironomidae).

O camarão de água doce (Macrobrachium sp) foi um item alimentar muito importante sendo consumido nos três últimos reservatórios do sistema Tietê (Promissão, Nova Avanhandava e Três Irmãos).

Segundo HARMELIN-VIVIEN \& BOUCHON (1976)² apud HAHN (1991) peixes que consomem peixes, insetos e crustáceos podem apresentar proporções diferentes desses itens nas suas dietas.

BRAGA (1998) estudando a alimentação da corvina (P. squamosissimus) no reservatório de Barra Bonita classificou a espécie com hábito alimentar piscívoro, consumindo em menor escala ninfas de Odonata e de Ephemeroptera, não sendo registrada a ocorrência de crustáceos.

HAHN et al. (1997) classificou P. squamossisimus no reservatório de Itaipu e na planície de inundação do Alto Rio Paraná, como uma espécie essencialmente piscívora. Os autores também registraram o consumo de formas imaturas de insetos, como ninfas de Odonata, Ephemeroptera e larvas de Diptera (Chironomidae) e uma pequena participação de crustáceos decápodas.

\footnotetext{
${ }^{2}$ Harmelin-Vivien, M. L.; Bouchon, C. 1976. Feeding behavior of some carnivorous fishes (Serranidae and Scorpianidade) from Tulear (Madagascar). Mar. Biol, 37, p. 329-340.
} 
Nas regiões norte e nordeste, a alimentação da corvina baseia-se principalmente em peixes, insetos e crustáceos da espécie Machobrachium amazonicus (BRAGA, 1990).

GOULDING \& FERREIRA (1984), estudando a dieta de P. squamosissimus em diversos rios da Amazônia, caracterizou a espécie como especializada em comer camarões, embora tenha verificado que em águas pretas, a espécie utiliza mais peixes, sugerindo que isto deva ocorrer em função da baixa densidade de camarões neste ambiente.

A variabilidade na composição da dieta de uma dada espécie, embora relacionada a limitações comportamentais e morfológicas, está associada fortemente com diferenças na disponibilidade local do alimento (POPOVA, 1978).

A disponibilidade alimentar depende em grande parte das características físicas e químicas nas quais se encontram os reservatórios. Isto pode ser facilmente compreendido pelo fato de existir no Baixo Tietê uma condição propícia para o desenvolvimento de crustáceos (camarão de água doce).

Segundo ESTEVES (1998) em águas com elevada transparência há uma maior penetração de luz, ocasionando o máximo de biomassa e abundância de fitoplâncton e zooplâncton, importantes itens alimentares para os camarões, que se adaptam facilmente ao ambiente com grande oferta de alimento.

Nos três últimos reservatórios (Promissão, Nova Avanhandava e Três Irmãos) do sistema em cascata, o camarão (Macrobrachium sp), tem uma distribuição mais ampla e foi um importante recurso alimentar utilizado pela corvina (P. squamosissimus).

Segundo ALMEIDA et al. (1997), espécies predadoras completam a sua dieta com insetos aquáticos e crustáceos. Esse fato foi constatado na presente pesquisa.

Durante a análise de conteúdos estomacais, foram encontrados pequenos alevinos da P. squamosissimus, evidenciando o canibalismo, no reservatório de Barra Bonita e de Bariri.

No trabalho realizado por BRAGA (1998) em Barra Bonita, o autor verificou a ocorrência de canibalismo, com a ingestão de jovens de $P$. squamosissimus nos meses de março e maio de 1991 e fevereiro de 1992, logo após o período reprodutivo, mostrando que os indivíduos predados foram os que nasceram após o período reprodutivo. 
No reservatório de Barra Bonita foi registrado o canibalismo no mês novembro de 2002. Existe, portanto elevada concordância entre a dieta caracterizada para a corvina, no presente estudo, e aquela reportada anteriormente pelo referido autor.

Segundo WOOTON (1999) peixes canibais consomem uma dieta de alta qualidade e quimicamente muito parecida com sua própria constituição, o que lhes permite um crescimento mais rápido e maior fecundidade.

A ingestão de juvenis corrobora o fato de espécies introduzidas tomarem como presas indivíduos da mesma espécie (BRAGA, 1998). Neste estudo o canibalismo foi considerado esporádico, tendo sido registrado apenas em dois, dos seis reservatórios estudados.

Sobre as baixas incidências de canibalismo, NIKOLSKY (1963) comenta que, apesar deste ser um fenômeno muito difundido entre os peixes, na maioria dos casos não atinge proporções significativas.

$\mathrm{Na}$ análise da repleção gástrica de $P$. squamosissimus verificou-se uma incidência elevada de estômagos vazios. Este fato, também foi observado foi HAHN (1991) no reservatório de Itaipu e na planície de inundação do rio Paraná.

Elevadas freqüências de estômagos vazios tem sido associados à piscivoria (KAWAKAMI, 1975). A saciação em peixes carnívoros ocorre num período temporal mais curto, proporcionando a frequência alta de estômagos vazios (ZAVALA-CAMIN, 1996).

Neste trabalho a quantidade de estômagos vazios parece ser alta, mas é justificada pelo fato dos peixes piscívoros não se alimentarem continuamente, o que aumenta a probabilidade de serem capturados nesta situação (RABELO \& ARAUJOLIMA, 2002).

Um outro fator importante que pode influenciar a frequência de estômagos com alimento nos exemplares amostrados é a regurgitação, principalmente quando o instrumento de pesca utilizado é a rede de espera, que deve estressar os peixes e provocar a expulsão do alimento.

A plasticidade alimentar da corvina (Plagioscion squamosissimus) demonstrada nesse estudo explica o fato desta espécie ter sido bem sucedida na colonização dos reservatórios do Médio e Baixo rio Tietê.

Segundo AGOSTINHO et al., (2005) a espécie P. squamosissimus está estabelecida, sendo encontrada com abundância em toda bacia do rio Paraná. 
A plasticidade da espécie, demonstrada pela grande quantidade de itens alimentares registradas no seu estômago, pode afetar os estoques de outras populações de peixes desta comunidade, por exemplo, por meio da competição com espécies nativas que utilizem os mesmos recursos alimentares, como o acará (Geophagus brasiliensis), ou com espécies com hábito alimentar carnívoro como a traíra (Hoplias malabaricus) e pirambeba (Serrasalmus spilopleura).

\subsubsection{Variação Temporal na dieta de Plagioscion squamosissimus no Reservatório de Bariri no ano de 2003.}

No reservatório de Bariri, as populações de peixes foram amostradas quatro vezes. Duas coletas foram realizadas no período chuvoso (fevereiro e novembro) e duas no período seco (junho e setembro) durante o ano de 2003.

A precipitação acumulada, o volume total, a vazão defluente e o tempo de residência da água no reservatório de Bariri, para os meses amostrados estão apresentados na Tabela 16. A maior precipitação foi registrada no mês de novembro, embora em fevereiro também tenham sido registrados altos valores.

A operação da barragem e o nível da água são mantidos constantes pelo controle da vazão defluente da água no reservatório de Bariri. Como conseqüência, ocorre um curto tempo de residência, entre 10,0 e 28,0 dias. Observações locais indicam que o nível da água no reservatório flutua em torno de 1,0 metro no máximo.

Tabela 16: Precipitação acumulada no mês $(\mathrm{mm})$; volume total do reservatório $\left(\mathrm{m}^{3}\right)$, vazão defluente $\left(\mathrm{m}^{3} / \mathrm{s}\right)$ e tempo de residência (dias) para o reservatório de Bariri durante os meses de fevereiro, junho, setembro e novembro.

\begin{tabular}{ccccc}
\hline Meses & $\begin{array}{c}\text { Precipitação } \\
\text { acumulada no mês } \\
(\mathbf{m m})\end{array}$ & $\begin{array}{c}\text { Volume total do } \\
\text { reservatório } \\
(\mathbf{m 3})\end{array}$ & $\begin{array}{c}\text { Vazão } \\
\text { defluente } \\
(\mathbf{m 3} / \mathbf{s})\end{array}$ & $\begin{array}{c}\text { Tempo de } \\
\text { residência } \\
\text { (dias) }\end{array}$ \\
\hline Fevereiro & 116,3 & $546,81 \times 106$ & 796 & 10,0 \\
Junho & 11,8 & $547,35 \times 106$ & 230 & 28,0 \\
Setembro & 18,9 & $548,11 \times 106$ & 282 & 25,06 \\
Novembro & 231,2 & $547,84 \times 106$ & 368 & 18,6 \\
\hline
\end{tabular}

Foram analisados os conteúdos estomacais de 258 indivíduos de $P$. squamosissimus. Destes, 184 estômagos continham alimentos e 74 estavam vazios.

No mês de fevereiro o item alimentar mais importante foi Campsurinae (fragmentos de Ephemeroptera) (62,2\%), seguidos dos itens alimentares massa de ovos 
de Ephemerotera (37,7\%), fragmentos de peixe (26,2\%), peixe (não identificado) $(16,3 \%)$ e material vegetal $(13,1 \%)$ (Figura 26$)$.

Em junho o item mais importante em relação à freqüência de ocorrência foi fragmentos de peixe $(33,8 \%)$, seguido do item Campsurinae (fragmentos de Ephemeroptera) (32,2\%) (Figura 27).

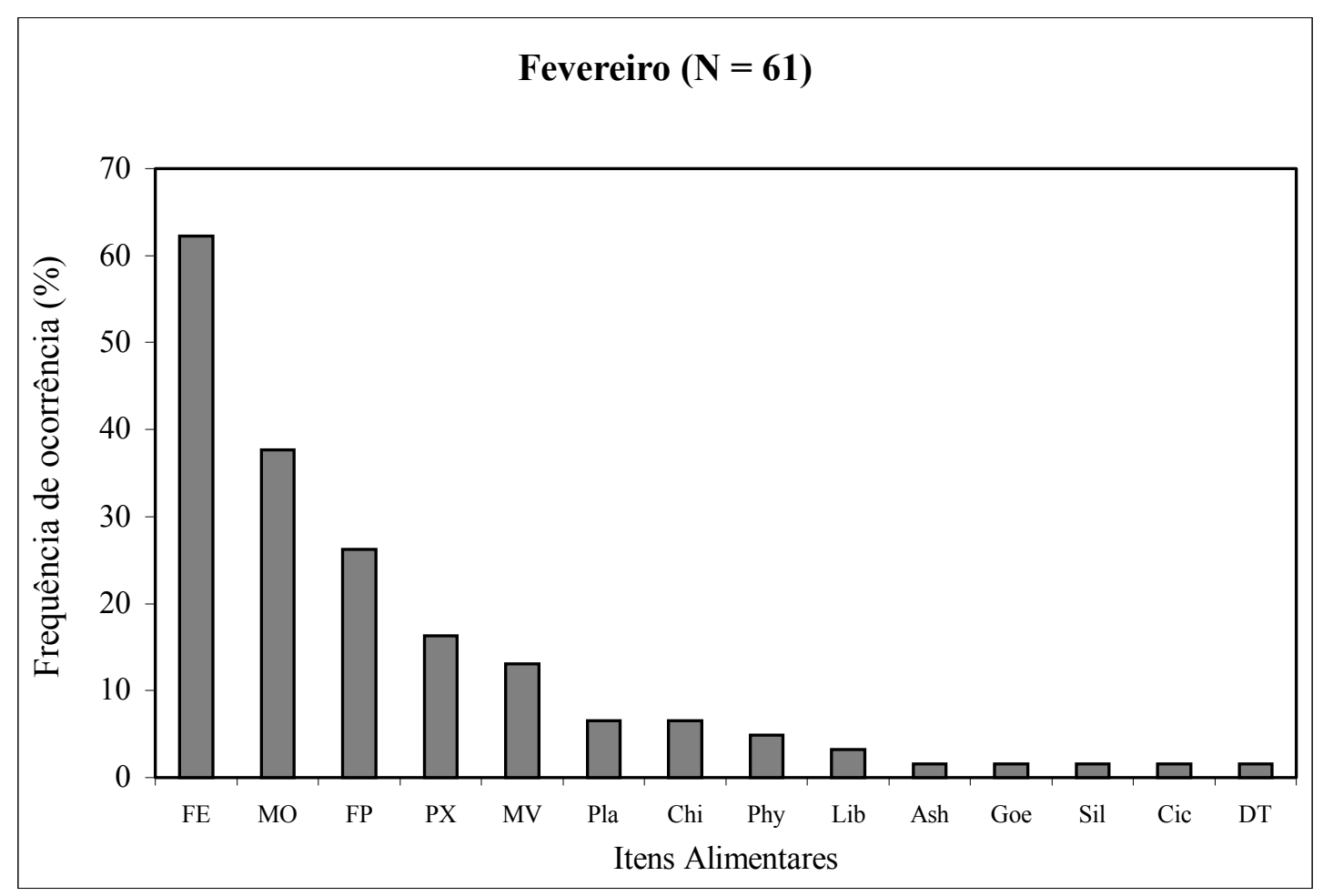

Figura 26: Freqüência de ocorrência (\%) dos itens alimentares consumidos pela corvina $(P$. squamosissimus), no reservatório de Bariri, Médio Tietê, no mês de fevereiro de 2003. FE = Campsurinae (Fragmento de Ephemeroptera); $\mathrm{MO}=$ Massa de Ovos; FP $=$ Fragmentos de Peixe; $\mathrm{PX}=$ peixe (não identificado) $\mathrm{MV}=$ Material Vegetal; Pla = Plagioscion squamosissimus; Chi = Pupa de Chironomidae (Diptera); Phy = Phlyllocycla $\mathrm{sp}$ (Ninfa de Odonata); Lib = Libellulidae (Ninfa de Odonata); Ash = Asheum sp (Larva de Diptera); Goe = Goeldichironomus sp (Larva de Diptera); Sil = Siluriformes; $\mathrm{Cic}=$ Cichlidae; DT= Detritos. 


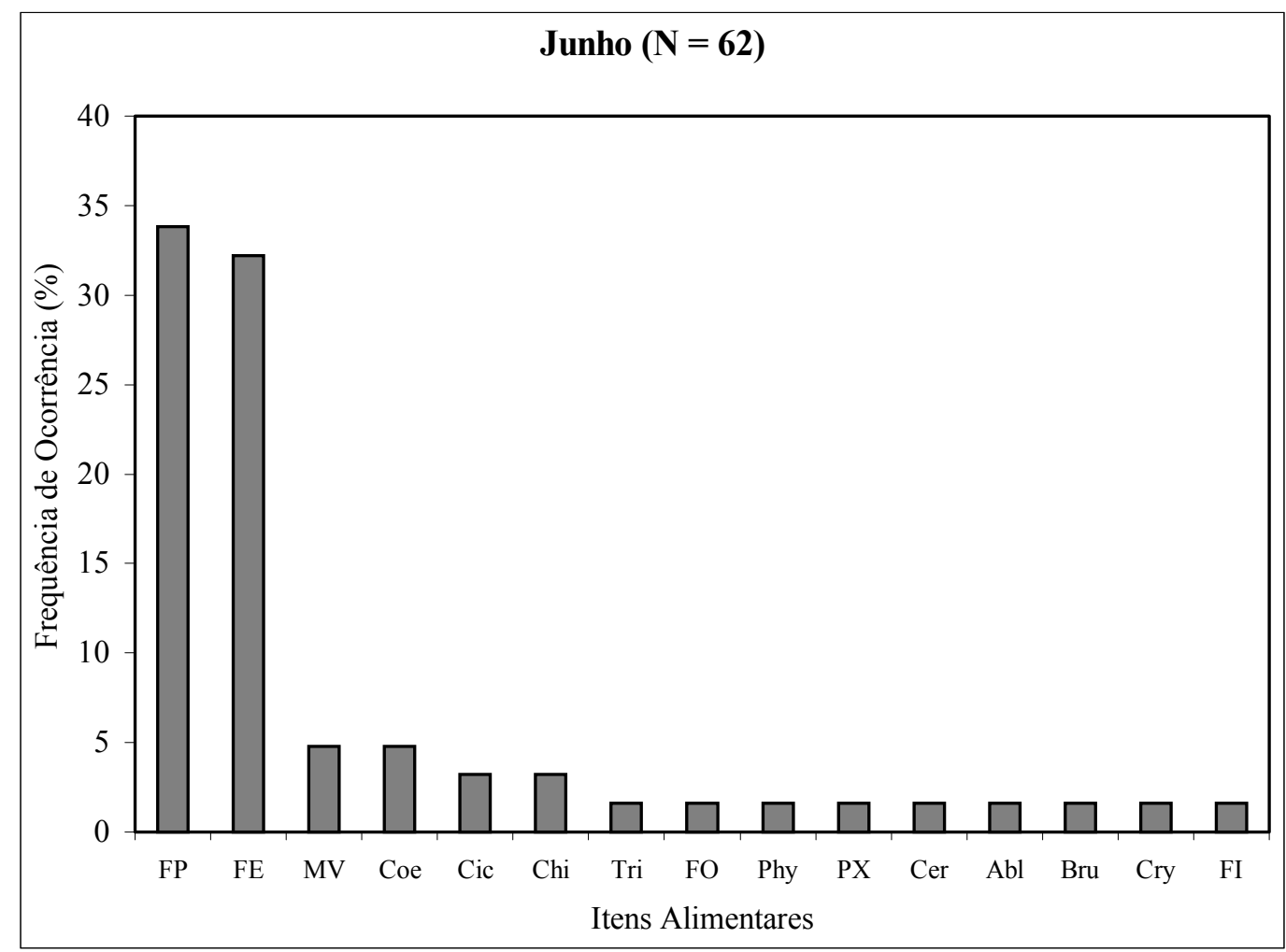

Figura 27: Freqüência de ocorrência (\%) dos itens alimentares consumidos pela corvina $(P$. squamosissimus), no reservatório de Bariri, Médio Tietê, no mês de junho de 2003. FP = Fragmentos de Peixe; FE = Fragmentos de Ephemeroptera; MV = Material Vegetal; Coe = Coelotanypus sp (Larva de Diptera); Cic = Cichlidae; Chi= Pupa de Chironomidae (Diptera); Tri $=$ Larva de Trichoptera; FO $=$ Fragmentos de Odonata; Phy $=$ Phlyllocycla $\mathrm{sp}($ Ninfa de Odonata); PX = Peixe; Cer = Ceratopogonidae (Larva de Diptera); Abl = Ablabesmyia $\mathrm{sp}$ (Larva de Diptera); Bru = Brundiniella sp (Larva de Diptera); Cry $=$ Cryptochironomus $\mathrm{sp}$ (Larva de Diptera); FI = Fragmentos de inseto.

No mês de setembro Campsurinae (fragmentos de Ephemeroptera) e pupa de Chironomidae (Diptera) foram os itens mais importantes representando $23 \%$ da freqüência, seguido dos itens massa de ovos de Ephemeroptera e fragmentos de peixe, ambos com 19,2\% (Figura 28). 


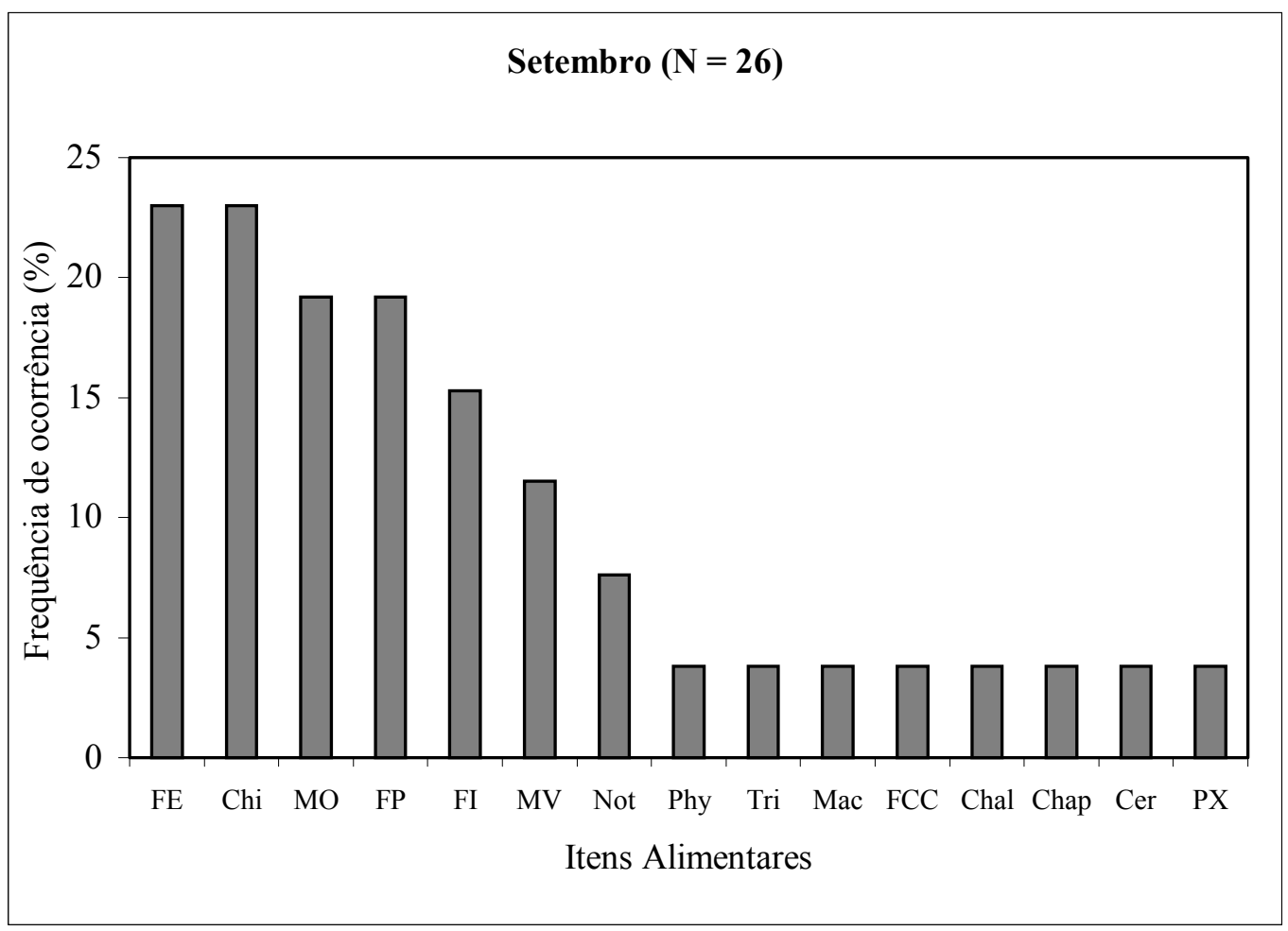

Figura 28: Freqüência de ocorrência (\%) dos itens alimentares consumidos pela corvina (P. squamosissimus), no reservatório de Bariri, Médio Tietê, no mês de setembro de 2003. MV = Material vegetal; FE $=$ Fragmentos de Ephemeroptera; Chi $=$ Pupa de Chironomidae (Diptera); $\mathrm{MO}=$ Massa de ovos; FP = Fragmentos de peixe; FI = Fragmentos de inseto; Not = Notodiaptomus sp (Copepoda Calanoida); Phy = Phlyllocycla sp (Ninfa de Odonata); Tri = Larva de Trichoptera; Mac = Macrobrachium sp (Camarão); FCC = Fragmentos de Copepoda Calanoida; Chal = Larva de Chaoborus sp (Diptera); Chap = Pupa de Chaoborus sp (Diptera); Cer = Larva de Ceratopogonidae (Diptera); PX = Peixe (não identificado).

Em novembro fragmentos de peixe $(57,1 \%)$ e material vegetal $(28,5 \%)$ foram os itens mais significativos (Figura 29). 


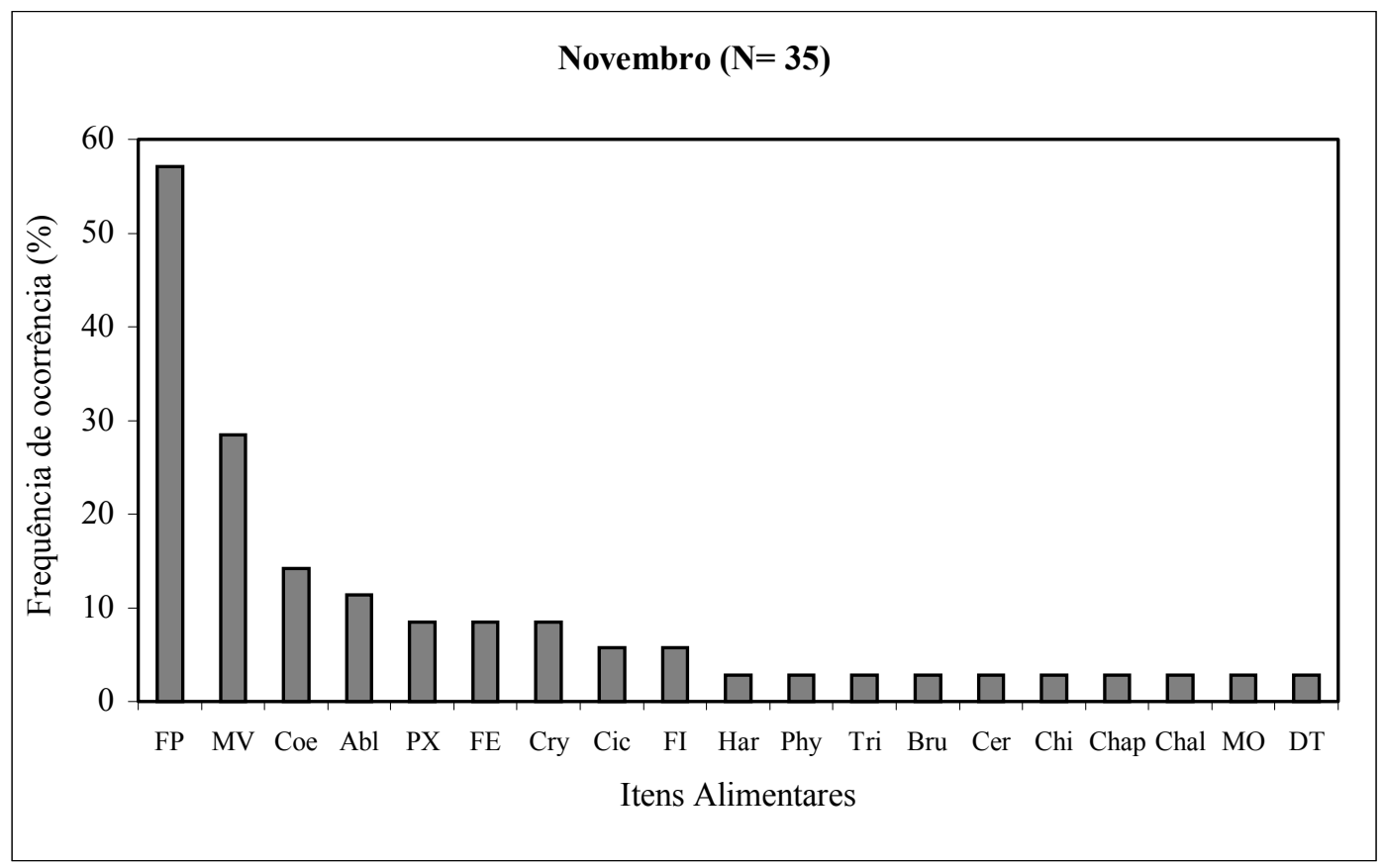

Figura 29: Freqüência de ocorrência (\%) dos itens alimentares consumidos pela corvina (P. squamosissimus), no reservatório de Bariri, Médio Tietê, no mês de novembro de 2003. FP = Fragmentos de Peixe; $\mathrm{MV}=$ Material vegetal; Coe $=$ Larva de Coelotanypus sp (Diptera); Abl = Larva de Ablabesmyia sp (Diptera); PX = peixe; FE = Fragmentos de Ephemeroptera; Cry = Larva de Cryptochironomus sp (Diptera); Cic = Cichlidae; FI $=$ Fragmentos de inseto; Har = Larva de Harnischia $\mathrm{sp}$ (Diptera); Phy = Phyllocycla $\mathrm{sp}$ (Ninfa de Odonata); Tri = larva de Trichoptera; Bru = Larva de Brundiniella $\mathrm{sp}$ (Diptera); Cer = Larva de Ceratopogonidae (Diptera); Chi = Pupa de Chironomidae (Diptera); Chap = Pupa de Chaoborus sp (Diptera); Chal = Larva de Chaoborus sp (Diptera); $\mathrm{MO}=$ Massa de ovos; DT = Detritos.

Baseado nos resultados obtidos, Plagioscion squamosissimus pode ser considerado um peixe com hábito alimentar piscívoro. Entretanto, outros itens alimentares também foram consumidos, incluindo muitos insetos aquáticos (ninfas de Odonata, Ephemeroptera e larvas de Trichoptera) e material vegetal.

BRAGA (1990), estudando aspectos da alimentação de algumas espécies de peixes do rio Tocantins, verificou que peixes foi o principal componente alimentar na dieta da corvina (P. squamosissimus).

A similaridade ou alterações nos itens consumidos por P. squamossissimus entre os quatro períodos amostrados foram comparados por uma análise de agrupamento (Figura 30). 


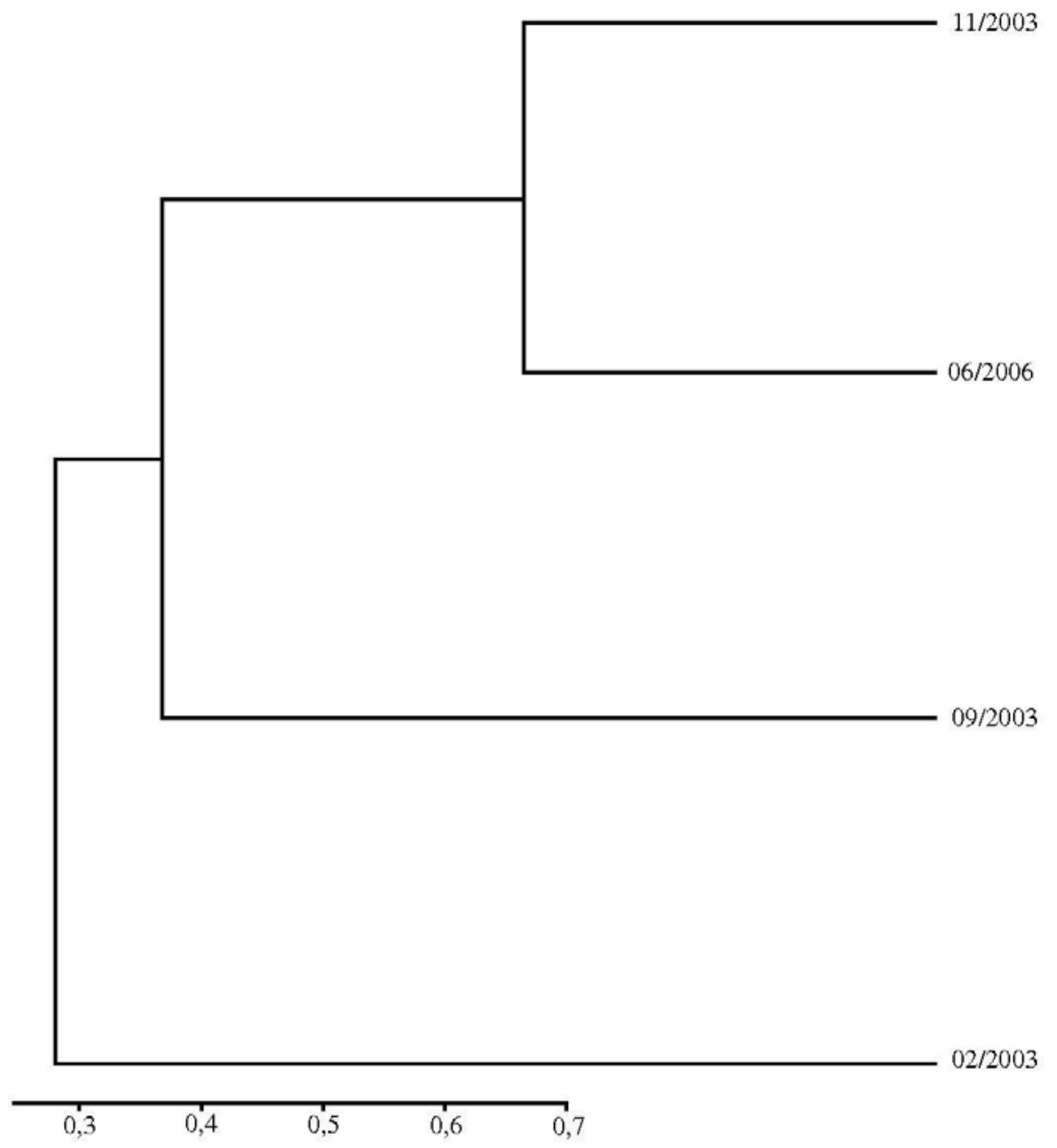

Figura 30: "Cluster" dos quatro períodos estudados no reservatório de Bariri de acordo com a dieta alimentar de Plagioscion squamosissimus. $(\mathrm{cf}=0,97)$.

Os meses novembro e junho apresentaram uma grande similaridade, sendo consumidos 19 e 15 itens alimentares, respectivamente. Nesses dois meses 14 itens alimentares em comum fizeram parte da dieta da corvina (P. squamosissimus).

Em setembro foram 16 itens alimentares utilizados pela espécie em estudo. Somente nesse período foram consumidos camarão de água doce (Macrobrachium sp) e o microcrustáceo Notodiaptomus sp (Copepoda Calanoida).

O mês de fevereiro aparece isolado com baixa similaridade com os outros períodos. Nesse mês foram consumidos 14 itens alimentares, com alta frequência de insetos, principalmente fragmentos e massa de ovos de Ephemeroptera, pupas de Chironomidae (Diptera) e ninfas de Phyllocycla sp e Libellulidae (Odonata).

Ainda nesse mês foi registrada à ocorrência de peixes da ordem Silurifomes e indivíduos da própria espécie Plagioscion squamossisimus, no conteúdo estomacal, evidenciando o canibalismo. 
MARCIANO (2005) estudando a reprodução da corvina (P. squamosissimus) no reservatório de Bariri, nos meses de fevereiro, junho, setembro e novembro do ano de 2003, verificou elevada atividade reprodutiva desta espécie no mês de fevereiro.

Segundo WOOTON (1999) o canibalismo pode ser classificado em dois tipos: o intra-coorte, ocorrendo entre indivíduos nascidos na mesma ocasião, e inter-coorte, no qual o consumo de jovens é feito por peixes de classes etárias mais velhas. No presente trabalho pode ser observado apenas o segundo tipo, onde os alevinos foram predados por indivíduos jovens ou adultos.

A análise de agrupamento revelou uma distinção na composição da dieta entre fevereiro e os outros períodos. O mês de fevereiro coincide com o período chuvoso, com menor volume de água, maior vazão defluente e menor tempo de residência da água. $\mathrm{O}$ aumento da temperatura estimula a emergência dos insetos aquáticos, e influencia na reprodução dos peixes, principalmente de P. squamosissimus que apresenta o seu pico reprodutivo em fevereiro.

\subsubsection{Variação Ontogenética na alimentação de Plagioscion squamosissimus no reservatório de Bariri}

Dietas distintas dentro de uma mesma espécie são freqüentemente encontradas conforme os estágios de desenvolvimento dos indivíduos, decorrentes das diferenças na demanda energética e nas limitações morfológicas, implicando em dietas diferenciadas durante o desenvolvimento (ABELHA et al, 2001).

Por isso optou-se por classificar os indivíduos em 7 classes modais de comprimento padrão $(2,3$ a $36,9 \mathrm{~cm})$ de maneira a verificar as possíveis diferenças dos itens consumidos por P. squamosissimus no reservatório de Bariri.

Para a espécie Plagioscion squamossisimus, os indivíduos da classe 1 (8,3 a 12,3 $\mathrm{cm}$ ) consumiram fragmentos de peixe, fragmentos de insetos, 5 espécies de larva de Diptera (Coelotanypus sp, Ablabesmyia sp, Brundiniella sp, Chaoborus sp e Ceratopogonidae), pupa de Chironomidae (Diptera), material vegetal, fragmentos de Odonata, Phyllocycla sp (ninfa de Odonata), massa de ovos de Ephemeroptera, fragmentos de Copepoda e indivíduos jovens de peixes. Os itens fragmentos de peixe (FP), Campsurinae (fragmentos de Ephemeroptera) (FE) e material vegetal (MV) apresentaram maiores freqüências. 
Os indivíduos com comprimento padrão entre 12,4 e 16,4 (classe 2) consumiram fragmentos de peixe, fragmentos de inseto, 7 espécies de larvas de Diptera (Coelotanypus sp, Ablabesmyia sp, Cryptochironomus sp, Harnischia sp, Chaoborus sp, Asheum sp e Goeldichironomus sp), Campsurinae (fragmentos de Ephemeroptera), larvas de Trichoptera, pupa de Chironomidae (Diptera), material vegetal, massa de ovos de Ephemeroptera, Notodiaptomus sp (Copepoda Calanoida), além de indivíduos jovens de peixes incluindo os da família Cichlidae e Scianidae (Plagioscion squamosissimus). Os itens fragmentos de peixe (FP), Campsurinae (fragmentos de Ephemeroptera) (FE) e pupa de Chironomidae (Diptera) (Chi) foram consumidos com maior freqüência.

Os itens alimentares consumidos por indivíduos da classe $3(16,5$ a 20,5 cm) foram fragmentos de peixe, fragmentos de inseto, fragmentos de Ephemeroptera (Campsurinae), 4 espécies de larva de Diptera (Ceratopogonidae, Chironomidae, Goeldichironomus sp e Chaoborus sp), larva de Trichoptera, 2 espécies de pupa de Diptera (Chironomidae e Chaoborus sp), material vegetal, fragmentos de Odonata, Phyllocycla sp (ninfas de Odonata) e massa de ovos de Ephemeroptera, pequenos ciclídeos, Siluriformes e alguns indivíduos de peixes que não puderam ser identificados.

Da mesma maneira que as duas classes anteriores, os itens fragmentos de peixe (FP), Campsurinae (fragmentos de Ephemeroptera) foram os mais consumidos seguidos dos itens peixe (PX) e massa de ovos (MO).

Os indivíduos da classe 4 (20,6 a 24,6 cm) consumiram fragmentos de peixe, fragmentos de inseto, fragmentos de Ephemeroptera, peixes (P. squamosissimus e não identificados), material vegetal, 2 espécies de larva de Diptera (Chironomidae, Chaoborus sp), pupa de Chaoborus sp (Diptera), fragmentos de Odonata, Phyllocycla sp (ninfas de Odonata), Libellulidae (ninfas de Odonata), massa de ovos de Ephemeroptera, Macrobrachium sp (Crustácea) e detritos. Os itens Campsurinae (fragmentos de Ephemeroptera) (FE), fragmentos de peixe (FP) e massa de ovos (MO) foram os mais frequentes.

Indivíduos com comprimento padrão entre 24,7 e 28,7 cm (classe 5) consumiram fragmentos de peixe e material vegetal. Indivíduos da classe $6(28,8$ a $32,8 \mathrm{~cm})$, consumiram fragmentos de peixe, fragmentos de Ephemeroptera, peixe (não identificado), material vegetal e massa de ovos de Ephemeroptera. O item fragmentos de peixe (FP) foi o mais representativo. 
Na classe 7 (32,9 a 36,9 cm) os itens consumidos foram fragmentos de peixe, material vegetal e massa de ovos de Ephemeroptera, sendo fragmentos de peixe (FP) o item com maior freqüência (Figura 31).

De um modo geral, pode-se observar que nas menores classes de tamanho não houve preferência por algum item alimentar específico caracterizando, desta forma, indivíduos com um hábito mais generalista. Segundo ABELHA et al. (2001) e WOOTTON (1999) as espécies podem ser classificadas como generalistas quando apresentam um amplo espectro alimentar.

Nas maiores classes de tamanho por sua vez, houve preferência pelos itens fragmentos de peixes, Campsurinae (fragmentos de Ephemeroptera) e massa de ovos de Ephemeroptera, o que evidencia um hábito alimentar mais específico para os indivíduos maiores.

As variações na dieta da corvina em função da fase de desenvolvimento dos indivíduos foram marcadas principalmente pela maior exploração de larvas de Diptera (Chaoboridae e Chironomidae) e insetos aquáticos (formas imaturas) pelas classes jovens, de menor tamanho, e pela mudança para uma dieta composta preferencialmente por peixes, nos indivíduos adultos.

HAHN (1991), estudando a dinâmica da nutrição de P. squamosissimus, no rio Paraná, observou que indivíduos jovens consumiram principalmente insetos aquáticos, enquanto os indivíduos adultos predaram preferencialmente peixes. Houve, portanto, similaridade quanto às variações ontogenéticas na alimentação nesta espécie de peixe, em ambas localidades em que a dieta da espécie foi estudada.

O consumo de quironomídeos pela corvina diminuiu com o desenvolvimento da espécie, provavelmente por se tratarem de pequenas larvas. Conforme o peixe cresce, a captura de organismos pequenos se torna menos conveniente para o predador (HYNES, 1950). Capturar organismos pequenos, a não ser que sejam muito abundantes, resulta provavelmente em baixa eficiência de forrageamento e menor retorno energético.

Segundo WOOTON (1999), a dieta de um peixe varia com o seu crescimento por causa das alterações morfológicas que acompanham o crescimento e também devido à melhoria na habilidade de locomoção. Deve-se ressaltar, no entanto, que indivíduos de P. squamosissimus adultos também consumiram ninfas de Odonata e ninfas de Ephemeroptera, apresentando um amplo espectro alimentar. 
$\mathrm{F}(\%)$

Classes de tamanho $x$ Itens alimentares

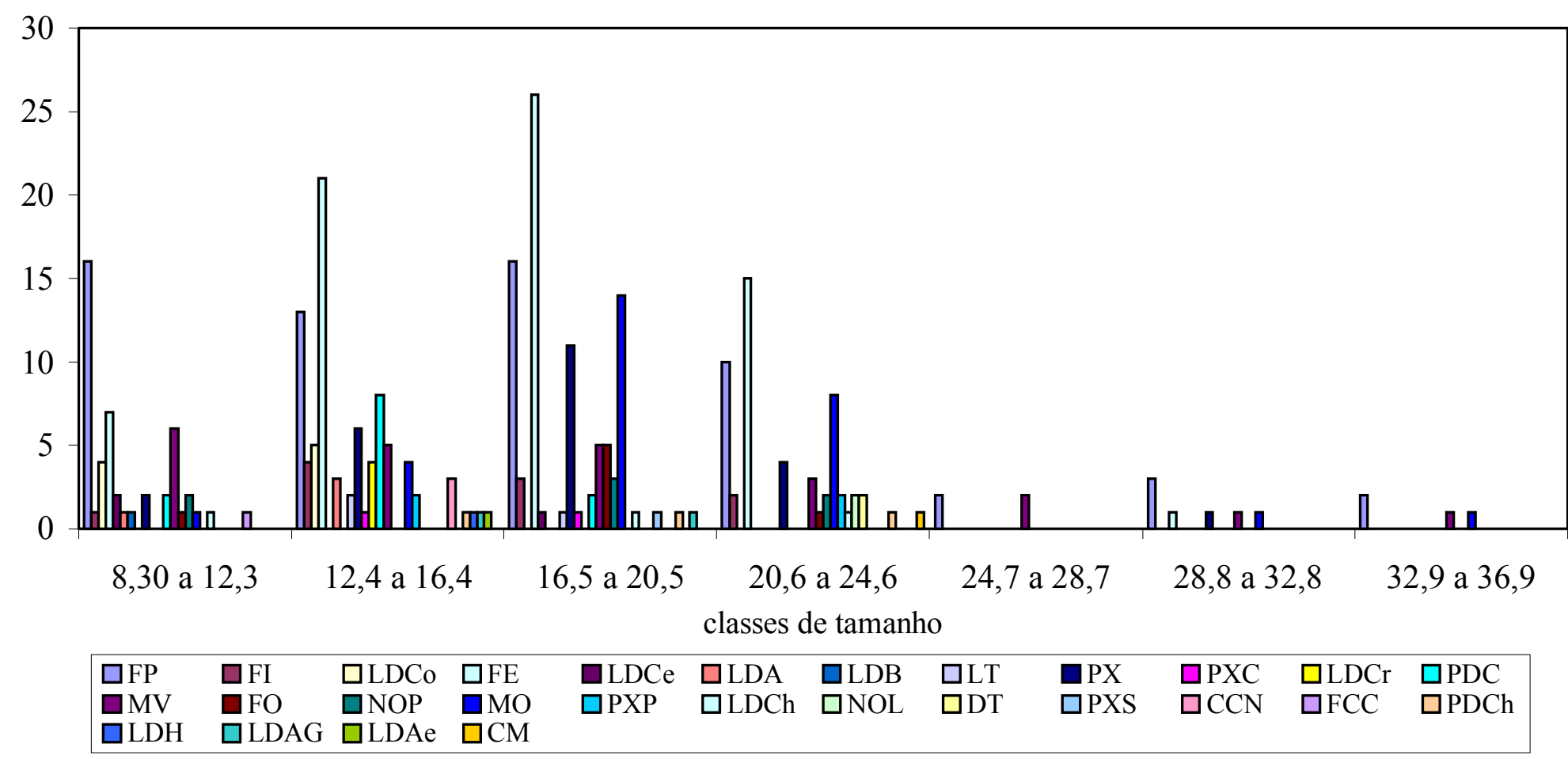

Figura 31: Itens alimentares consumidos por Plagioscion squamosissimus no reservatório de Bariri, pelas diferentes classes de tamanho. $\mathrm{FP}=\mathrm{Fragmentos}$ de peixe, $\mathrm{PX}=$ peixe, $\mathrm{Pla}=$ Plagioscion squamosissimus, $\mathrm{Sil}=$ Siluriformes, $\mathrm{Cic}=$ Cichlidae, $\mathrm{FE}=$ Campsurinae $($ Fragmentos de Ephemeroptera $), \mathrm{MO}=$ massa de ovos, Phy = Phyllocycla $\mathrm{sp}$ (ninfa de Odonata), Lib $=$ Libellulidae $($ ninfa de Odonata), FO = fragmentos de Odonata, Tri $=$ larva de Trichoptera, FI $=$ fragmentos de inseto, $\mathrm{Chi}=$ pupa de Chironomidae (Díptera), $\mathrm{Goe}=$ Goeldichironomus $\mathrm{sp}$ (larva de Diptera), Coe = Coelotanypus sp (larva de Diptera), Cer $=$ Ceratopogonidae (larva de Diptera), $\mathrm{Abl}=$ Ablabesmyia $\mathrm{sp}$ (larva de Diptera), Bru = Brundiniella $\mathrm{sp}$ (larva de Diptera), Cry $=$ Cryptochironomus $\mathrm{sp}$ (larva de Diptera), Har = Harnischia sp (larva de Díptera), Ash = Asheum sp (larva de Diptera), Chap = pupa de Chaoborus sp (Diptera), Chal = larva de Chaoborus sp (Diptera), FCC $=$ fragmentos de Copepoda Calanoida, Not = Notodiaptomus $\mathrm{sp}$ (Copepoda Calanoida), Mac $=$ Machobrachium $\mathrm{sp}$ (Crustacea), MV = material vegetal, DT = detritos. 


\subsection{Cichla cf. ocellaris}

No reservatório de Bariri, foram coletados apenas três indivíduos do tucunaré (C. ocellaris) e durante a análise do conteúdo estomacal verificou-se que apenas um estômago estava completamente cheio de alimento (grau 4) e os outros dois estavam com $1 / 4$ do estômago com alimento (Figura 32).

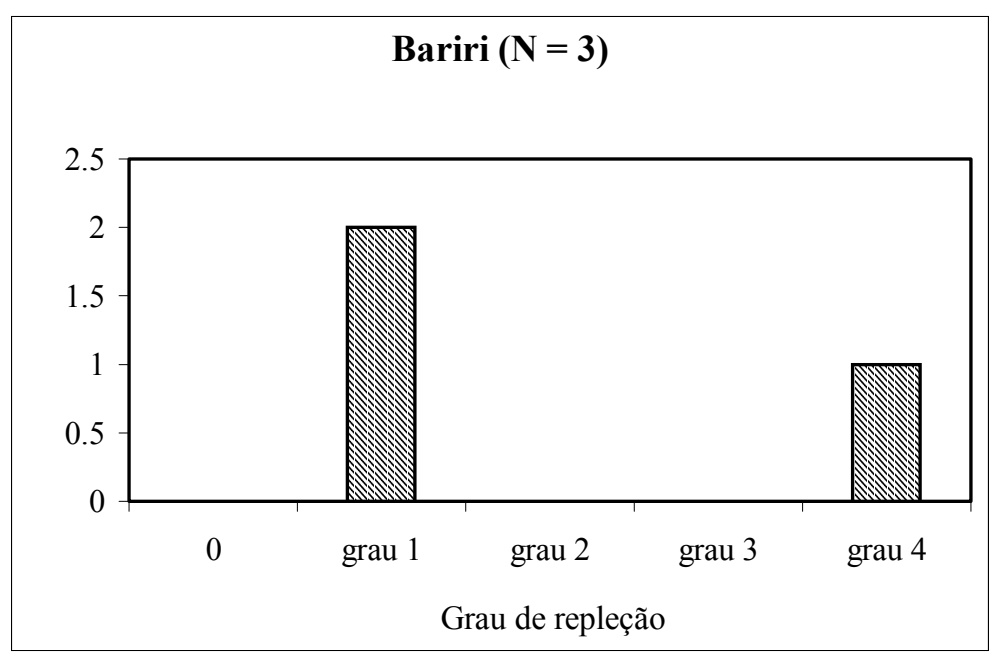

Figura 32: Grau de repleção dos estômagos dos tucunarés (C. ocellaris), coletados no reservatório de Bariri no mês de novembro de 2003.

Apenas dois itens alimentares foram consumidos por $C$. ocellaris. $\mathrm{O}$ item mais freqüente foi fragmentos de peixe $(66,7 \%)$, seguido do item material vegetal $(33,3 \%)$ (Figura 33).

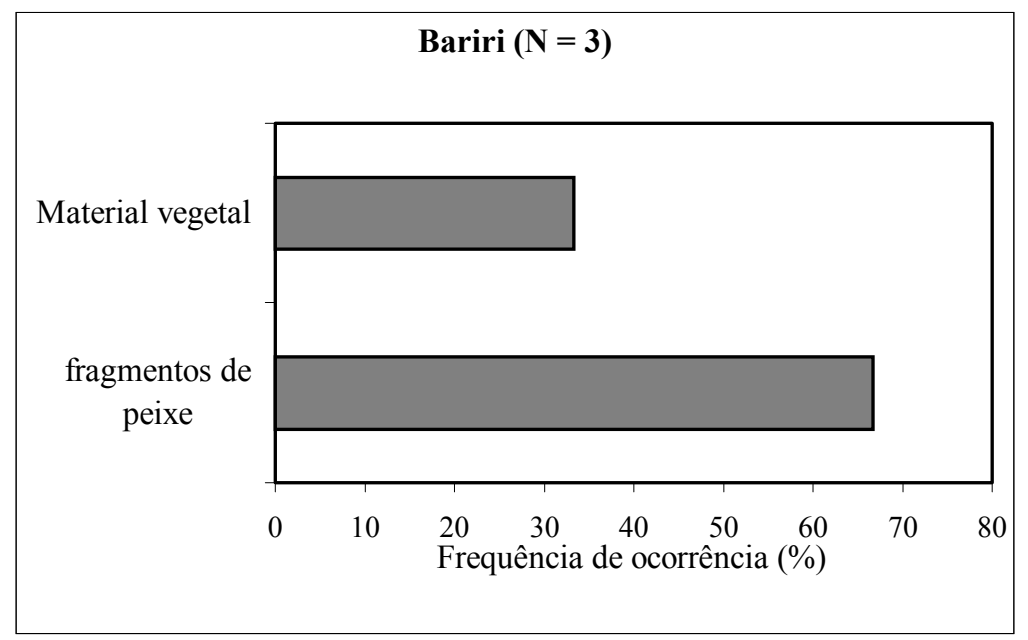

Figura 33: Freqüência de ocorrência (\%) dos itens alimentares encontrados nos estômagos de C. ocellaris, coletados no reservatório de Bariri, em novembro de 2003. 
O item fragmentos de peixe foi o mais importante em relação ao volume e peso, representado $100 \%$ e $96,4 \%$, respectivamente. Para o item material vegetal, não foi possível obter o volume, por causa da quantidade do item alimentar encontrado no estômago (Tabela 17).

Tabela 17: Abundância numérica, volume (\%) e peso seco (\%) dos itens alimentares consumidos por $C$. ocellaris, coletados no reservatório de Bariri, no mês de novembro de 2003.

\begin{tabular}{lccc}
\hline \multicolumn{1}{c}{ Itens Alimentares } & Abundância & Volumétrico & Gravimétrico \\
& $\mathrm{N}$ & $\mathrm{V}(\%)$ & $\mathrm{P}(\%)$ \\
\hline fragmentos de peixes & - & 100 & 96,4 \\
material vegetal & - & 0 & 3,6 \\
\hline
\end{tabular}

No reservatório de Ibitinga, o tucunaré (C. ocellaris) foi coletado em dezembro de 2002 e fevereiro de 2004. Foram analisados oito estômagos, sendo que dois deles estavam completamente cheios de alimento (Figura 34).

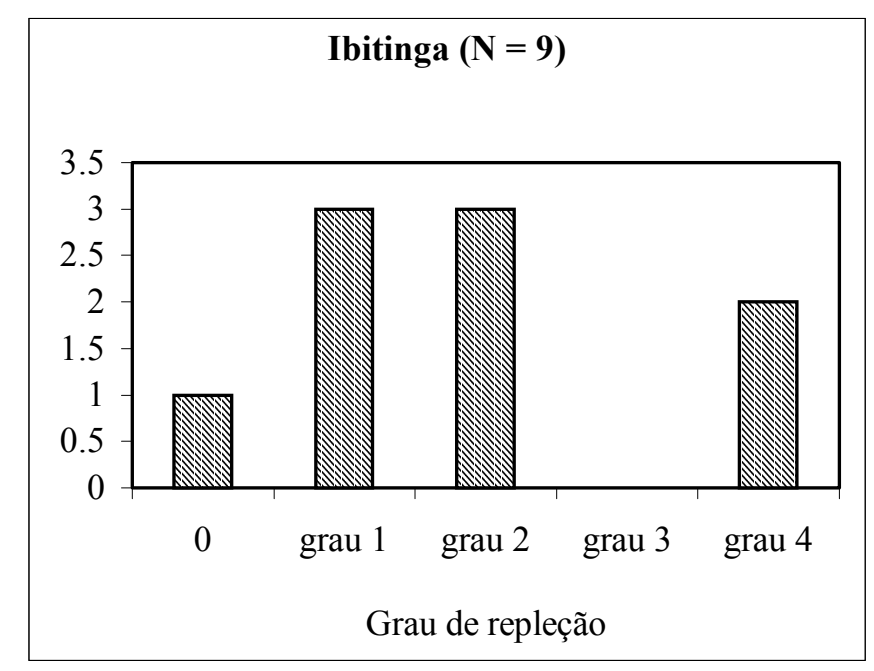

Figura 34: Grau de repleção dos estômagos dos tucunarés (C. ocellaris), coletados no reservatório de Ibitinga nos meses de dezembro de 2002 e fevereiro de 2004.

O item alimentar mais importante consumido por C. ocellaris foi peixes (não identificado) (50\%), seguido dos itens fragmentos de peixe (25\%), Cichlidae (peixe) (25\%), Serrasalmus spilopleura (peixe) (12,5\%) e Macrobrachium sp (camarão de água doce) $(12,5 \%)$ (Figura 35). 


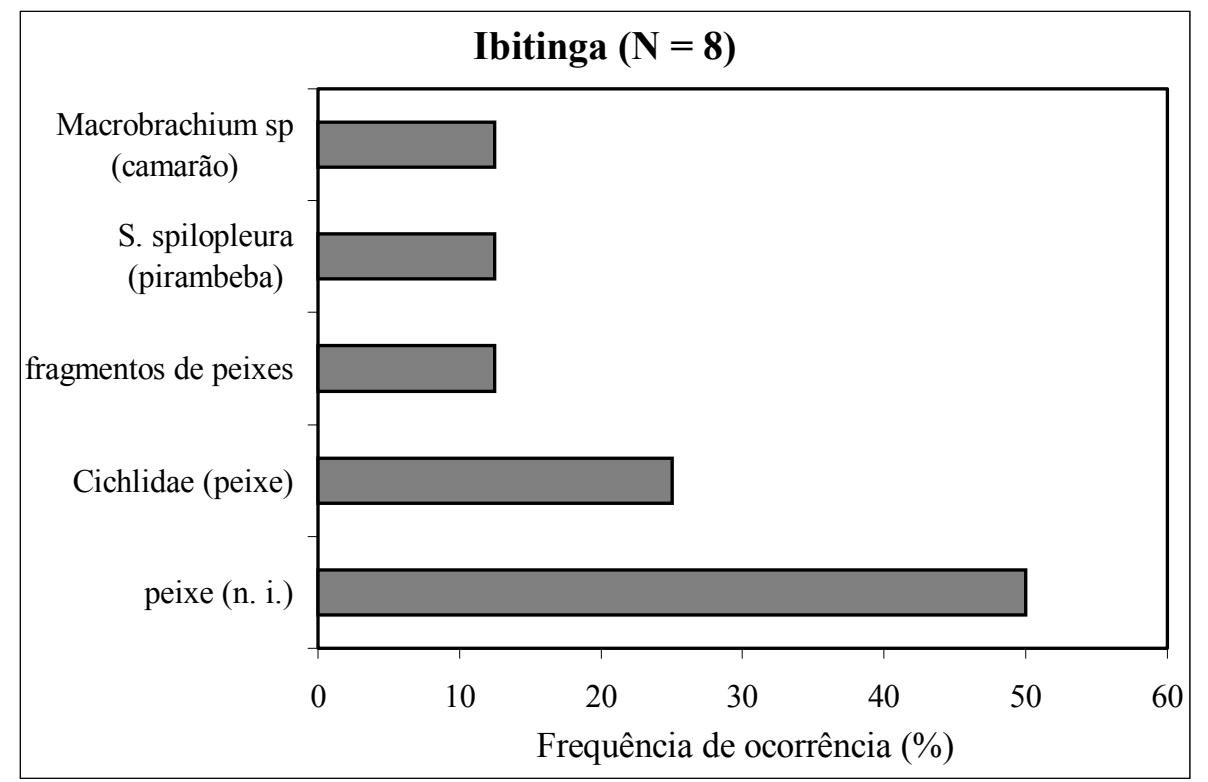

Figura 35: Freqüência de ocorrência (\%) dos itens alimentares encontrados nos estômagos de $C$. ocellaris, coletados no reservatório de Ibitinga, nos meses de dezembro de 2002 e fevereiro de 2004. (n. i. = não identificado).

Em termos de abundância os itens alimentar peixe (não identificado), fragmentos de peixe, Serrassalmus spilopleura (pirambeba) e Cichidae, juntos foram os mais importantes, sendo registrados 45 indivíduos. Em relação ao volume e a biomassa esse item também foi o mais representativo, com 53,4\% e 36\%, respectivamente (Tabela 18).

Tabela 18: Abundância numérica, volume (\%) e peso seco (\%) dos itens alimentares consumidos por $C$. ocellaris, coletados no reservatório de Ibitinga, nos meses de dezembro de 2002 e fevereiro de 2004. (n. i. = não identificado).

\begin{tabular}{lccc}
\hline \multicolumn{1}{c}{ Itens Alimentares } & $\begin{array}{c}\text { Abundância } \\
\mathbf{N}\end{array}$ & $\begin{array}{c}\text { Volumétrico } \\
\mathbf{V ~ ( \% )}\end{array}$ & $\begin{array}{c}\text { Gravimétrico } \\
\mathbf{P ~ ( \% )}\end{array}$ \\
\hline Peixe & $\mathbf{4 5}$ & $\mathbf{9 3}$ & $\mathbf{8 0}$ \\
Peixe (n. i.) & 36 & 53,4 & 36 \\
fragmentos de peixes & - & 18,6 & 10 \\
Cichlidae & 8 & 7 & 2 \\
Serrasalmus spilopleura (pirambeba) & 1 & 14 & 32 \\
Crustacea (camarão de água doce) & & & \\
Macrobrachium sp & 1 & 7 & 20 \\
\hline
\end{tabular}

No reservatório de Promissão, foram analisados 25 indivíduos de C. ocellaris, 13 indivíduos foram encontrados com o estômago vazio (Figura 36). 


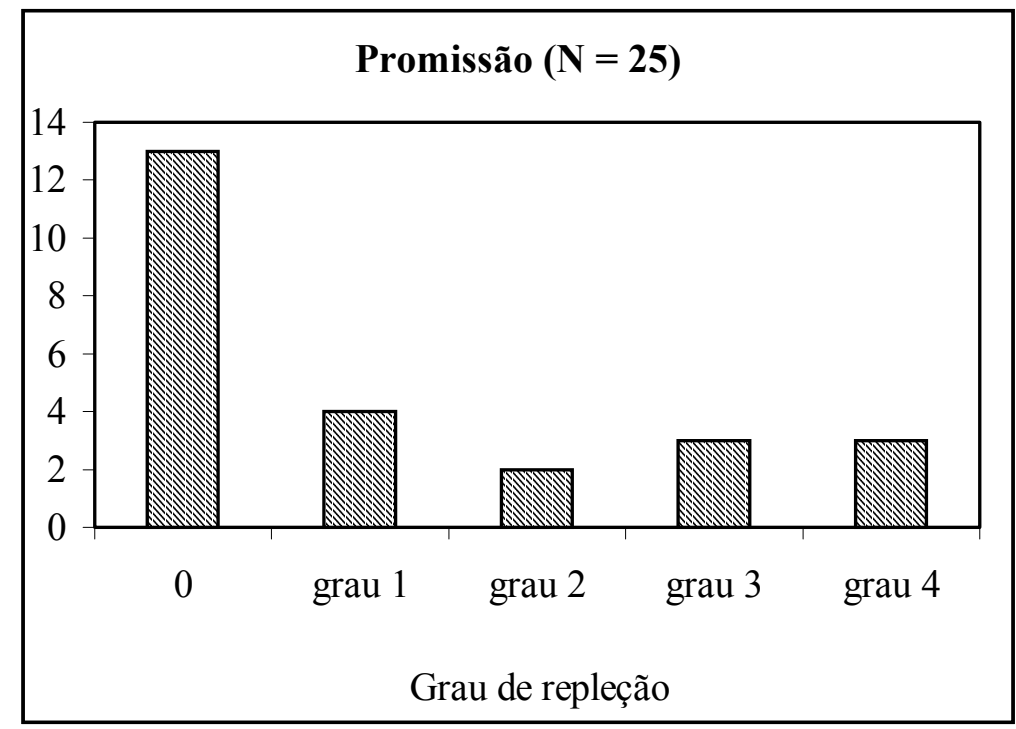

Figura 36: Grau de repleção dos estômagos dos tucunarés (C. ocellaris) coletados no reservatório de Promissão, nos meses de maio e dezembro de 2003.

Os itens alimentares mais importantes em relação à freqüência de ocorrência foram Macrobrachium sp (camarão) (41,6\%) e fragmentos de peixe (25\%), seguido dos itens Coenagrionidae (ninfa de Odonata), Macrobrachium sp (pós larva de camarão), material vegetal, Melanoides tuberculata (Mollusca), peixe (não identificado) e Characidae (peixe) com 8,3\% (Figura 37).

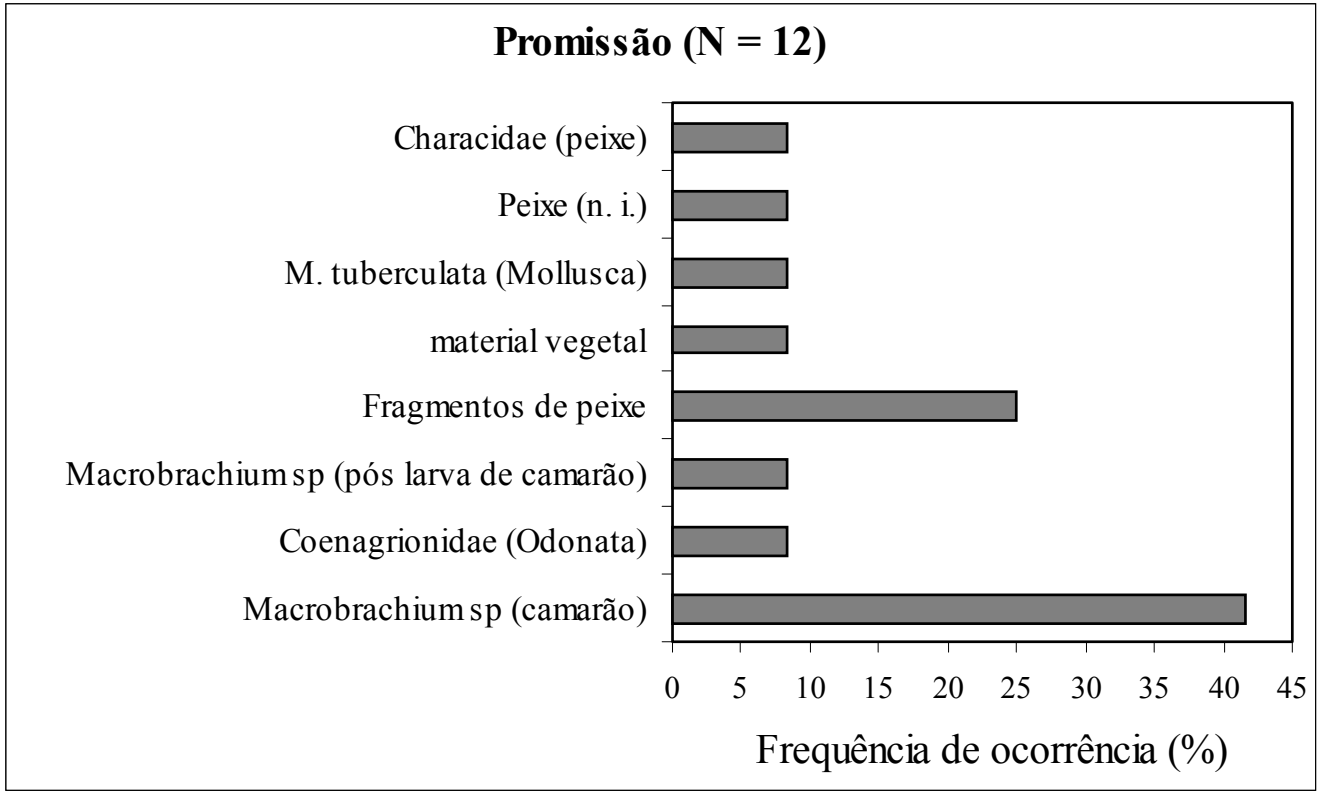

Figura 37: Freqüência de ocorrência (\%) dos itens alimentares encontrados nos estômagos de $C$. ocellaris, coletados no reservatório de Promissão, nos meses de maio e dezembro de 2003. (n. i. = não identificado). 
O camarão (Macrobrachium $\mathrm{sp}$ ) foi o item mais consumido, tendo sido registrados 16 indivíduos nos estômagos analisados. Além disso, esse item também foi o mais representativo em relação ao volume e biomassa, registrando 36,5\% e 33,3\%, respectivamente (Tabela 19).

Tabela 19: Abundância numérica, volume (\%) e peso seco (\%) dos itens alimentares consumidos por $C$. ocellaris, coletados no reservatório de Promissão nos meses de maio e dezembro de 2003. (n. i. = não identificado).

\begin{tabular}{lccc}
\hline \multicolumn{1}{c}{ Itens Alimentares } & $\begin{array}{c}\text { Abundância } \\
\text { N }\end{array}$ & $\begin{array}{c}\text { Volumétrico } \\
\text { V (\%) }\end{array}$ & $\begin{array}{c}\text { Gravimétrico } \\
\mathbf{P ~ ( \% )}\end{array}$ \\
\hline Crustacea (camarão de água doce) & $\mathbf{1 6}$ & $\mathbf{3 6 , 5}$ & $\mathbf{3 3 , 4}$ \\
Macrobrachium sp & 14 & 36,5 & 33,3 \\
Macrobrachium sp (pós larva) & 2 & 0 & 0,1 \\
Peixe & $\mathbf{2}$ & $\mathbf{5 3 , 7}$ & $\mathbf{5 7 , 7}$ \\
Peixe (n. i.) & 1 & 7,3 & 6,6 \\
Characidae (peixe) & 1 & 24,4 & 40 \\
Fragmentos de peixe & - & 22 & 11,1 \\
Outros & & & \\
Coenagrionidae (Odonata) & 1 & 2,4 & 0,6 \\
Melanoides tuberculata (Mollusca) & 2 & 4,9 & 6,6 \\
material vegetal & - & 2,4 & 2,2 \\
\hline
\end{tabular}

No reservatório de Nova Avanhandava foram analisados sete estômagos do tucunaré (C. ocellaris). Dois estavam completamente cheios (grau 4) e dois estômagos com a metade preenchida de alimento (Figura 38).

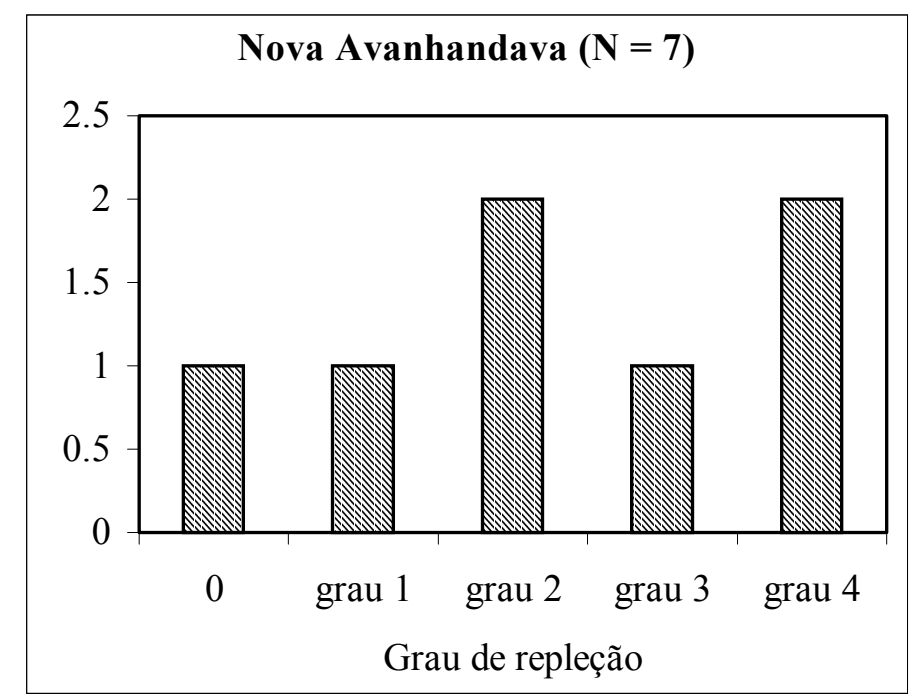

Figura 38: Grau de repleção dos estômagos dos tucunarés (C. ocellaris), coletados no reservatório de Nova Avanhandava, nos meses de maio e dezembro de 2003. 
Os itens alimentares mais importantes consumidos pelo tucunaré foram Hyphessobrycon sp (peixe) e fragmentos de peixe, com 33,3\% da freqüência, cada (Figura 39).

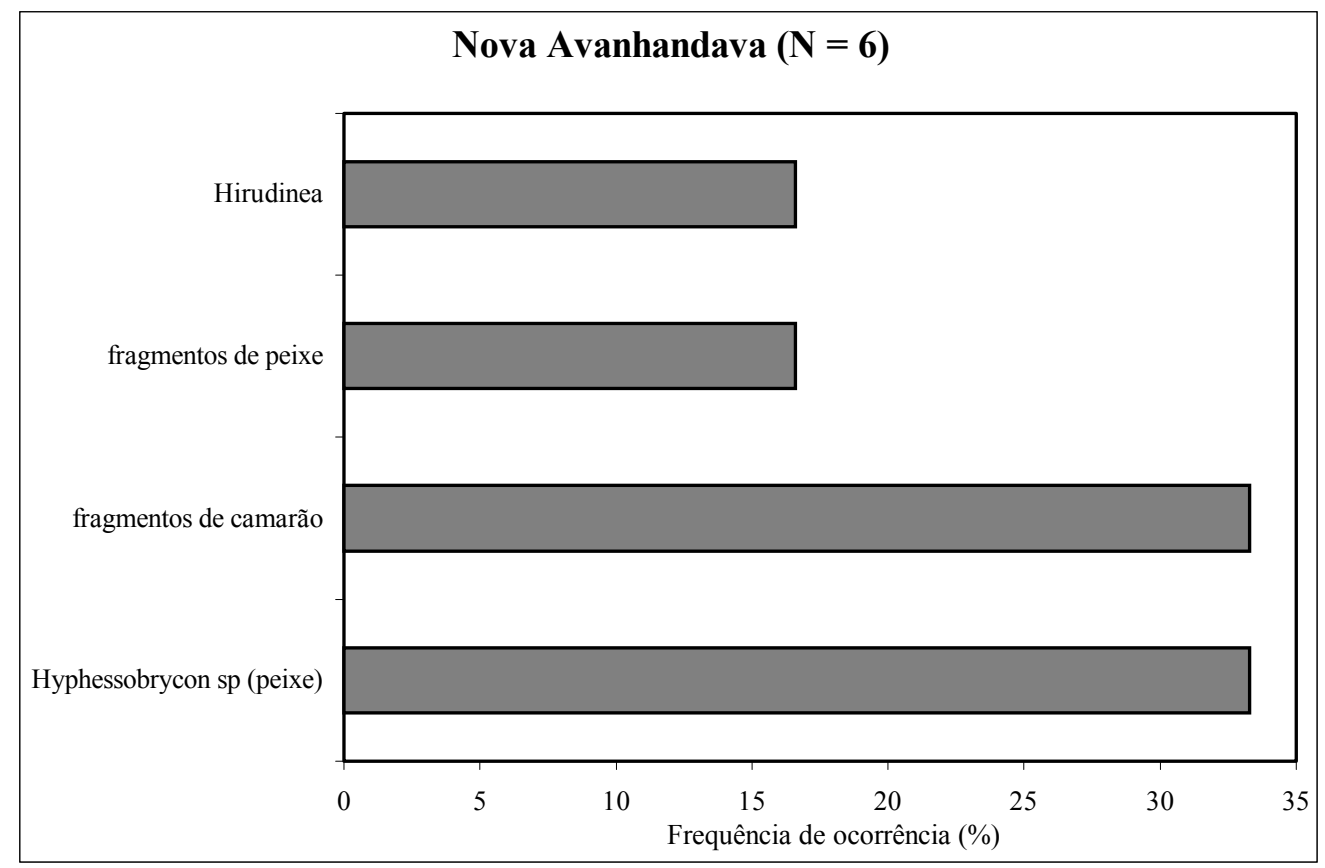

Figura 39: Freqüência de ocorrência (\%) dos itens alimentares encontrados nos estômagos de $C$. ocellaris, coletados no reservatório de Nova Avanhandava, nos meses de dezembro de 2002 e janeiro de 2004.

Fragmentos de peixe foi o item mais importante em relação ao volume e a biomassa, registrando $14,8 \%$ e $34,7 \%$, respectivamente.

Em relação à abundância, Hirudinea foi o mais significativo, sendo encontrados 13 indivíduos (Tabela 20).

Tabela 20: Abundância numérica, volume (\%) e peso seco (\%) dos itens alimentares consumidos por $C$. ocellaris, coletados no reservatório de Nova Avanhandava, nos meses de dezembro de 2002 e janeiro de 2004. (n. i. = não identificado)

\begin{tabular}{lccc}
\hline \multicolumn{1}{r}{ Itens Alimentares } & Abundância & Volumétrico & Gravimétrico \\
& $\mathrm{N}$ & $\mathrm{V}(\%)$ & $\mathrm{P}(\%)$ \\
\hline Peixe & $\mathbf{4}$ & $\mathbf{8 7 , 7}$ & 98,5 \\
Hyphessobrycon sp (peixe) & 4 & 14,8 & 34,7 \\
Fragmentos de peixe & - & 72,9 & 63,8 \\
Fragmentos de camarão & - & 12 & 2,2 \\
Hirudinea & & & \\
Hirudinea (n. i.) & 13 & 1,3 & 0,1 \\
\hline
\end{tabular}


No reservatório de Três Irmãos foram analisados 11 estômagos de C. ocellaris, desses 5 estavam completamente vazios (Figura 40).

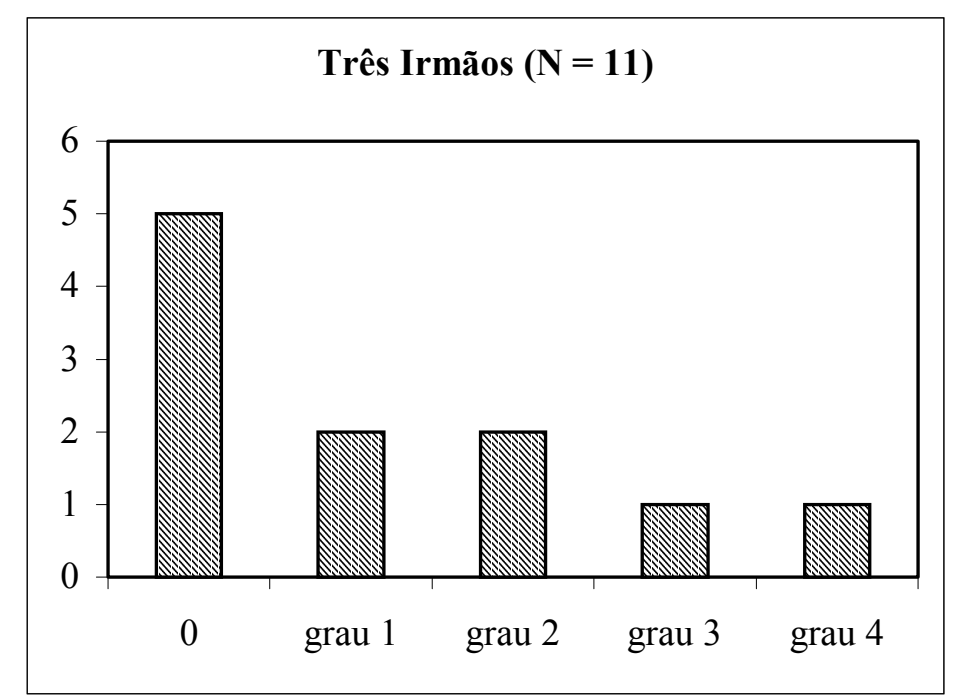

Figura 40: Grau de repleção dos estômagos dos tucunarés (C. ocellaris), coletados no reservatório de Três Irmãos, nos meses de maio de 2003 e janeiro de 2004

Foram consumidos sete itens alimentares, que apresentaram a mesma freqüência de ocorrência (16,6\%) (Figura 41).

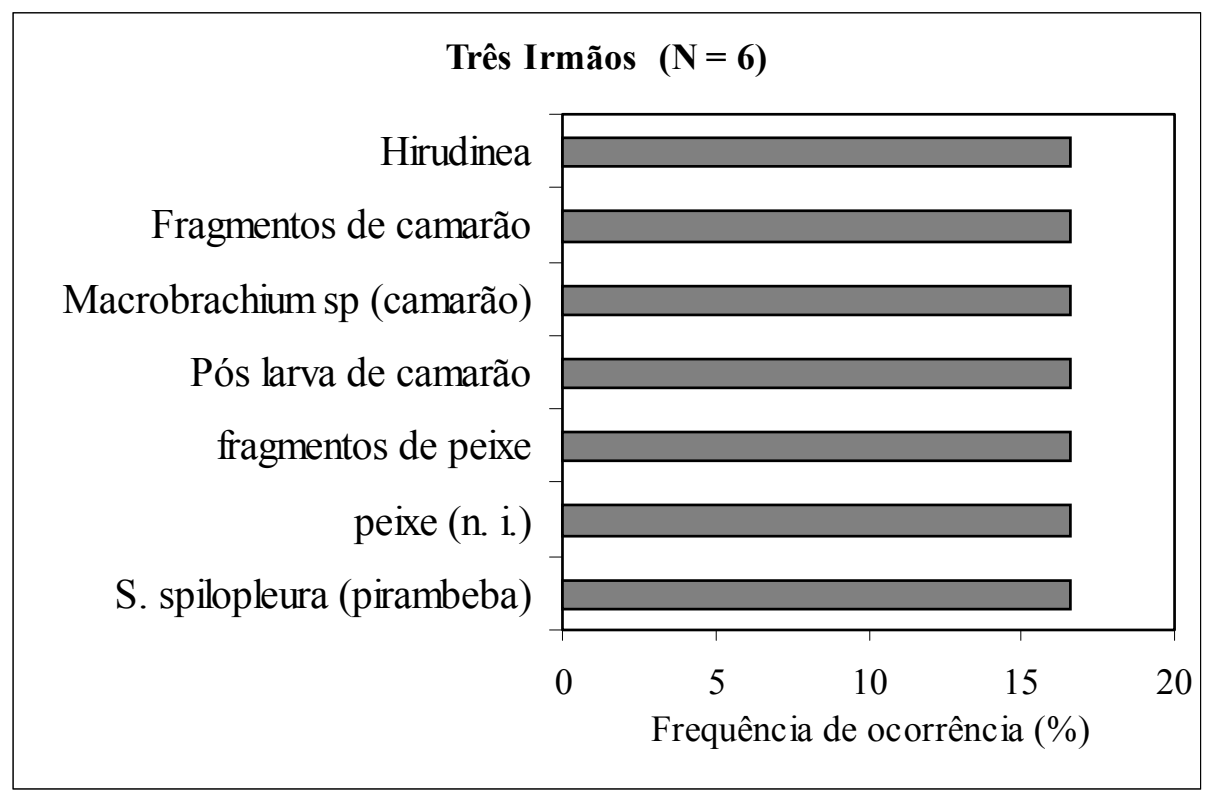

Figura 41: Freqüência de ocorrência (\%) dos itens alimentares encontrados nos estômagos dos tucunarés (C. ocellaris), coletados no reservatório de Três Irmãos, nos meses de maio e dezembro de 2003. (n. i. = não identificado). 
O item mais abundante foi camarão (Macrobrachium sp), sendo encontrados 4 indivíduos nos estômagos analisados. Em relação ao volume e a biomassa o item fragmentos de peixe foi o mais importante, com $78 \%$ e $82 \%$, respectivamente (Tabela 21).

Tabela 21: Abundância numérica, volume (\%) e peso seco (\%) dos itens alimentares consumidos por $C$. ocellaris, coletados no reservatório de Três Irmãos, nos meses de maio de 2003 e janeiro de 2004. (n. i. = não identificado)

\begin{tabular}{lccc}
\hline \multicolumn{1}{c}{ Itens Alimentares } & $\begin{array}{c}\text { Abundância } \\
\text { N }\end{array}$ & $\begin{array}{c}\text { Volumétrico } \\
\text { V (\%) }\end{array}$ & $\begin{array}{c}\text { Gravimétrico } \\
\mathbf{P ~ ( \% )}\end{array}$ \\
\hline Peixe & $\mathbf{2}$ & $\mathbf{1 4 , 3}$ & $\mathbf{1 5}$ \\
Serrasalmus spilopleura (pirambeba) & 1 & 6,5 & 6 \\
Peixe (n. i.) & 1 & 7,8 & 9 \\
Fragmentos de peixe & - & 78 & 82 \\
Crustacea (camarão de água doce) & $\mathbf{4}$ & $\mathbf{1 5 , 5 9}$ & $\mathbf{3 , 7}$ \\
Macrobrachium sp & 3 & 3,9 & 2 \\
Macrobrachium sp (Pós-larva) & 1 & 1,29 & 1 \\
Fragmentos de camarão & - & 2,5 & 0,7 \\
Hirudinea & & & \\
Hirudinea (n. i.) & 2 & 0 & 0,1 \\
\hline
\end{tabular}

No total foram analisados 61 estômagos do tucunaré (Cichla cf. ocellaris), coletados nos reservatórios do médio e baixo rio Tietê (Bariri, Ibitinga, Nova Avanhandava e Três Irmãos).

O grande número de indivíduos com estômagos vazios observados no decorrer do trabalho é corroborado pelo hábito alimentar piscívoro que a espécie apresenta. A saciação em peixes carnívoros (piscívoros) ocorre num período temporal mais curto, proporcionando a freqüência alta de estômagos vazios (ZAVALA-CAMIN, 1996).

A análise dos conteúdos estomacais permitiu caracterizar a espécie como piscívora, consumindo principalmente peixes (Characidae, Cichlidae e Serrassalminae), fragmentos de peixes, pós larva de camarão e camarão (Macrobrachium sp) e ninfa de Odonata (Coenagrionidae).

Cichla sp, na bacia do Orinoco, durante a estação seca, consumiu principalmente peixes das ordens Characiformes, Perciformes e Siluriformes (WINEMILLER et al, 1997).

SANTOS et al. (2001), estudando a alimentação de Cichla monoculus no reservatório de Lajes (RJ), classificou a espécie como piscívora, verificando que a dieta 
consistiu basicamente de peixes (Cichlidae e Characidae), crustáceos, insetos (ninfa de Odonata) e resíduos orgânicos.

VELLUDO et al. (2005) verificou que Cichla cf. ocellaris na represa do Lobo (Broa), apresentou um hábito alimentar piscívoro, predominando indivíduos da família Cichlidae, principalmente da espécie Geophagus brasiliensis.

ASSUMPÇÃO et al., (2005) verificaram que na lagoa Dom Helvécio (Vale do Rio Doce-MG), C. ocellaris apresentou uma dieta variada, de origem animal e vegetal, consumindo cladóceros, copépodos e indivíduos do acará (Geophagus brasiliensis).

Pela diversidade de itens alimentares consumidos e pelo hábito alimentar piscívoro, a espécie $C$. ocellaris pode ocasionar impactos relevantes na cadeia trófica dos reservatórios.

O tucunaré é um peixe altamente profílico e que se adapta muito bem às condições lênticas (ZARET, 1980), motivos pelos quais suas populações se expandem rapidamente em reservatórios.

A presença desse predador altamente adaptado e sua proliferação podem causar sérios danos na comunidade, como a predação, competição e efeitos em cascata por toda cadeia trófica (ZARET \& PAINE, 1973; GOMIERO \& BRAGA, 2004).

\section{Considerações finais}

A introdução de espécies não-nativas seja casual ou intencional tem sido um dos temas mais inquietantes da ecologia nas últimas décadas (RODRÍGUEZ, 2001).

Segundo SIMBERLOFF (2003) a introdução de novos elementos na biota constitui na segunda maior causa de extinções de espécies, sendo superada apenas pela degradação de habitats.

De acordo com os trabalhos desenvolvidos por ROSS (1991) o principal impacto gerado pela introdução de espécies é a predação, tendo como principal conseqüência à redução e eliminação de populações de espécies nativas.

A voracidade das espécies introduzidas (Plagioscion squamosissimus e Cichla cf. ocellaris) sugere que esses organismos invasores podem predar algumas espécies nativas, principalmente peixes das famílias Characidae e Cichlidae, alterando a cadeia trófica ou ainda competir por alimento com as espécies nativas. 
Desta forma, ações de manejo e controle são necessárias para determinar os impactos causados pelas espécies introduzidas e estabelecidas no sistema Tietê sobre as espécies nativas.

Segundo ESPINDOLA et al. (2005), a erradicação das espécies invasoras no sistema Tietê é praticamente impossível de ser realizada, pois a distribuição é ampla em todos os reservatórios e rios tributários, verificando-se que, de um modo geral a introdução e dispersão foram bem sucedidas.

No entanto, as espécies Plagioscion squamosissimus e Cichla cf. ocellaris devem ser manejadas para que não venham extinguir as espécies nativas. Assim, algumas ações podem ser implementadas para evitar novas introduções e controlar a expansão das espécies introduzidas.

Para isso recomendam-se algumas ações de manejo:

- Divulgação das informações científicas sobre as espécies invasoras, junto à população usuária dos reservatórios e junto aos órgãos administrativos e ambientais;

- Elaboração e distribuição de folders (Anexo E), posters e cartilhas junto às escolas (municipais, estaduais e particulares), Ongs e prefeituras.

- Realização de palestras nas escolas (Ensino Fundamental e Médio) para a apresentação do tema;

- Criação de jogos educativos sobre a biologia das espécies de peixes nativas e introduzidas (Anexo E), para ser distribuídos nas escolas.

- Fiscalização de pesque-pague, com o objetivo de minimizar o risco de introdução de espécies exóticas por escapes ou soltura deliberada. 


\section{6 . Conclusões}

- O acará (Geophagus brasiliensis) apresentou um hábito alimentar onívoro nos reservatórios estudados, consumindo principalmente microcrustáceos, larvas de Diptera e detritos.

- A corvina (Plagioscion squamosissimus) apresentou um hábito alimentar piscívoro e grande plasticidade alimentar, consumindo diversos outros itens.

- P. squamosissimus apresentou uma preferência alimentar pelos Characiformes e Perciformes (famílias Characidae e Cichlidae).

- O camarão foi um recurso alimentar muito importante para P. squamosissimus nos reservatórios de Promissão, Nova Avanhandava e Três Irmãos.

- Não houve mudanças no hábito alimentar de P. squamosissimus, em relação a diferentes períodos (seco e chuvoso), no reservatório de Bariri.

- P. squamosissimus apresentou mudanças no seu hábito alimentar, conforme os estágios de desenvolvimento, consumindo larvas de Diptera e insetos aquáticos quando jovens e peixes quando adultos.

- Indivíduos jovens de P. squamosissimus podem competir por alimento com a espécie nativa Geophagus brasiliensis.

- O tucunaré (Cichla cf. ocellaris) apresentou um hábito alimentar piscívoro, consumindo principalmente peixes das famílias Cichlidae e Characidae.

- As espécies introduzidas podem causar danos na cadeia trófica e extinções de espécies nativas. 


\section{Referências Bibliográficas}

AESTIETÊ. Disponível em: www.aestiete.com.br, acessado em 03/01/2005.

ABElHA, M. C. F.; AgOSTINHO, A. A.; GOUlART, E. Plasticidade trófica em peixes de água doce. Acta Scientiarum, 23: 125-434, 2001.

AgOstinhO, A. A., JULIO JR., H. F., \& TORLONI, C. E., Impactos causados pela introdução e transferência de espécies aquáticas: uma síntese. In: Seminário Sobre a Fauna Aquática e o Setor Elétrico Brasileiro. Caderno II. Rio de Janeiro, COMASE/Eletrobrás, 1994.

\& JULIO Jr, H. F. Peixes de outras águas. Ciência Hoje. 21(124): 26-44, 1996. et al. Ictiofauna de dois reservatórios do rio Iguaçu em diferentes fases de colonização: Segredo e Foz de Areia. In: AGOSTINHO, A. A.; GOMES, L. C. (Eds.). Reservatório de Segredo: bases ecológicas para manejo. Maringá:Nupelia. EDUEM, p. 275-292, 1997.

\& JULIO JR., H. F. Peixes da Bacia do Alto Paraná. In: Lowe-McConnell, R. H. (ed.), Estudos Ecológicos de Comunidades de Peixes Tropicais. EDUSP, 534 p., 1999.

; PELICICE, F. M.; JULIO Jr, H. F. Introdução de espécies de peixes em águas continentais brasileiras: uma síntese. In: In: ROCHA, O; ESPÍNDOLA, E. L. G.; FENERICH-VERANI, N.; VERANI, J.R.; RIETZLER, A. C. (Orgs.). Espécies invasoras em águas doces: estudos de caso e propostas de manejo. 416 p., 2005.

ALMEIDA, V. L. L; HAHN, N. S. VAZZOLER, A. E. M. Feedinga patterns in five predatory fishes of the high Parana river floodplain (PR, Brazil). Ecology of Freshwater Fish. 6:123-133, 1997.

ARCIFA, M. S. FROELICH, O. NORTHCOTE, T. G. Distribution and feeding ecology of fishes in a tropical Brazilian reservoir. Mem. Soc. Cienc. Nat. La Salle, 48:301-326, 1988. 
ASSUMPÇÃO et al. Análise do conteúdo estomacal de Cichla ocellaris e Pygocentrus nattereri (espécies introduzidas) e Geophagus brasiliensis e Astyanax bimaculatus (espécies nativas) de lagos do Vale do Rio Doce-MG e sua implicações. In: ROCHA, O; ESPÍNDOLA, E. L. G.; FENERICH-VERANI, N.; VERANI, J.R.; RIETZLER, A. C. (Orgs.). Espécies invasoras em águas doces: estudos de caso e propostas de manejo. 416 p, 2005.

BARBOSA, et al., The Cascading Reservoir Continuum Concept (CRCC) and its Application to the River Tietê-Basin, São Paulo State, Brazil. In: TUNDISI, J. G. \& STRASKRABA, M. Theoetical reservoir ecology and its applications. 585 p.1999.

BARREllA, W.; BEAUMORD, A. C.; PETRERE Jr, M. Comparacion de la comunidad de peces de los rios Manso (MT) y Jacaré Pepira (SP), Brazil. Acta Biol. Venez. 15(2):11-20, 1994.

BARRELLA, W.; PETRERE Jr., M. Fish community alterations due to pollution and damming In Tietê and Paranapanema rivers (Brazil). River Res. Applic., v. 19, p. 5976, 2003.

BRAGA, F M. S. Aspectos da reprodução e alimentação de peixes comuns em um trecho do rio Tocantins entre Imperatriz e Estreito, estados do Maranhão e Tocantins, Brasil. Rev. Brasil. Biol. 50(3):547-558, 1990

BRAGA, F. M. S., Alimentação de Plagioscion squamosissimus (Osteichthyes, Sciaenidae) no reservatório de Barra Bonita, Estado de São Paulo. Iheringia, Sér. Zool., $84: 11-19,1998$

BRITSKI, H. A.; SATO, Y.; ROSA, A. B. S. Manual de identificação de peixes da bacia do São Francisco - Brasília. Câmara dos Deputados, Coordenação de Publicações - CODEVASF, Divisão de Piscicultura e Pesca, 143p., 1984. 
CESP. Conservação e manejo nos reservatórios: limnologia, ictiologia e pesca. $163 p ., 1998$.

CETESB, Relatório da qualidade ambiental das águas interiores do estado de São Paulo. São Paulo, Série Relatórios, Secretaria do Meio Ambiente, 2001.

CASTRO, A. C. L. Ictiofauna do reservatório de Barra Bonita-SP: aspectos ecológicos da comunidade e dinâmica populacional da corvina, Plagioscion squamosissimis (Heckel, 1840) (Acanthopterigii, Scianidae). 1994. Tese (Doutorado) Escola de Engenharia de São Carlos, Universidade de São Paulo, São Carlos.

ESTEVES, F. A. Fundamentos da limnologia. Rio de Janeiro: Interciências FINEP, 602 p., 1998.

ESPÍNDOLA, et al. Organismos Aquáticos. In: Rambaldi, D. M. \& Oliveira, D. A. S. (orgs.), Fragmentação de ecossistemas: causas, efeitos sobre a biodiversidade e recomendações de políticas públicas. Brasília.MMA/SBF, 510 p., 2003.

FRACÁCIO, R. Utilização de bioensaios ecotoxicológicos com Danio rerio (Cypriniformes, Cyprinidae) e análises limnológicas para a avaliação ambiental dos reservatórios do Médio e Baixo rio Tietê (SP). 2001. 233 f. Dissertação (Mestrado) - Escola de Engenharia de São Carlos, Universidade de São Paulo, São Carlos.

FONTEles FILHO, A. A. Recursos Pesqueiros: biologia e dinâmica populacional. Fortaleza, CE. Imprensa Oficial do Ceará. 296 p., 1989.

GOULDING, M. \& FERREIRA, E. J. G. Shrimp-eating fishes and a case of preyswitching in Amazon rivers. Revta. Brasil Zool. 2(3):85-97, 1984.

GOMIERO, L. M.; BRAGA, F. M. S. Reproduction of species of the genus Cichla in a reservoir in Southeastern. Brazil. Brazi. J. Biol., v. 63, n. 3B, p. 613-624, 2004. 
HAHN, N. S., 1991, Alimentação e dinâmica da nutrição da curvina Plagioscion squamosissimus (Heckel, 1840) (Pisces, Perciformes) e aspectos da estrutura trófica da ictiofauna acompanhante no rio Paraná. 1991. 287 f. Tese (Doutorado), UNESP, Rio Claro.

HAHN, N. S., AGOSTINHO, A. A. \& GOITEIN R. Feeding ecology of curvina Plagioscion squamosissimus (Heckel, 1840) (Osteichthyes, Perciformes) in the Itaipu reservoir and Porto Rico floodplanin. Acta Limnologica Brasiliensia. 9:11-22, 1997.

HAHN, et al. Dieta e atividade alimentar de peixes do reservatório de Segredo. In: Agostinho, A. A., GOMES, L. C. (Eds.). Reservatório de Segredo: bases ecológicas para o manejo. Maringá: Nupelia, EDUEM, p. 142-162, 1997.

HERRÁN, R. A. Analisis de contenidos estomacales em peces. Revision bibliografica de los objetivo y la metodologia. If. Tec. Inst. Esp. Ocenaograf. 63: 1-73, 1988.

HYNES, H. B. N. The food of freshwater sticklebacks (Gasterosteus aculeatus and Pigosteus pungitius), with a review of method used in studies of the food of fishes. Journal Anim. Ecol., 19:36-56, 1950.

HUTCHINSON, G.E. A treatise on Limnology. The Zoobenthos. $4^{\mathrm{o}}$ Vol., John Wiley \& Sons, New York, 964p., 1993.

KAWAKAMI, E. Alimentação de Pleuronictiformes (Análise comparativa e bionomia). 1975. 150 f. Dissertação (Mestrado) - Instituto Oceanográfico, Universidade de São Paulo, São Paulo.

McCAFFERTY, W. P. Aquatic Entomology: the fishermens's and ecologist's illustraded guide to insects and their relatives. Boston: Jones and Bartlett Publishers, $448 \mathrm{p}, 1983$. 
MESCHIATTI, A. J. \& ARCIFA, M. S. Early life stages of fish and the relationships with zooplankton in a tropical brazilian reservoir: lake Monte Alegre. Braz, J. Biol. 62(1): 41-50, 2002.

MARCIANO, F. T. Composição, abundância e aspectos reprodutivos das espécies de peixes do reservatório Álvaro de Souza Lima (Bariri, SP) e sua relação com as características ambientais do sistema. 2005. 220 f. Tese (Doutorado) - Escola de Engenharia de São Carlos, Universidade de São Paulo.

NIKOLSKY, G. V. The ecology of fishes. London: Academic Press, 352 p.,1963.

PENNAK, R.W. Fresh-water Invertebrates of the United States, 3rd ed. John Wiley \& Sons. New York, New York, USA, 1989.

PEREIRA, R. H. G., Análise da Distribuição, Densidade e Diversidade de Copepoda Calanoida e Cyclopoida nos Reservatórios e Tributários do Médio e Baixo rio Tietê e sua Relação com as Características Limnológicas do Sistema. 2003. 287 f. Tese (Doutorado) - Escola de Engenharia de São Carlos, Universidade de São Paulo, São Carlos.

PEREIRA, C. G. F. P. et al; Hábitos alimentícios de nueve espécies de peces del embalse de Três Irmãos, São Paulo, Brasil. Universidad y Ciência, 1:33-38, 2004.

POPOVA, O. A. The role of predaceus fish in Ecosystems. In: GERKING, S. D. (Ed.) Ecology of freshwater fish production. Oxford: Blackwell Scientific Publications, p. 215-249, 1978.

RABELO, H. \& ARAUJO-LIMA, C. A. R. M. A dieta e o consumo diário de alimentoo de Cichla monoculus na Amazônia Central. Acta Amazônica, 32(4): 707-724, 2002. RIBEIRO FILHO, A. R. Caracterização de dietas alimentares de peixes predadores em açudes de Pernambuco e no lago Paranoá. 39 f. 1999. Monografia (graduação) Curso de Engenharia de Pesca, Universidade Federal Rural de Pernambuco. 
ROCHA, O. et al. O problema das invasões biológicas em águas doces. In: ROCHA, O., ESPÍNDOLA, E. L. G, FENERICH-VERANI, N.; VERANI, J. R.; RIETZLER, A. C. (orgs). Espécies Invasoras em Águas Doces: estudos de caso e propostas de manejo. São Carlos-SP, p. 9-12, 2005.

ROCHE, K. F.; RIETZLER, A. C. \& ROCHA, O. Dieta de Astyanax bimaculatus, Cheirodon stenodon, Serrasalmus spilpleura e Plagioscion squamosissimus em duas represas com ênfase nos indivíduos juvenis. In: ROCHE, K. F. \& ROCHA, O. (Orgs.). A ecologia trófica de peixes: com ênfase na planctivoria em ambientes lênticos de água doce no Brasil. São Carlos. RiMa, 2005, 9 - 81-92.

RODRÍGUEZ, J. P.Exotic species introductions into South América: na underestimated threat? Biodiversity and Conservation. 10:1938-1996, 2001.

ROSS, S, T. Mechanisms structuring stream fish assemblages: are there lessons from introduced species? Enviromental biology of fishes. 30:359-368. 1991.

SANTOS, L. N., GONZALEZ, A. F. \& ARAUJO, F. G. A dieta do tucunaré-amarelo Cichla monoculus (Bloch \& Schneider) (Osteichthyes, Cichlidae), no reservatório de Lajes, Rio de Janeiro, Brasil. Revta. Bras. Zool. 18(1): 191-204, 2001.

SIMBERLOFF, D. Confronting introduced species: a form of xenophobia? Biological Invasions. 5:179-192, 2003.

SMITH, W. S. et al. Impactos dos reservatórios do médio e baixo Tietê (SP) na composição das espécies de peixes e na atividade de pesca. In: ESPÍNDOLA, E. L. G.; MAUAD, F. F.; SCHALCH, V.; ROCHA, O.; FELICIDADE, N.; RIETZLER, A. C. (Eds.). Recursos hidroenergéticos: usos, impactos e planejamento integrado. São Carlos: RiMa, p. 57-72. 2002.

A importância dos tributários, a influência da fragmentação artificial de rios e da introdução de espécies exóticas na comunidade de peixes dos reservatórios do Médio e Baixo Tietê. 2004. 295 f. Tese (Doutorado) - Escola de Engenharia de São Carlos, Universidade de São Paulo, São Carlos. 
; ESPÍNDOLA, E. L. G. \& ROCHA, O. As introduções de espécies de peixes exóticos e alóctones em bacias hidrográficas brasileiras. In: ROCHA, O.; ESPÍNDOLA, E. L. G., FENERICH-VERANI, N.; VERANI, J. R. \& RIETZLER, A. C. (orgs). Espécies Invasoras em Águas Doces: estudos de caso e propostas de manejo. São Carlos-SP, 2005.

STURGES, H. A. The choice of a class interval. Journal of the American Statistical Association, v. 21, p. 65-66, 1926.

STRIXINO, G.; TRIVINHO-STRIXINO, S. Povoamentos de Chironomidae (Diptera) em lagos artificiais. In: NESSIMIAN, J. L.;CARVALHO, A.L. (Eds). Ecologia de insetos aquáticos. Série Oecologia Brasiliensis, PPGE-UFRJ, 5: 141-154 p., 1998.

STRAUSS, R. E. Reliability estimates of Ivlevs electivity index, the forage ratio, and a proposed linear index food selection. Trans. Am. Fish. Soc. 108: 344-352, 1979.

SURIANI, A. L., A estrutura da comunidade de macro-invertebrados bentônicos em três represas do médio rio Tietê (SP), com ênfase nas espécies exóticas Melanoides tuberculata (Gastropoda, Thiaridae) e Corbicula fluminae (Bivalve, Corbiculidae). 2006. 155 f. Dissertação (Mestrado) - Programa de Pós-Graduação em Ecologia e Recursos Naturais, Universidade Federal de São Carlos, São Carlos.

UIEDA, V. S. Comunidade de peixes de um rio litorâneo: Composição, Habitat e Hábitos. 1995. Tese (doutorado), Unicamp, Campinas (SP).

VELLUDO, et al. Dinâmica alimentar de Cichla cf. ocellaris Spix \& Agassiz, 1831 (Perciformes, Cichlidae), introduzido na represa do Lobo (Broa), Brotas-Itirapina, SP. In: ROCHA, O.; ESPÍNDOLA, E. L. G., FENERICH-VERANI, N.; VERANI, J. R. \& RIETZLER, A. C. (orgs). Espécies Invasoras em Águas Doces: estudos de caso e propostas de manejo. São Carlos-SP, 73-85, 2005. 
VOROS, et al. Size-selective filtration and taxon-specific digestion of plankton algae by silver carp (Hypophthalmichthys molitrix Val.). Hydrobiologia, 342/343, p. 223-228, 1997.

WELCOMME, R. L. International introductions of inland aquatic species. FAO Fish. Tec. Papers. 294 p, 1988.

WINEMILLER, K. O.; TAPHORN, D. C.\& BARBARINO-DUQUE, A. Ecology of Cichla (Cichlidae) in two blackwater rivers of Southern Venezuela, Copeia, p. 690-696, 1997.

WOOTTON, R. J., 1999, Ecology of teleost fish. London, Chapman \& Hall. 404p.

ZARET, T. M.; Life history and growth relationships of Cichla ocellaris, a predatory South American cichlid. Biotropica, 12(2): 144-157, 1980.

ZARET, T. M.; PAINE, R. T. Species introduction in a tropical lake. Science, 182(2): 449-455, 1973.

ZAVALA-CAMIN, L. A. Introdução aos estudos sobre alimentação natural em peixes. Maringá:Nupelia, EDUEM, 129 p., 1996. 
ANEXOS 


\section{ANEXO A - Espécie Geophagus brasiliensis}

Tabela A - Grau de repleção dos estômagos dos acarás (Geophagus brasiliensis), coletados no reservatório de Barra Bonita, em novembro de 2002 e novembro de 2003.

\begin{tabular}{ccc}
\hline Grau de Repleção & $\mathbf{N}^{\mathbf{0}}$ de estômagos & $\mathbf{\%}$ \\
\hline 0 & 32 & 43,24 \\
Grau 1 & 10 & 13,51 \\
Grau 2 & 12 & 16,22 \\
Grau 3 & 13 & 17,57 \\
Grau 4 & 7 & 9,46 \\
$\Sigma$ & $\mathbf{7 4}$ & $\mathbf{1 0 0}$ \\
\hline
\end{tabular}

Tabela B - Freqüência de ocorrência (\%) dos itens alimentares encontrados no estômago do acará (Geophagus brasiliensis) no reservatório de Barra Bonita, em novembro de 2002 e novembro de 2003. $\mathrm{N}$ = número de estômagos onde o item foi encontrado.

\begin{tabular}{lcc}
\hline \multicolumn{1}{c}{ Itens alimentares } & \multicolumn{2}{c}{ Freqüência de } \\
& $\mathrm{N}$ & $(\%)$ \\
\hline Larva de Diptera & 7 & 16,6 \\
Aedokritus sp & 1 & 2,3 \\
Coelotanypus sp & 12 & 28,5 \\
Harnischia sp & 1 & 2,3 \\
Procladius sp & 2 & 4,7 \\
Tanytarsus sp & 3 & 7,1 \\
Chironomidae & & \\
Copepoda & 9 & 21,4 \\
Cyclopoida & 6 & 14,2 \\
Calanoida & & \\
Cladocera & 1 & 2,3 \\
Daphnia gessneri & 2 & 4,7 \\
Daphnia sp & 1 & 2,3 \\
Bosminidae & 3 & 7,1 \\
Chydoridae & 3 & 7,1 \\
Cladocera (não identificado) & & \\
Outros & 1 & 2,3 \\
Ostracoda & 2 & 4,7 \\
Hirudinea & 1 & 2,3 \\
Hymenoptera & 12 & 28,5 \\
Fragmento de inseto & 1 & 2,3 \\
Peixe (não identificado) & 2 & 9,5 \\
Escama & 1 & 2,3 \\
Material vegetal & 8 & 19 \\
Detritos & & \\
\hline
\end{tabular}


Tabela C - Grau de repleção dos estômagos dos acarás (Geophagus brasiliensis), coletados no reservatório de Bariri, nos meses de fevereiro, junho, setembro e novembro de 2003.

\begin{tabular}{ccc}
\hline Grau de Repleção & $\mathbf{N}^{\mathbf{0}}$ de estômagos & $\mathbf{\%}$ \\
\hline 0 & 59 & 49,16 \\
Grau 1 & 31 & 25,84 \\
Grau 2 & 11 & 9,17 \\
Grau 3 & 11 & 9,17 \\
Grau 4 & 8 & 6,66 \\
$\Sigma$ & $\mathbf{1 2 0}$ & $\mathbf{1 0 0}$ \\
\hline
\end{tabular}

Tabela D - Freqüência de ocorrência (\%) dos itens alimentares encontrados nos estômagos dos acarás (Geophagus brasiliensis), coletados no reservatório de Bariri, nos meses de fevereiro, junho, setembro e novembro de 2003. $\mathrm{N}=$ número de estômagos onde o item foi encontrado.

\begin{tabular}{|c|c|c|}
\hline \multirow[t]{2}{*}{ Itens alimentares } & \multicolumn{2}{|c|}{$\begin{array}{c}\text { Frequência de } \\
\text { Ocorrência }\end{array}$} \\
\hline & $\mathbf{N}$ & $(\%)$ \\
\hline \multicolumn{3}{|l|}{ Larva de Diptera } \\
\hline Ablabesmyia sp & 3 & 4,9 \\
\hline Asheum sp & 1 & 1,6 \\
\hline Coelotanypus sp & 2 & 3,2 \\
\hline Cryptochironomus sp & 1 & 1,6 \\
\hline Goeldichironomus sp & 1 & 1,6 \\
\hline Polypedilum sp & 1 & 1,6 \\
\hline Procladius sp & 1 & 1,6 \\
\hline Saetheria $\mathrm{sp}$ & 1 & 1,6 \\
\hline Chironomidae & 9 & 14,7 \\
\hline Chaoborus sp & 1 & 1,6 \\
\hline Ceratopogonidae & 1 & 1,6 \\
\hline \multicolumn{3}{|l|}{ Copepoda } \\
\hline Cyclopoida & 3 & 4,9 \\
\hline fragmentos de Copepoda & 1 & 1,6 \\
\hline \multicolumn{3}{|l|}{ Cladocera } \\
\hline Moina $\mathrm{sp}$ & 1 & 1,6 \\
\hline Cladocera (não identificado) & 1 & 1,6 \\
\hline \multicolumn{3}{|l|}{ Oligochaeta } \\
\hline Oligochaeta & 2 & 3,2 \\
\hline Fragmentos de Oligochaeta & 1 & 1,6 \\
\hline \multicolumn{3}{|l|}{ Outros } \\
\hline Pupa de Chironomidae (Diptera) & 1 & 1,6 \\
\hline Fragmentos de inseto & 6 & 9,8 \\
\hline Hirudinea & 6 & 9,8 \\
\hline Nematoda & 2 & 3,2 \\
\hline Fragmento de Ephemeroptera & 1 & 1,6 \\
\hline Peixe (não identificado) & 1 & 1,6 \\
\hline Escama & 4 & 6,5 \\
\hline
\end{tabular}


material vegetal $10 \quad 16,3$

Detritos $35 \quad 57,3$

Tabela E - Grau de repleção dos estômagos dos acarás (Geophagus brasiliensis), coletados no reservatório de Ibitinga, no mês de dezembro de 2002.

\begin{tabular}{ccc}
\hline Grau de Repleção & $\mathbf{N}^{\mathbf{0}}$ de estômagos & $\mathbf{\%}$ \\
\hline 0 & 13 & 76,47 \\
Grau 1 & 4 & 23,53 \\
Grau 2 & 0 & 0 \\
Grau 3 & 0 & 0 \\
Grau 4 & 0 & 0 \\
$\Sigma$ & $\mathbf{1 7}$ & $\mathbf{1 0 0}$ \\
\hline
\end{tabular}

Tabela F - Freqüência de ocorrência (\%) dos itens alimentares encontrados nos estômagos dos acarás (Geophagus brasiliensis), coletados no reservatório de Ibitinga, no mês de dezembro de 2002. $\mathrm{N}$ = número de estômagos onde o item foi encontrado.

\begin{tabular}{|c|c|c|}
\hline \multirow[t]{2}{*}{ Itens alimentares } & \multicolumn{2}{|c|}{$\begin{array}{c}\text { Frequência de } \\
\text { Ocorrência }\end{array}$} \\
\hline & $\mathrm{N}$ & $(\%)$ \\
\hline \multicolumn{3}{|l|}{ Larva de Diptera } \\
\hline Ablabesmyia sp & 1 & 25 \\
\hline Aedokritus sp & 1 & 25 \\
\hline \multicolumn{3}{|l|}{ Outros } \\
\hline Fragmentos de inseto & 2 & 50 \\
\hline Fragmentos de peixe & 1 & 25 \\
\hline material vegetal & 1 & 25 \\
\hline
\end{tabular}




\section{ANEXO B - Espécie Plagioscion squamosissimus}

Tabela A - Grau de repleção dos estômagos das corvinas ( $P$. squamosissimus) coletadas no reservatório de Barra Bonita, nos meses de novembro de 2002 e novembro de 2003.

\begin{tabular}{ccc}
\hline Grau de Repleção & $\mathbf{N}^{\mathbf{0}}$ de estômagos & $\mathbf{\%}$ \\
\hline 0 & 38 & 24,52 \\
Grau 1 & 30 & 19,35 \\
Grau 2 & 14 & 9,03 \\
Grau 3 & 17 & 10,97 \\
Grau 4 & 18 & 11,61 \\
$\Sigma$ & $\mathbf{1 1 7}$ & $\mathbf{1 0 0}$ \\
\hline
\end{tabular}

Tabela B - Freqüência de ocorrência (\%) dos itens alimentares encontrados nos estômagos de $P$. squamosissimus, coletados no reservatório de Barra Bonita, nos meses de novembro de 2002 e novembro de 2003. $\mathrm{N}$ = número de estômagos onde o item foi encontrado.

\begin{tabular}{lcc}
\hline \multicolumn{1}{c}{ Itens alimentares } & Frequência de Ocorrência \\
& $\mathrm{N}$ & $(\%)$ \\
\hline Peixe & 50 & 63,2 \\
Fragmentos de peixe & 17 & 21,5 \\
Peixe (não identificação) & 3 & 3,7 \\
Cichlidae & 1 & 1,2 \\
Characidae & 1 & 1,2 \\
Plagioscion squamosissimus & 1 & 1,2 \\
Astyanax altiparanae & & \\
Larva de Diptera & 2 & 2,5 \\
Cryptochironomus sp & 2 & 2,5 \\
Chironomidae & & \\
Outros & 3 & 3,7 \\
Phyllocycla sp (ninfa de Odonata) & 1 & 1,2 \\
Fragmentos de inseto & 1 & 1,2 \\
Notodiaptomus sp (Copepoda Calanoida) & 3 & 3,7 \\
Material vegetal & 1 & 1,2 \\
$\quad$ Detritos & & \\
\hline
\end{tabular}


Tabela C - Grau de repleção dos estômagos das corvinas (P. squamosissimus), coletadas no reservatório de Bariri, nos meses de fevereiro, junho, setembro e novembro de 2003.

\begin{tabular}{ccc}
\hline Grau de Repleção & $\mathbf{N}^{\mathbf{0}}$ de estômagos & $\mathbf{\%}$ \\
\hline 0 & 74 & 28,7 \\
Grau 1 & 46 & 17,83 \\
Grau 2 & 32 & 12,40 \\
Grau 3 & 59 & 22,86 \\
Grau 4 & 47 & 18,21 \\
$\Sigma$ & $\mathbf{2 5 8}$ & $\mathbf{1 0 0}$ \\
\hline
\end{tabular}

Tabela D - Freqüência de ocorrência (\%) dos itens alimentares encontrados nos estômagos de $P$. squamosissimus, coletados no reservatório de Bariri, nos meses de fevereiro, junho, setembro e novembro de 2003. $\mathrm{N}$ = número de estômagos onde o item foi encontrado.

\begin{tabular}{|c|c|c|}
\hline \multirow{2}{*}{ Itens alimentares } & \multicolumn{2}{|c|}{ Frequência de Ocorrência } \\
\hline & $\mathbf{N}$ & $(\%)$ \\
\hline \multicolumn{3}{|l|}{ Peixe } \\
\hline Fragmentos de peixe & 62 & 33,6 \\
\hline Peixe (não identificado) & 19 & 10,3 \\
\hline Plagioscion squamosissimus & 3 & 1,6 \\
\hline Cichlidae & 3 & 1,6 \\
\hline Siluriformes & 1 & 0,5 \\
\hline \multicolumn{3}{|l|}{ Ephemeroptera } \\
\hline Campsurinae & 67 & 36,4 \\
\hline Massa de ovos & 27 & 14,6 \\
\hline \multicolumn{3}{|l|}{ Odonata } \\
\hline Phyllocycla $\mathrm{sp}$ & 7 & 3,8 \\
\hline Libellulidae & 3 & 1,6 \\
\hline Fragmentos de Odonata & 1 & 0,5 \\
\hline Pupa de Chironomidae (Diptera) & 14 & 7,6 \\
\hline Fragmentos de inseto & 10 & 5,4 \\
\hline \multicolumn{3}{|l|}{ Larva de Diptera } \\
\hline Coelotanypus sp & 8 & 4,3 \\
\hline Ablabesmyia sp & 4 & 2,1 \\
\hline Cryptochironomus sp & 4 & 2,1 \\
\hline Chaoborus sp & 3 & 1,6 \\
\hline Asheum sp & 1 & 0,5 \\
\hline Brundiniella sp & 1 & 0,5 \\
\hline Goeldichironomus sp & 1 & 0,5 \\
\hline Harnischia sp & 1 & 0,5 \\
\hline Ceratopogonidae & 3 & 1,6 \\
\hline \multicolumn{3}{|l|}{ Copepoda } \\
\hline Calanoida & 2 & 1,08 \\
\hline Fragmentos de Copepoda & 1 & 0,5 \\
\hline \multicolumn{3}{|l|}{ Outros } \\
\hline Material vegetal & 23 & 12,5 \\
\hline Pupa de Chaoborus sp (Diptera) & 3 & 1,6 \\
\hline
\end{tabular}


Larva de Trichoptera

Macrobrachium sp (Camarão)

Detritos

$\begin{array}{cc}2 & 1,08 \\ 1 & 0,5 \\ 1 & 0,5\end{array}$

Tabela E - Grau de repleção dos estômagos das corvinas (P. squamosissimus), coletadas nos meses de dezembro de 2002, dezembro de 2003 e fevereiro de 2004, no reservatório de Ibitinga.

\begin{tabular}{ccc}
\hline Grau de Repleção & $\mathbf{N}^{\mathbf{0}}$ de estômagos & $\mathbf{\%}$ \\
\hline 0 & 79 & 39,7 \\
Grau 1 & 38 & 19,1 \\
Grau 2 & 27 & 13,57 \\
Grau 3 & 34 & 17,08 \\
Grau 4 & 21 & 10,55 \\
$\Sigma$ & $\mathbf{1 9 9}$ & $\mathbf{1 0 0}$ \\
\hline
\end{tabular}

Tabela F - Freqüência de ocorrência (\%) dos itens alimentares encontrados nos estômagos de $P$. squamosissimus, coletados no reservatório de Ibitinga, nos meses de dezembro de 2002, dezembro de 2003 e fevereiro de 2004. $\mathrm{N}$ = número de estômagos onde o item foi encontrado.

\begin{tabular}{lcc}
\hline \multicolumn{1}{c}{ Itens alimentares } & Frequência de Ocorrência \\
& $\mathbf{N}$ & $\mathbf{( \% )}$ \\
\hline Peixe & 22 & 18,3 \\
Fragmentos de peixe & 7 & 5,8 \\
Peixe (não identificado) & & \\
Odonata & 43 & 35,8 \\
Phyllocycla sp & 9 & 7,5 \\
Libellulidae & 7 & 5,8 \\
Fragmentos de Odonata & & \\
Copepoda & 1 & 0,8 \\
Calanoida & 1 & 0,8 \\
Cyclopoida & & \\
Cyanophyceae & 1 & 0,8 \\
Pseudoanabaena sp & 1 & 0,8 \\
Oscillatoria sp & & \\
Outros & 8 & 6,6 \\
Larva de Trichoptera & 6 & 5 \\
Larva de Chaoborus sp (Diptera) & 2 & 1,6 \\
Pupa de Chironomidae (Diptera) & 1 & 0,8 \\
Hyallela sp (Amphioda) & 7 & 5,8 \\
Campsurinae (Fragmentos de Ephemeroptera) & 1 & 0,8 \\
Gastropoda (Mollusca) & 19 & 15,8 \\
Fragmentos de inseto & 5 & 4,1 \\
Material vegetal & 3 & 2,5 \\
Escama & & \\
\hline
\end{tabular}


Tabela G - Grau de repleção dos estômagos das corvinas ( $P$. squamosissimus), coletadas no reservatório de Promissão, em maio e dezembro de 2003.

\begin{tabular}{ccc}
\hline Grau de Repleção & $\mathbf{N}^{\mathbf{0}}$ de estômagos & $\mathbf{\%}$ \\
\hline 0 & 44 & 32,84 \\
Grau 1 & 20 & 14,92 \\
Grau 2 & 13 & 9,70 \\
Grau 3 & 21 & 15,67 \\
Grau 4 & 36 & 26,87 \\
$\Sigma$ & $\mathbf{1 3 4}$ & $\mathbf{1 0 0}$ \\
\hline
\end{tabular}

Tabela H - Freqüência de ocorrência (\%) dos itens alimentares encontrados nos estômagos de $P$. squamosissimus, coletados no reservatório de Promissão, nos períodos de maio e dezembro de 2003. $\mathrm{N}$ = número de estômagos onde o item foi encontrado.

\begin{tabular}{|c|c|c|}
\hline \multirow{2}{*}{ Itens alimentares } & \multicolumn{2}{|c|}{ Frequência de Ocorrência } \\
\hline & $\mathrm{N}$ & $(\%)$ \\
\hline \multicolumn{3}{|l|}{ Peixe } \\
\hline Fragmentos de Peixe & 5 & 5,8 \\
\hline Peixe (não identificado) & 3 & 3,4 \\
\hline Serrassalmus spilopleura & 1 & 1,1 \\
\hline \multicolumn{3}{|l|}{ Odonata } \\
\hline Phyllocycla sp & 20 & 23,2 \\
\hline Libellulidae & 10 & 11,6 \\
\hline Fragmentos de Odonata & 4 & 4,6 \\
\hline Coenagrionidae & 1 & 1,1 \\
\hline \multicolumn{3}{|l|}{ Ephemeroptera } \\
\hline Campsurinae (fragmentos) & 8 & 9,3 \\
\hline Massa de ovos & 2 & 2,3 \\
\hline \multicolumn{3}{|l|}{ Crustacea (Camarão de água doce) } \\
\hline Macrobrachium sp & 49 & 56,9 \\
\hline Macrobrachium sp (pós larva) & 3 & 3,4 \\
\hline Larva de Diptera & 7 & \\
\hline Chironomidae & 2 & 2,3 \\
\hline Ablabesmyia $\mathrm{sp}$ & 1 & 1,1 \\
\hline Aedokritus sp & 1 & 1,1 \\
\hline Chaoborus sp & 1 & 1,1 \\
\hline Coelotanypus sp & 1 & 1,1 \\
\hline Goeldichironomus sp & 1 & 1,1 \\
\hline \multicolumn{3}{|l|}{ Pupa de Diptera } \\
\hline Chironomidae & 2 & 2,3 \\
\hline Chaborus sp & 1 & 1,1 \\
\hline \multicolumn{3}{|l|}{ Outros } \\
\hline Hemiptera & 6 & 6,9 \\
\hline Larvas de Trichoptera & 2 & 2,3 \\
\hline Fragmentos de inseto & 3 & 3,4 \\
\hline Copepoda Calanoida & 2 & 2,3 \\
\hline Arachnida & 1 & 1,1 \\
\hline
\end{tabular}


Coleoptera

Melanoides tuberculata (Mollusca)

Material vegetal

Detritos

$1+1,1$

$1 \quad 1,1$

$1 \quad 1,1$

1

Tabela I - Grau de repleção dos estômagos das corvinas (P. squamosissimus) coletadas, no reservatório de Nova Avanhandava nos meses de dezembro de 2002 e janeiro de 2004.

\begin{tabular}{ccc}
\hline Grau de Repleção & $\mathbf{N}^{\mathbf{0}}$ de estômagos & $\mathbf{\%}$ \\
\hline 0 & 35 & 23,33 \\
Grau 1 & 33 & 22 \\
Grau 2 & 17 & 11,33 \\
Grau 3 & 22 & 14,67 \\
Grau 4 & 43 & 28,67 \\
$\Sigma$ & $\mathbf{1 5 0}$ & $\mathbf{1 0 0}$ \\
\hline
\end{tabular}

Tabela J - Freqüência de ocorrência (\%) dos itens alimentares encontrados nos estômagos de P. squamosissimus, coletados no reservatório de Nova Avanhandava, nos meses de dezembro de 2002 e janeiro de 2004. $\mathrm{N}$ = número de estômagos onde o item foi encontrado.

\begin{tabular}{lcc}
\hline \multicolumn{1}{c}{ Itens alimentares } & Frequência de Ocorrência \\
& $\mathbf{N}$ & $\mathbf{( \% )}$ \\
\hline Peixe & 11 & 9,5 \\
fragmentos de peixe & 5 & 4,3 \\
$\quad$ Peixe (não identificado) & 1 & 0,8 \\
Characidae & 1 & 0,8 \\
Astyanax sp & 2 & 1,7 \\
Serrasalmus spilopleura & 2 & 1,7 \\
Characiformes & & \\
Crustacea (Camarão de água doce) & 37 & 32,1 \\
Macrobrachium sp (pós larva) & 34 & 29,5 \\
Macrobrachium sp & 2 & 1,7 \\
fragmentos de camarão & & \\
Odonata & 22 & 19,1 \\
Phyllocycla sp & 10 & 8,6 \\
Libellulidae & 2 & 1,7 \\
Coenagrionidae & 1 & 0,8 \\
$\quad$ Ninfa de Odonata (não identificado) & 14 & 12,1 \\
$\quad$ fragmentos de Odonata & & \\
Larva de Díptera & 2 & 1,7 \\
Chironomidae & 2 & 1,7 \\
$\quad$ Goeldichironomus sp & 1 & 0,8 \\
Tanytarsus sp & & \\
Outros & 26 & 22,6 \\
fragmentos de Ephemeroptera & &
\end{tabular}


Pupa de Chironomidae

material vegetal

fragmentos de inseto

Larva de Trichoptera

Hemiptera

Melanoides tuberculata (Mollusca)

0,8

Crustacea

Anexo K - Grau de repleção dos estômagos das corvinas (P. squamosissimus) coletadas, no reservatório de Três Irmãos, nos meses de maio de 2003 e janeiro de 2004.

\begin{tabular}{ccc}
\hline Grau de Repleção & $\mathbf{N}^{\mathbf{0}}$ de estômagos & $\mathbf{\%}$ \\
\hline 0 & 39 & 27,47 \\
Grau 1 & 23 & 16,2 \\
Grau 2 & 13 & 9,15 \\
Grau 3 & 28 & 19,72 \\
Grau 4 & 53 & 27,46 \\
$\Sigma$ & $\mathbf{1 4 2}$ & $\mathbf{1 0 0}$ \\
\hline
\end{tabular}

Tabela L - Freqüência de ocorrência (\%) dos itens alimentares encontrados nos estômagos de $P$. squamosissimus, coletados no reservatório de Três Irmãos, nos meses de maio de 2003 e janeiro de 2004. $\mathrm{N}$ = número de estômagos onde o item foi encontrado.

\begin{tabular}{|c|c|c|}
\hline \multirow{2}{*}{ Itens alimentares } & \multicolumn{2}{|c|}{ Frequência de Ocorrência } \\
\hline & $\mathbf{N}$ & $(\%)$ \\
\hline \multicolumn{3}{|l|}{ Peixe } \\
\hline fragmentos de peixe & 15 & 12,8 \\
\hline Cichlidae & 4 & 3,4 \\
\hline Peixe (não identificado) & 2 & 1,7 \\
\hline \multicolumn{3}{|l|}{ Custacea (Camarão de água doce) } \\
\hline Macrobrachium sp (pós larva) & 87 & 50,4 \\
\hline Macrobrachium sp & 56 & 47,9 \\
\hline fragmentos de camarão & 2 & 1,7 \\
\hline \multicolumn{3}{|l|}{ Odonata } \\
\hline Phyllocycla $\mathrm{sp}$ & 6 & 5,1 \\
\hline Libellulidae & 3 & 2,5 \\
\hline Coenagrionidae & 2 & 0,8 \\
\hline Ninfa de Odonata & 4 & 3,4 \\
\hline fragmentos de Odonata & 14 & 11,9 \\
\hline Larva de Díptera & 2 & 1,6 \\
\hline Goeldichironomus sp & 1 & 0,8 \\
\hline Coelotanypus sp & 1 & 0,8 \\
\hline \multicolumn{3}{|l|}{ Outros } \\
\hline fragmentos de Ephemeroptera & 1 & 0,8 \\
\hline Melanoides tuberculata (Mollusca) & 1 & 0,8 \\
\hline
\end{tabular}


material vegetal

pupa de Chironomidae (Diptera)

7

4

5,9

3,4

Tabela M - Valores do volume útil ( $\mathrm{Km}^{3} / 24$ horas) e vazão defluente $\left(\mathrm{m}^{3} / \mathrm{s}\right)$ nos meses de fevereiro e junho de 2003, no reservatório de Bariri. Fonte: AES/Tietê AS, 2006.

\begin{tabular}{|c|c|c|c|c|c|}
\hline \multicolumn{3}{|c|}{ Fevereiro } & \multicolumn{3}{|c|}{ Junho } \\
\hline Data & $\begin{array}{l}\text { Volume } \\
\text { útil ( } 24 \\
\text { horas) }\end{array}$ & $\begin{array}{c}\text { Vazão } \\
\text { defluente }\end{array}$ & Data & $\begin{array}{c}\text { Volume } \\
\text { útil ( } 24 \\
\text { horas) }\end{array}$ & $\begin{array}{c}\text { Vazão } \\
\text { defluente }\end{array}$ \\
\hline $01 / 02 / 2003$ & 82,38 & 1459 & $01 / 06 / 2003$ & 95,83 & 218 \\
\hline $02 / 02 / 2003$ & 86,50 & 1052 & $02 / 06 / 2003$ & 95,83 & 214 \\
\hline $03 / 02 / 2003$ & 89,60 & 678 & $03 / 06 / 2003$ & 96,87 & 219 \\
\hline $04 / 02 / 2003$ & 84,43 & 789 & $04 / 06 / 2003$ & 96,87 & 231 \\
\hline $05 / 02 / 2003$ & 74,18 & 603 & $05 / 06 / 2003$ & 95,83 & 237 \\
\hline $06 / 02 / 2003$ & 83,40 & 441 & $06 / 06 / 2003$ & 86,50 & 284 \\
\hline $07 / 02 / 2003$ & 84,43 & 434 & $07 / 06 / 2003$ & 81,35 & 241 \\
\hline $08 / 02 / 2003$ & 86,50 & 352 & $08 / 06 / 2003$ & 78,27 & 240 \\
\hline $09 / 02 / 2003$ & 78,27 & 349 & $09 / 06 / 2003$ & 72,14 & 226 \\
\hline $10 / 02 / 2003$ & 75,20 & 350 & $10 / 06 / 2003$ & 68,07 & 237 \\
\hline $11 / 02 / 2003$ & 80,32 & 444 & $11 / 06 / 2003$ & 66,04 & 251 \\
\hline $12 / 02 / 2003$ & 79,29 & 403 & $12 / 06 / 2003$ & 69,08 & 239 \\
\hline $13 / 02 / 2003$ & 84,43 & 353 & $13 / 06 / 2003$ & 72,14 & 269 \\
\hline $14 / 02 / 2003$ & 89,60 & 259 & $14 / 06 / 2003$ & 78,27 & 214 \\
\hline $15 / 02 / 2003$ & 88,57 & 495 & $15 / 06 / 2003$ & 85,47 & 222 \\
\hline $16 / 02 / 2003$ & 80,32 & 704 & $16 / 06 / 2003$ & 84,43 & 232 \\
\hline $17 / 02 / 2003$ & 83,40 & 844 & $17 / 06 / 2003$ & 85,47 & 244 \\
\hline $18 / 02 / 2003$ & 75,20 & 938 & $18 / 06 / 2003$ & 86,50 & 218 \\
\hline $19 / 02 / 2003$ & 81,35 & 1926 & $19 / 06 / 2003$ & 82,38 & 238 \\
\hline $20 / 02 / 2003$ & 65,03 & 1802 & $20 / 06 / 2003$ & 81,35 & 230 \\
\hline $21 / 02 / 2003$ & 79,29 & 1510 & $21 / 06 / 2003$ & 80,32 & 201 \\
\hline $22 / 02 / 2003$ & 75,20 & 1557 & $22 / 06 / 2003$ & 81,35 & 184 \\
\hline $23 / 02 / 2003$ & 74,18 & 1288 & $23 / 06 / 2003$ & 80,32 & 198 \\
\hline $24 / 02 / 2003$ & 79,29 & 779 & $24 / 06 / 2003$ & 83,40 & 226 \\
\hline $25 / 02 / 2003$ & 76,22 & 623 & $25 / 06 / 2003$ & 85,47 & 226 \\
\hline $26 / 02 / 2003$ & 75,20 & 546 & $26 / 06 / 2003$ & 88,57 & 228 \\
\hline \multirow[t]{4}{*}{$27 / 02 / 2003$} & 81,35 & 520 & $27 / 06 / 2003$ & 90,64 & 237 \\
\hline & & & $28 / 06 / 2003$ & 84,43 & 217 \\
\hline & & & $29 / 06 / 2003$ & 85,47 & 239 \\
\hline & & & $30 / 06 / 2003$ & 84,43 & 239 \\
\hline
\end{tabular}


Tabela $\mathrm{N}$ - Valores do volume útil $\left(\mathrm{Km}^{3} / 24\right.$ horas) e vazão defluente $\left(\mathrm{m}^{3} / \mathrm{s}\right)$ nos meses de setembro e novembro de 2003, no reservatório de Bariri. Fonte: AES/Tietê AS, 2006.

\begin{tabular}{|c|c|c|c|c|c|}
\hline \multicolumn{3}{|c|}{ Setembro } & \multicolumn{3}{|c|}{ Novembro } \\
\hline Data & $\begin{array}{l}\text { Volume } \\
\text { útil ( } 24 \\
\text { horas) }\end{array}$ & $\begin{array}{c}\text { Vazão } \\
\text { defluente }\end{array}$ & Data & $\begin{array}{c}\text { Volume } \\
\text { util (24 } \\
\text { horas) }\end{array}$ & $\begin{array}{c}\text { Vazão } \\
\text { defluente }\end{array}$ \\
\hline $01 / 09 / 2003$ & 87,53 & 244 & $01 / 11 / 2003$ & 87,53 & 284 \\
\hline $02 / 09 / 2003$ & 91,67 & 244 & $02 / 11 / 2003$ & 90,64 & 252 \\
\hline $03 / 09 / 2003$ & 95,83 & 261 & $03 / 11 / 2003$ & 90,64 & 277 \\
\hline $04 / 09 / 2003$ & 93,75 & 264 & $04 / 11 / 2003$ & 88,57 & 301 \\
\hline $05 / 09 / 2003$ & 93,75 & 336 & $05 / 11 / 2003$ & 82,38 & 302 \\
\hline $06 / 09 / 2003$ & 97,91 & 303 & $06 / 11 / 2003$ & 79,29 & 307 \\
\hline $07 / 09 / 2003$ & 95,83 & 256 & $07 / 11 / 2003$ & 81,35 & 288 \\
\hline $08 / 09 / 2003$ & 95,83 & 302 & $08 / 11 / 2003$ & 82,38 & 287 \\
\hline $09 / 09 / 2003$ & 100,00 & 255 & 09/11/2003 & 84,43 & 266 \\
\hline $10 / 09 / 2003$ & 100,00 & 291 & $10 / 11 / 2003$ & 95,83 & 333 \\
\hline $11 / 09 / 2003$ & 100,00 & 316 & $11 / 11 / 2003$ & 87,53 & 371 \\
\hline $12 / 09 / 2003$ & 88,57 & 312 & $12 / 11 / 2003$ & 82,38 & 381 \\
\hline $13 / 09 / 2003$ & 79,29 & 190 & $13 / 11 / 2003$ & 85,47 & 331 \\
\hline $14 / 09 / 2003$ & 83,40 & 91 & $14 / 11 / 2003$ & 86,50 & 296 \\
\hline $15 / 09 / 2003$ & 79,29 & 219 & $15 / 11 / 2003$ & 82,38 & 302 \\
\hline $16 / 09 / 2003$ & 81,35 & 202 & $16 / 11 / 2003$ & 83,40 & 286 \\
\hline $17 / 09 / 2003$ & 91,67 & 246 & $17 / 11 / 2003$ & 95,83 & 296 \\
\hline $18 / 09 / 2003$ & 96,87 & 356 & $18 / 11 / 2003$ & 93,75 & 339 \\
\hline $19 / 09 / 2003$ & 84,43 & 510 & $19 / 11 / 2003$ & 83,40 & 373 \\
\hline $20 / 09 / 2003$ & 90,64 & 206 & $20 / 11 / 2003$ & 76,22 & 401 \\
\hline $21 / 09 / 2003$ & 87,53 & 205 & $21 / 11 / 2003$ & 74,18 & 543 \\
\hline $22 / 09 / 2003$ & 80,32 & 272 & $22 / 11 / 2003$ & 71,12 & 562 \\
\hline $23 / 09 / 2003$ & 83,40 & 209 & $23 / 11 / 2003$ & 69,08 & 198 \\
\hline $24 / 09 / 2003$ & 84,43 & 222 & $24 / 11 / 2003$ & 75,20 & 526 \\
\hline $25 / 09 / 2003$ & 89,60 & 287 & $25 / 11 / 2003$ & 81,35 & 588 \\
\hline $26 / 09 / 2003$ & 98,96 & 657 & $26 / 11 / 2003$ & 92,71 & 524 \\
\hline $27 / 09 / 2003$ & 84,43 & 304 & $27 / 11 / 2003$ & 88,57 & 503 \\
\hline $28 / 09 / 2003$ & 83,40 & 177 & $28 / 11 / 2003$ & 79,29 & 537 \\
\hline $29 / 09 / 2003$ & 80,32 & 511 & $29 / 11 / 2003$ & 75,20 & 444 \\
\hline $30 / 09 / 2003$ & 77,24 & 200 & $30 / 11 / 2003$ & 71,12 & 327 \\
\hline
\end{tabular}


Tabela $\mathrm{O}$ - Valores de precipitação diária $(\mathrm{mm})$ na região de Bariri, nos meses de fevereiro e junho. Fonte: AES/Tietê AS, 2006.

\begin{tabular}{cccc}
\hline \multicolumn{2}{c}{ Fevereiro } & \multicolumn{2}{c}{ Junho } \\
\hline Data & Chuva & Data & Chuva \\
$1 / 02 / 2003$ & 18,0 & $1 / 06 / 2003$ & 0,0 \\
$2 / 02 / 2003$ & 0,0 & $2 / 06 / 2003$ & 0,0 \\
$3 / 02 / 2003$ & 0,0 & $3 / 06 / 2003$ & 0,0 \\
$4 / 02 / 2003$ & 0,0 & $4 / 06 / 2003$ & 6,0 \\
$5 / 02 / 2003$ & 0,0 & $5 / 06 / 2003$ & 0,8 \\
$6 / 02 / 2003$ & 4,4 & $6 / 06 / 2003$ & 5,0 \\
$7 / 02 / 2003$ & 0,0 & $7 / 06 / 2003$ & 0,0 \\
$8 / 02 / 2003$ & 0,0 & $8 / 06 / 2003$ & 0,0 \\
$9 / 02 / 2003$ & 0,0 & $9 / 06 / 2003$ & 0,0 \\
$10 / 02 / 2003$ & 0,0 & $10 / 06 / 2003$ & 0,0 \\
$11 / 02 / 2003$ & 0,0 & $11 / 06 / 2003$ & 0,0 \\
$12 / 02 / 2003$ & 0,0 & $12 / 06 / 2003$ & 0,0 \\
$13 / 02 / 2003$ & 0,5 & $13 / 06 / 2003$ & 0,0 \\
$14 / 02 / 2003$ & 21,0 & $14 / 06 / 2003$ & 0,0 \\
$15 / 02 / 2003$ & 10,0 & $15 / 06 / 2003$ & 0,0 \\
$16 / 02 / 2003$ & 15,0 & $16 / 06 / 2003$ & 0,0 \\
$17 / 02 / 2003$ & 30,0 & $17 / 06 / 2003$ & 0,0 \\
$18 / 02 / 2003$ & 2,0 & $18 / 06 / 2003$ & 0,0 \\
$19 / 02 / 2003$ & 0,5 & $19 / 06 / 2003$ & 0,0 \\
$20 / 02 / 2003$ & 0,0 & $20 / 06 / 2003$ & 0,0 \\
$21 / 02 / 2003$ & 11,0 & $21 / 06 / 2003$ & 0,0 \\
$22 / 02 / 2003$ & 3,9 & $22 / 06 / 2003$ & 0,0 \\
$23 / 02 / 2003$ & 0,0 & $23 / 06 / 2003$ & 0,0 \\
$24 / 02 / 2003$ & 0,0 & $24 / 06 / 2003$ & 0,0 \\
$25 / 02 / 2003$ & 0,0 & $25 / 06 / 2003$ & 0,0 \\
$26 / 02 / 2003$ & 0,0 & $26 / 06 / 2003$ & 0,0 \\
$27 / 02 / 2003$ & 0,0 & $27 / 06 / 2003$ & 0,0 \\
$28 / 02 / 2003$ & 0,0 & $28 / 06 / 2003$ & 0,0 \\
& & $29 / 06 / 2003$ & 0,0 \\
& & $30 / 06 / 2003$ & 0,0 \\
& & $\mathbf{1 1 , 8}$ \\
\hline
\end{tabular}


Tabela P - Valores de precipitação diária $(\mathrm{mm})$, na região de Bariri nos meses de setembro e novembro. Fonte: AES/Tietê AS, 2006.

\begin{tabular}{|c|c|c|c|}
\hline \multicolumn{2}{|c|}{ Setembro } & \multicolumn{2}{|c|}{ Novembro } \\
\hline Data & Chuva & Data & Chuva \\
\hline $1 / 09 / 2003$ & 0,0 & $1 / 11 / 2003$ & 0,0 \\
\hline $2 / 09 / 2003$ & 0,0 & $2 / 11 / 2003$ & 7,6 \\
\hline $3 / 09 / 2003$ & 0,0 & $3 / 11 / 2003$ & 3,0 \\
\hline $4 / 09 / 2003$ & 0,0 & $4 / 11 / 2003$ & 0,0 \\
\hline $5 / 09 / 2003$ & 0,0 & $5 / 11 / 2003$ & 0,0 \\
\hline $6 / 09 / 2003$ & 0,0 & $6 / 11 / 2003$ & 0,0 \\
\hline $7 / 09 / 2003$ & 0,0 & $7 / 11 / 2003$ & 1,0 \\
\hline $8 / 09 / 2003$ & 0,0 & $8 / 11 / 2003$ & 0,0 \\
\hline $9 / 09 / 2003$ & 0,4 & $9 / 11 / 2003$ & 0,0 \\
\hline $10 / 09 / 2003$ & 6,0 & $10 / 11 / 2003$ & 0,0 \\
\hline $11 / 09 / 2003$ & 5,3 & $11 / 11 / 2003$ & 0,0 \\
\hline $12 / 09 / 2003$ & 0,0 & $12 / 11 / 2003$ & 0,0 \\
\hline $13 / 09 / 2003$ & 0,0 & $13 / 11 / 2003$ & 36,0 \\
\hline $14 / 09 / 2003$ & 0,0 & $14 / 11 / 2003$ & 12,6 \\
\hline $15 / 09 / 2003$ & 0,0 & $15 / 11 / 2003$ & 0,0 \\
\hline $16 / 09 / 2003$ & 0,0 & $16 / 11 / 2003$ & 0,0 \\
\hline $17 / 09 / 2003$ & 0,0 & $17 / 11 / 2003$ & 54,0 \\
\hline $18 / 09 / 2003$ & 4,0 & $18 / 11 / 2003$ & 76,1 \\
\hline $19 / 09 / 2003$ & 0,0 & $19 / 11 / 2003$ & 1,6 \\
\hline $20 / 09 / 2003$ & 0,0 & $20 / 11 / 2003$ & 0,0 \\
\hline $21 / 09 / 2003$ & 0,0 & $21 / 11 / 2003$ & 0,0 \\
\hline $22 / 09 / 2003$ & 0,0 & $22 / 11 / 2003$ & 0,0 \\
\hline $23 / 09 / 2003$ & 0,0 & $23 / 11 / 2003$ & 0,0 \\
\hline $24 / 09 / 2003$ & 0,0 & $24 / 11 / 2003$ & 1,7 \\
\hline $25 / 09 / 2003$ & 0,0 & $25 / 11 / 2003$ & 12,0 \\
\hline 26/09/2003 & 0,0 & $26 / 11 / 2003$ & 1,6 \\
\hline 27/09/2003 & 0,0 & $27 / 11 / 2003$ & 23,0 \\
\hline 28/09/2003 & 3,2 & $28 / 11 / 2003$ & 1,0 \\
\hline 29/09/2003 & 0,0 & $29 / 11 / 2003$ & 0,0 \\
\hline $30 / 09 / 2003$ & 0,0 & $30 / 11 / 2003$ & 0,0 \\
\hline & 18,9 & & 231,2 \\
\hline
\end{tabular}


Tabela Q - Itens alimentares consumidos pelas diferentes classes de tamanho de Plagioscion squamosissimus, coletados no reservatório de Bariri, em fevereiro, junho, setembro e novembro de 2003.

\begin{tabular}{|c|c|c|c|c|c|c|c|c|c|c|c|c|c|c|c|c|c|c|c|c|c|c|c|c|c|c|c|c|}
\hline $\begin{array}{c}\text { Classes de tamanho } \\
(\mathrm{cm})\end{array}$ & FP & FI & Coe & Cam & Cer & Abl & Bru & Tri & $\mathbf{P x}$ & Cic & Cry & Chi & MV & FO & Phy & MO & Pla & Chal & Lib & DT & Sil & Not & FC & Chap & Har & Goe & Ash & Mac \\
\hline Classe $1(8,30$ a 12,3$)$ & 16 & 1 & 4 & 7 & 2 & 1 & 1 & & 2 & & & 2 & 6 & 1 & 2 & 1 & & 1 & & & & & 1 & & & & & \\
\hline Classe $2(12,4$ a 16,4$)$ & 13 & 4 & 5 & 21 & & 3 & & 2 & 6 & 1 & 4 & 8 & 5 & & & 4 & 2 & & & & & 3 & & 1 & 1 & 1 & 1 & \\
\hline Classe $3(16,5$ a 20,5$)$ & 16 & 3 & & 26 & 1 & & & 1 & 11 & 1 & & 2 & 5 & 5 & 3 & 14 & & 1 & & & 1 & & & 1 & & 1 & & \\
\hline Classe $4(20,6$ a 24,6$)$ & 10 & 2 & & 15 & & & & & 4 & & & & 3 & 1 & 2 & 8 & 2 & 1 & 2 & 2 & & & & 1 & & & & 1 \\
\hline Classe $5(24,7$ a 28,7$)$ & 2 & & & & & & & & & & & & 2 & & & & & & & & & & & & & & & \\
\hline Classe $6(28,8$ a 32,8$)$ & 3 & & & 1 & & & & & 1 & & & & 1 & & & 1 & & & & & & & & & & & & \\
\hline Classe $7(32,9$ a 36,9$)$ & 2 & & & & & & & & & & & & 1 & & & 1 & & & & & & & & & & & & \\
\hline
\end{tabular}

$\mathrm{FP}=$ Fragmentos de peixe, $\mathrm{Px}=$ peixe (não identificado), $\mathrm{Pla}=$ Plagioscion squamosissimus, $\mathrm{Sil}=$ Siluriformes, $\mathrm{Cic}=\mathrm{Cichlidae}, \mathrm{Cam}=\mathrm{Fragmentos}$ de Campsurinae (Ephemeroptera), MO = Massa de Ovos (Ephemeroptera), Phy = Phyllocycla $\mathrm{sp}$ (Odonata), Lib = Libellulidae $($ Odonata), FO = fragmentos de Odonata, Tri = larva de Trichoptera, FI = Fragmentos de Inseto, Chi = pupa de Chironomidae (Diptera), Goe = larva de Goeldichironomus sp (Diptera), Coe = larva de Coelotanypus sp (Diptera), Cer = larva de Ceratopogonidae, Abl = larva de Ablabesmyia sp (Diptera), $\mathrm{Bru}=$ larva de Brundiniella sp (Diptera), Cry = larva de Cryptochironomus sp (Diptera), Har = larva de Harnischia sp (Diptera), Ash = larva de Asheum sp (Diptera), Chap = pupa de Chaoborus sp (Diptera), Chal = larva de Chaoborus sp (Diptera), FC = fragmentos de Copepoda Calanoida, Not = Notodiaptomus sp (Copepoda Calanoida), Mac = Machobrachium sp (camarão), MV = Material Vegetal, DT $=$ detritos. 
ANEXO C - Espécie Cichla cf. ocellaris

Tabela A - Grau de repleção do tucunaré (C. ocellaris) no reservatório de Bariri, no período de novembro de 2003.

\begin{tabular}{ccc}
\hline Grau de Repleção & $\mathbf{N}^{\mathbf{0}}$ de estômagos & $\mathbf{\%}$ \\
\hline 0 & 0 & - \\
Grau 1 & 2 & 66,67 \\
Grau 2 & 0 & - \\
Grau 3 & 0 & - \\
Grau 4 & 1 & 33,33 \\
$\Sigma$ & $\mathbf{3}$ & $\mathbf{1 0 0}$ \\
\hline
\end{tabular}

Tabela B - Freqüência de ocorrência (\%) dos itens alimentares encontrados no estômago do tucunaré (C. ocellaris) no reservatório de Bariri, no período de novembro de 2003. N $=$ número de estômagos onde o item foi encontrado.

\begin{tabular}{lcc}
\hline \multicolumn{1}{c}{ Itens alimentares } & \multicolumn{2}{c}{ Frequência de } \\
& \multicolumn{2}{c}{ Ocorrência } \\
& N & $\mathbf{( \% )}$ \\
\hline fragmentos de peixe & 2 & 66,7 \\
material vegetal & 1 & 33,3 \\
\hline
\end{tabular}

Tabela C - Grau de repleção do tucunaré (C. ocellaris) no reservatório de Ibitinga, nos períodos de dezembro de 2002 e fevereiro de 2004.

\begin{tabular}{ccc}
\hline Grau de Repleção & $\mathbf{N}^{\mathbf{0}}$ de estômagos & $\mathbf{\%}$ \\
\hline 0 & 1 & 11,11 \\
Grau 1 & 3 & 33,33 \\
Grau 2 & 3 & 33,33 \\
Grau 3 & 0 & - \\
Grau 4 & 2 & 22,23 \\
$\Sigma$ & $\mathbf{9}$ & $\mathbf{1 0 0}$ \\
\hline
\end{tabular}


Tabela D - Freqüência de ocorrência (\%) dos itens alimentares encontrados no estômago do tucunaré (C. ocellaris) no reservatório de Ibitinga, nos períodos de dezembro de 2002 e fevereiro de 2004. $\mathrm{N}$ = número de estômagos onde o item foi encontrado.

\begin{tabular}{|c|c|c|}
\hline \multirow[t]{2}{*}{ Itens alimentares } & \multicolumn{2}{|c|}{$\begin{array}{c}\text { Frequência de } \\
\text { Ocorrência }\end{array}$} \\
\hline & $\mathrm{N}$ & $(\%)$ \\
\hline \multicolumn{3}{|l|}{ Peixe } \\
\hline peixe (não identificado) & 4 & 50 \\
\hline fragmentos de peixes & 1 & 12,5 \\
\hline Cichlidae & 2 & 25 \\
\hline Serrasalmus spilopleura & 1 & 12,5 \\
\hline \multicolumn{3}{|c|}{ Crustacea (camarão de água doce) } \\
\hline Macrobrachium $\mathrm{sp}$ & 1 & 12,5 \\
\hline
\end{tabular}

Tabela E - Grau de repleção do tucunaré (C. ocellaris) no reservatório de Promissão, nos meses de maio e dezembro de 2003.

\begin{tabular}{ccc}
\hline Grau de Repleção & $\mathbf{N}^{\mathbf{0}}$ de estômagos & $\mathbf{\%}$ \\
\hline 0 & 13 & 52 \\
Grau 1 & 4 & 16 \\
Grau 2 & 2 & 8 \\
Grau 3 & 3 & 12 \\
Grau 4 & 3 & 12 \\
$\Sigma$ & $\mathbf{2 5}$ & $\mathbf{1 0 0}$ \\
\hline
\end{tabular}

Tabela F - Freqüência de ocorrência (\%) dos itens alimentares encontrados no estômago do tucunaré (C. ocellaris) no reservatório de Promissão, nos meses de maio e dezembro de 2003. $\mathrm{N}=$ número de estômagos onde o item foi encontrado.

\begin{tabular}{llc}
\hline \multicolumn{1}{c}{ Itens alimentares } & \multicolumn{2}{c}{$\begin{array}{c}\text { Frequência de } \\
\text { Ocorrência }\end{array}$} \\
& $\mathrm{N}$ & $(\%)$ \\
\hline Crustacea (Camarão de água doce) & & \\
$\quad$ Macrobrachium sp & 5 & 41,6 \\
$\quad$ Macrobrachium sp (pós larva) & 1 & 8,3 \\
Peixe & & \\
$\quad$ Peixe (não identificado) & 1 & 8,3 \\
$\quad$ Fragmentos de peixe & 3 & 25 \\
$\quad$ Characidae & 1 & 8,3 \\
Outros & & \\
$\quad$ Melanoides tuberculata (Mollusca) & 1 & 8,3 \\
$\quad$ Coenagrionidae (ninfa de Odonata) & 1 & 8,3 \\
$\quad$ material vegetal & 1 & 8,3 \\
\hline
\end{tabular}


Tabela G - Grau de repleção dos estômagos dos tucunarés (C. ocellaris), coletados no reservatório de Nova Avanhandava, nos meses de dezembro de 2002 e janeiro de 2004.

\begin{tabular}{ccc}
\hline Grau de Repleção & $\mathbf{N}^{\mathbf{0}}$ de estômagos & $\mathbf{\%}$ \\
\hline 0 & 1 & 14,28 \\
Grau 1 & 1 & 14,28 \\
Grau 2 & 2 & 28,58 \\
Grau 3 & 1 & 14,28 \\
Grau 4 & 2 & 28,58 \\
$\Sigma$ & $\mathbf{1 0 0}$ \\
\hline
\end{tabular}

Tabela H - Freqüência de ocorrência (\%) dos itens alimentares encontrados nos estômagos dos tucunarés ( $C$. ocellaris), coletados no reservatório de Nova Avanhandava, nos meses de dezembro de 2002 e janeiro de 2004. $\mathrm{N}=$ número de estômagos onde o item foi encontrado.

\begin{tabular}{lcc}
\hline \multirow{1}{*}{ Itens alimentares } & \multicolumn{2}{c}{ Frequência de } \\
& \multicolumn{2}{c}{ Ocorrência } \\
& $\mathrm{N}$ & $(\%)$ \\
\hline Peixe & 2 & 33,3 \\
$\begin{array}{l}\text { Hyphessobrycon sp (peixe) } \\
\text { fragmentos de peixe }\end{array}$ & 2 & 33,3 \\
Outros & & \\
fragmentos de camarão & 1 & 16,6 \\
Hirudinea & 1 & 16,6 \\
\hline
\end{tabular}

Tabela G - Grau de repleção dos tucunarés (C. ocellaris), coletados no reservatório de Três Irmãos, nos meses de maio de 2003 e janeiro de 2004.

\begin{tabular}{ccc}
\hline Grau de Repleção & $\mathbf{N}^{\mathbf{0}}$ de estômagos & $\mathbf{\%}$ \\
\hline 0 & 2 & 40 \\
Grau 1 & 2 & 40 \\
Grau 2 & 1 & 20 \\
Grau 3 & 0 & - \\
Grau 4 & 0 & - \\
$\Sigma$ & $\mathbf{5}$ & $\mathbf{1 0 0}$ \\
\hline
\end{tabular}


Tabela H - Freqüência de ocorrência (\%) dos itens alimentares encontrados nos estômagos dos tucunarés ( $C$. ocellaris), coletados no reservatório de Três Irmãos, nos períodos de maio de 2003 e janeiro de 2004. $\mathrm{N}$ = número de estômagos onde o item foi encontrado.

\begin{tabular}{lcc}
\hline \multicolumn{1}{c}{ Itens alimentares } & \multicolumn{2}{c}{$\begin{array}{c}\text { Frequência de } \\
\text { Ocorrência }\end{array}$} \\
& $\mathrm{N}$ & $(\%)$ \\
\hline Peixe & 1 & 16,6 \\
$\quad$ Serrasalmus spilopleura & 1 & 16,6 \\
$\quad$ Peixe (não identificado) & 1 & 16,6 \\
$\quad$ Fragmentos de peixe & & \\
Crustacea (Camarão de água doce) & 1 & 16,6 \\
$\quad$ Macrobrachium sp (pós larva) & 1 & 16,6 \\
$\quad$ Macrobrachium sp & & \\
$\quad \begin{array}{l}\text { Outro } \\
\quad \text { Hirudinea }\end{array}$ & 1 & 16,6 \\
\hline
\end{tabular}

ANEXO D - No decorrer do projeto foi elaborado um banco de imagens dos principais itens alimentares consumidos pelas espécies Plagioscion squamossisimus, Geophagus brasiliensis e Cichla cf. monoculus, nos seis reservatórios do médio e baixo rio Tietê. 
Fotos de estruturas cefálicas de relevância na identificação taxonômica de Chironomidae

Fotografias em microscópio óptico
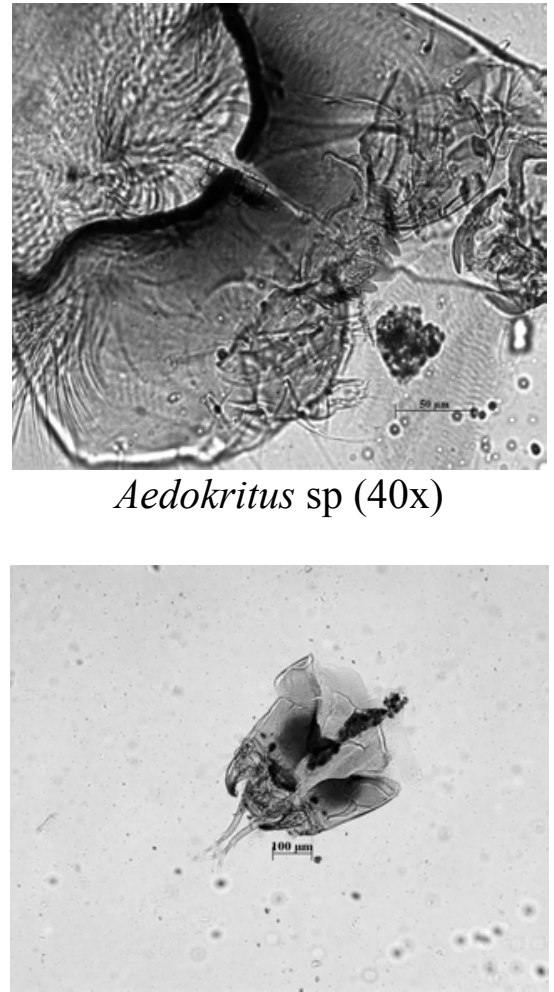

Tanytarsus $\mathrm{sp}(10 \mathrm{x})$

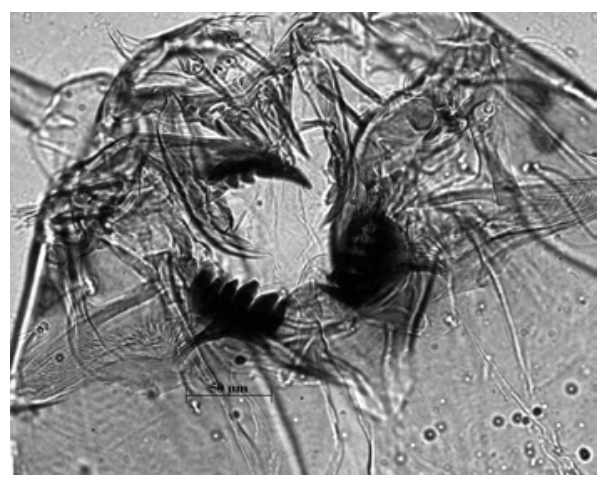

Cryptochironomus $\mathrm{sp}(40 \mathrm{x})$

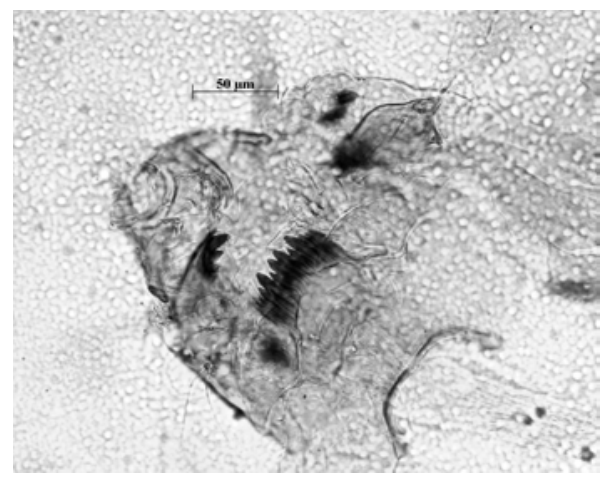

Polypedilum sp (40x)

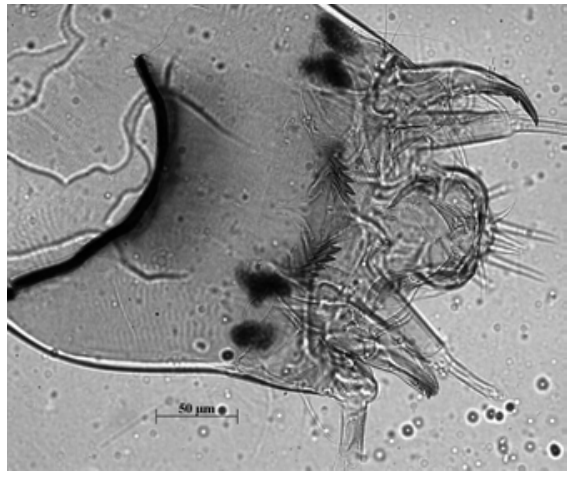

Harnischia sp (40x)

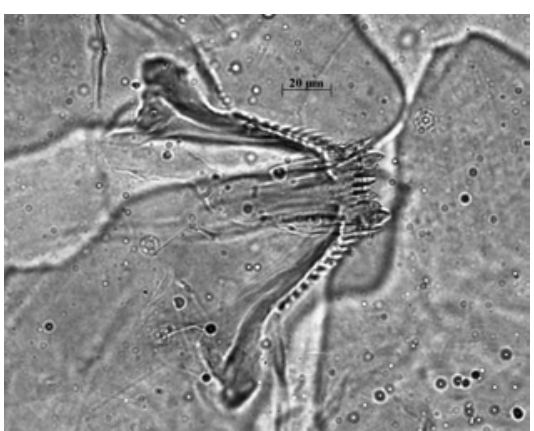

Coelotanypus sp (63x)

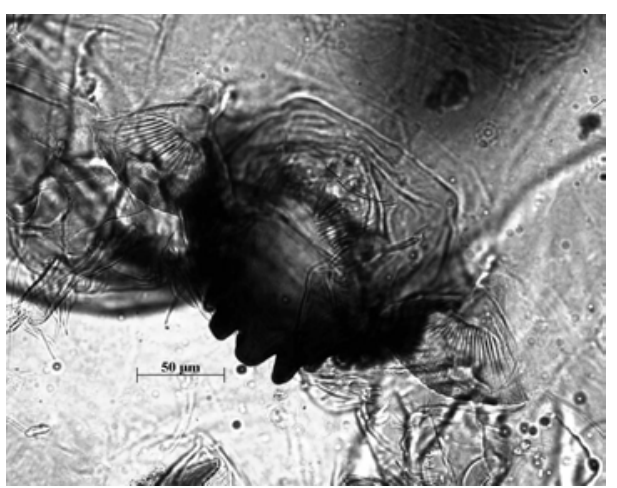

Goeldichironomus $\mathrm{sp}(40 \mathrm{x})$

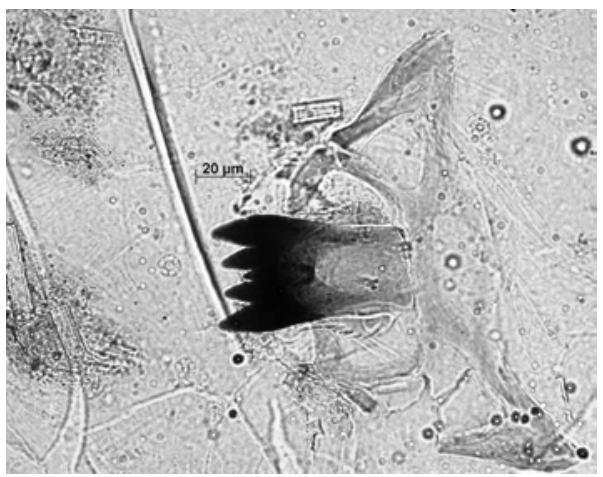

Procladius sp $(63 \mathrm{x})$ 

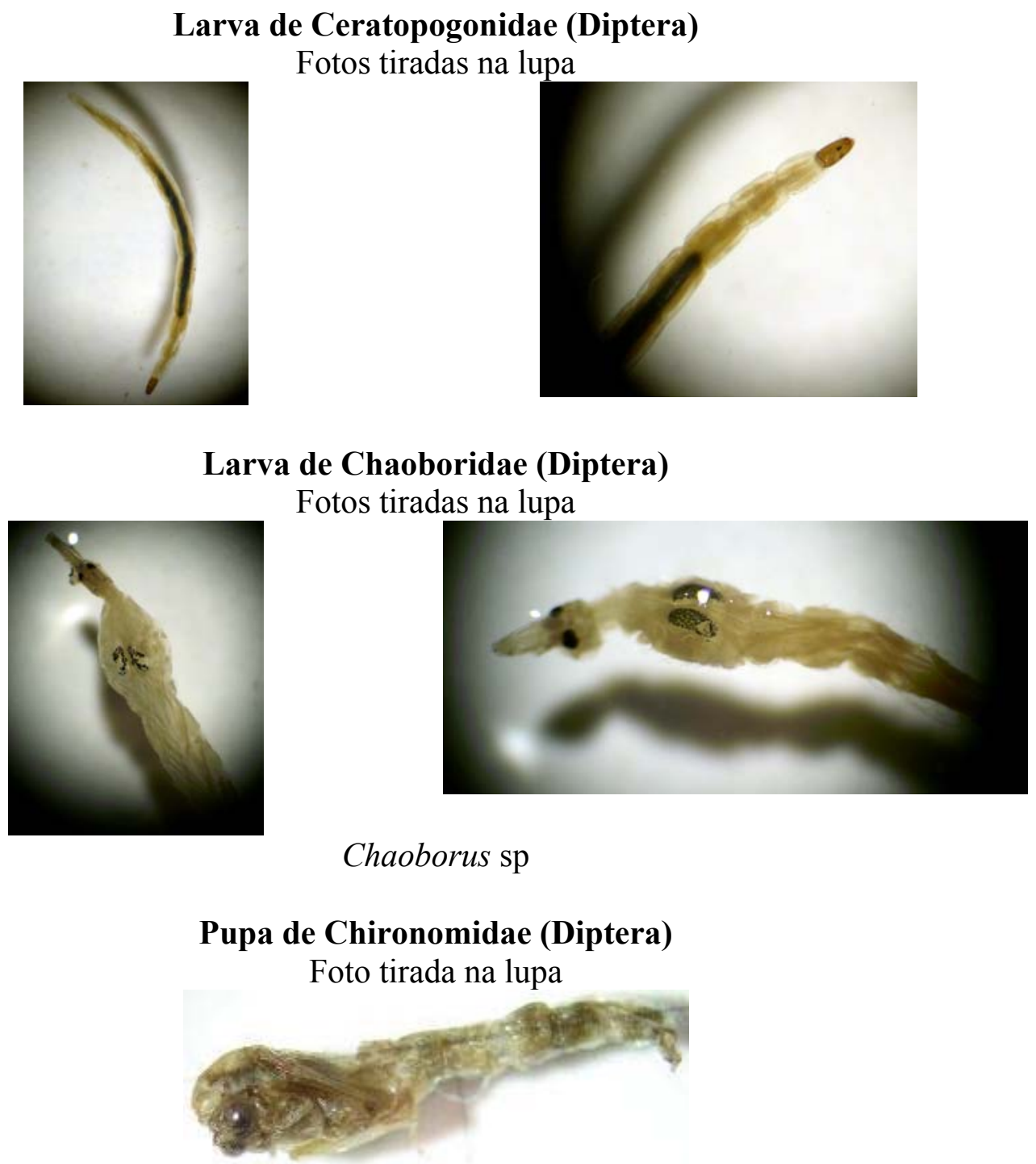

Odonata

Fotografias tiradas na lupa

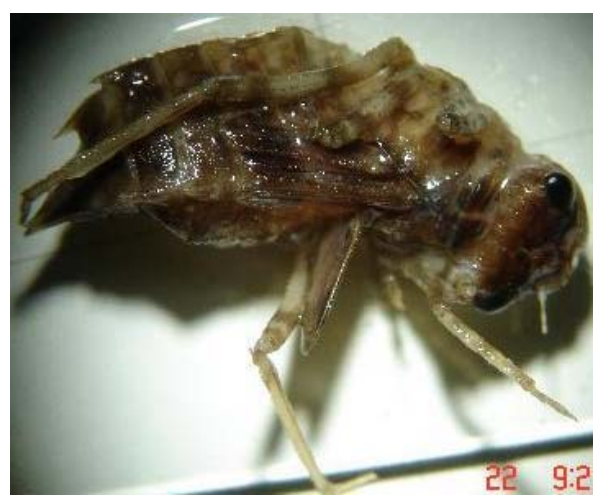

Libellulidae

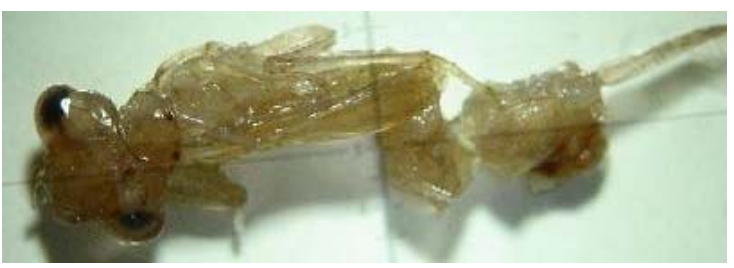

Coenagrionidae 


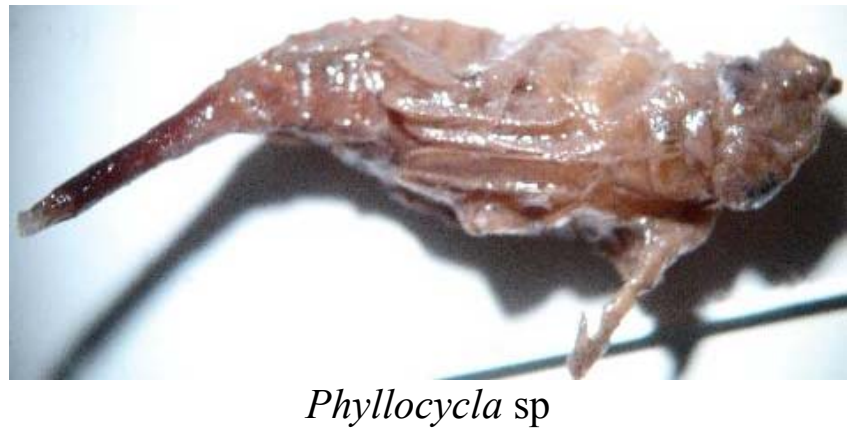

\section{Ephemeroptera}

Fotografias tiradas na lupa

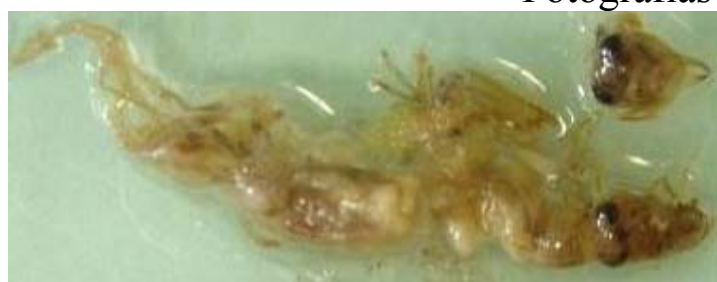

Campsurinae

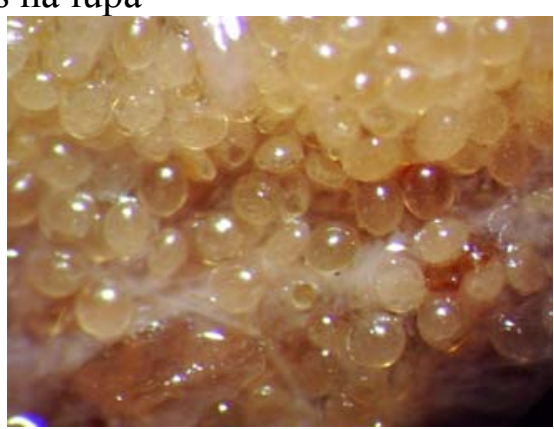

Massa de ovos

Trichoptera

Fotografias tiradas na lupa
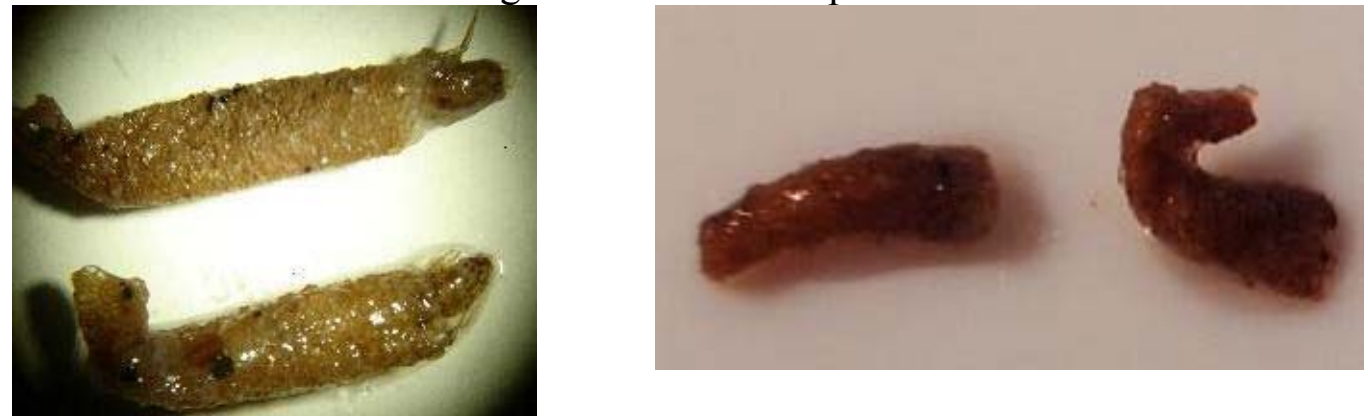

Hemiptera

Foto tirada na lupa

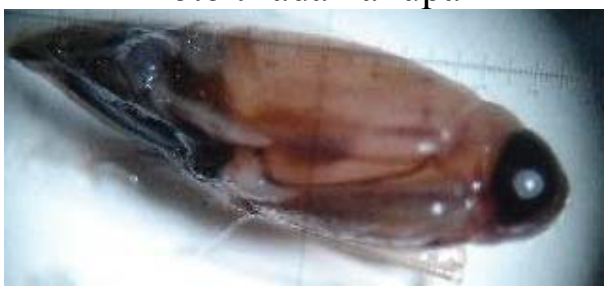

Notonectidae 


\section{Crustacea}

Foto tirada na lupa

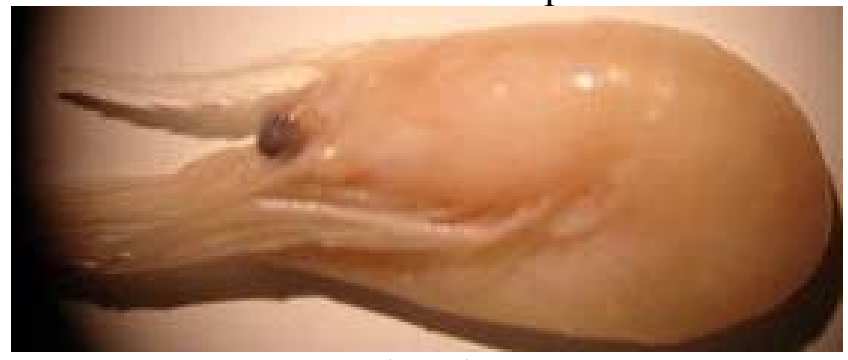

Macrobrachium sp

\section{Hirudinea}

Foto tirada na lupa

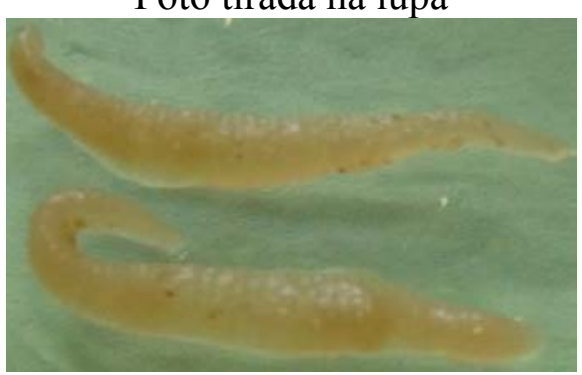

Mollusca (Gastropoda)

Fotografias tiradas na lupa

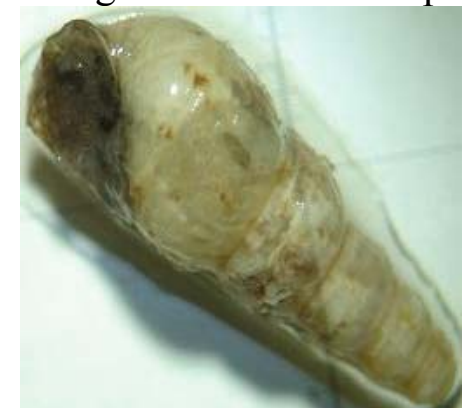

Melanoides tuberculata

Material vegetal

Foto tirada com a câmera digital

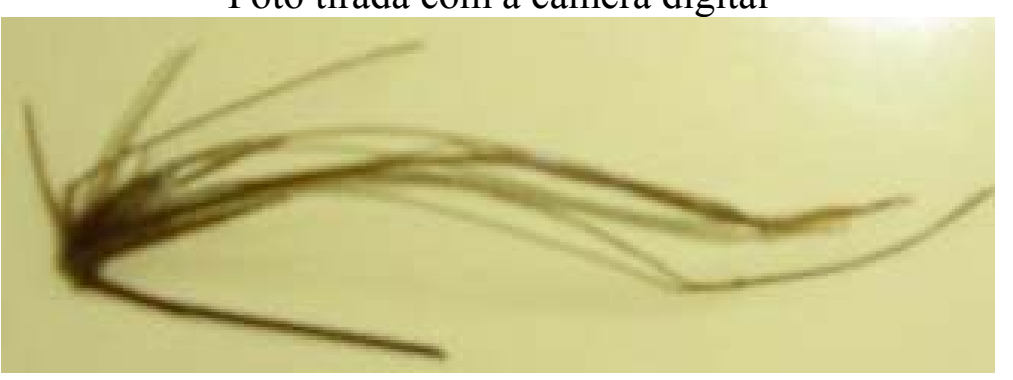




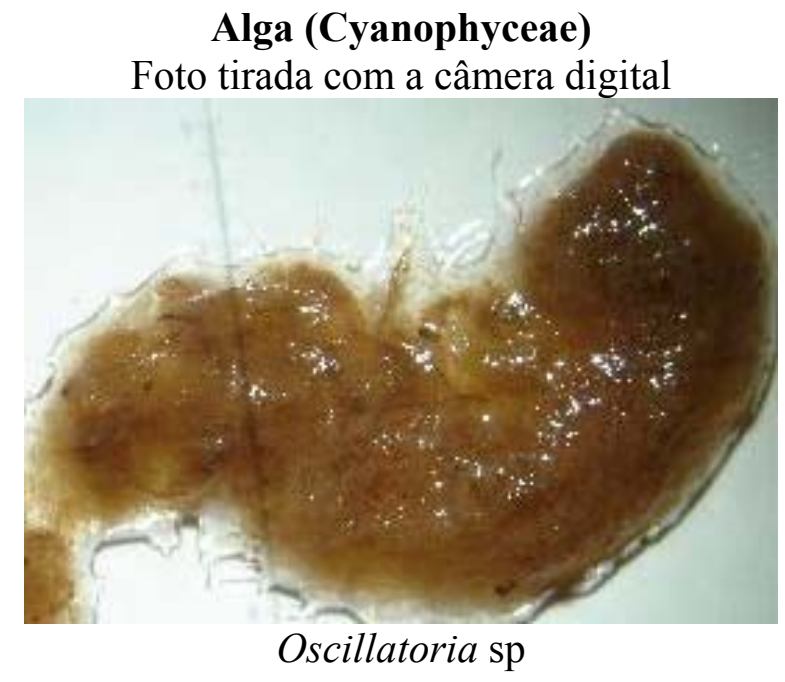

\section{Characiformes}

Fotos tirada na câmera digital

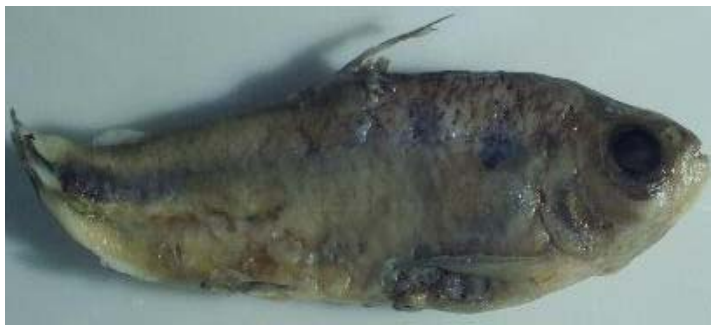

Astyanax sp

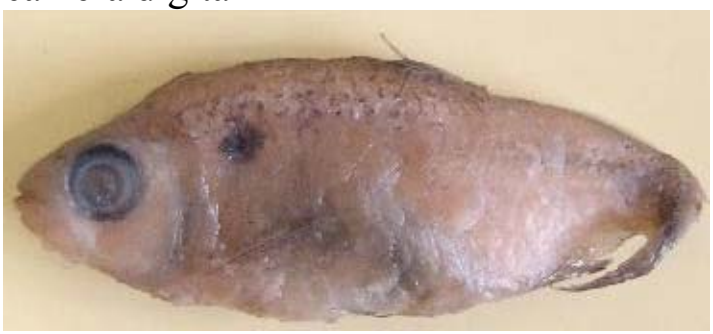

Characidae

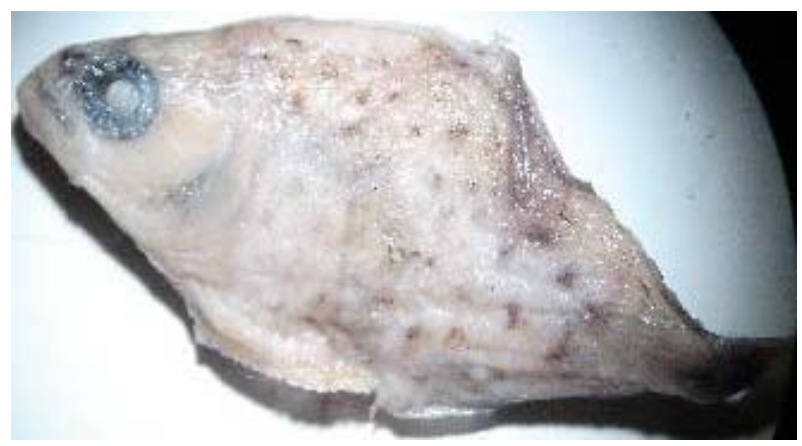

Serrasalmus spilopleura

Perciformes

Scianidae

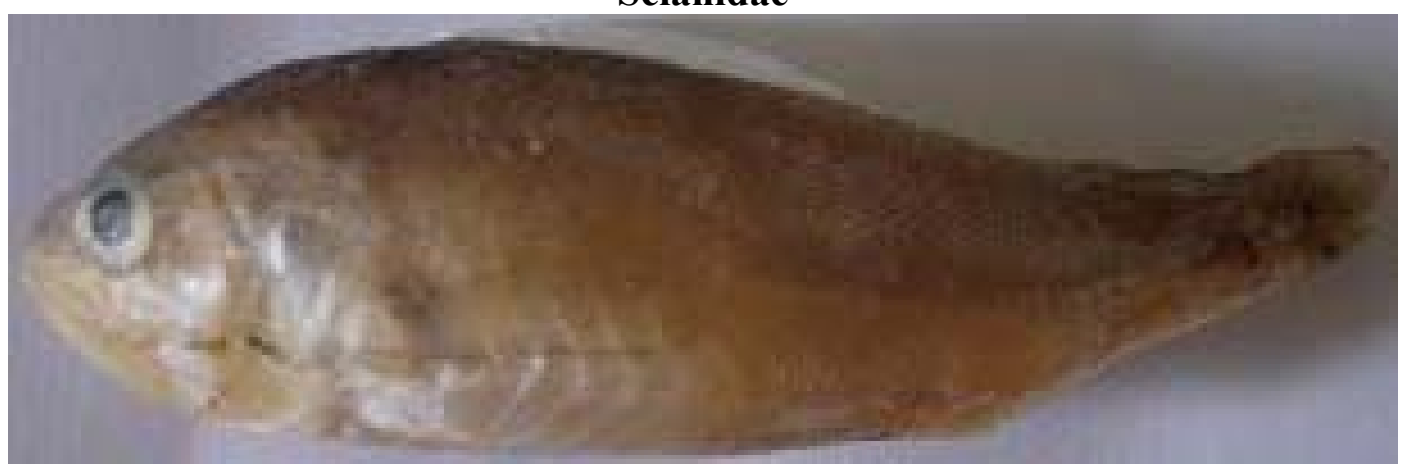

Plagioscion squamossisimus 


\section{Cichlidae}

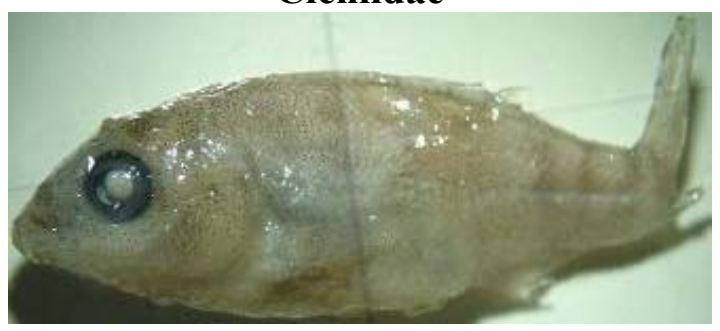

Siluriformes

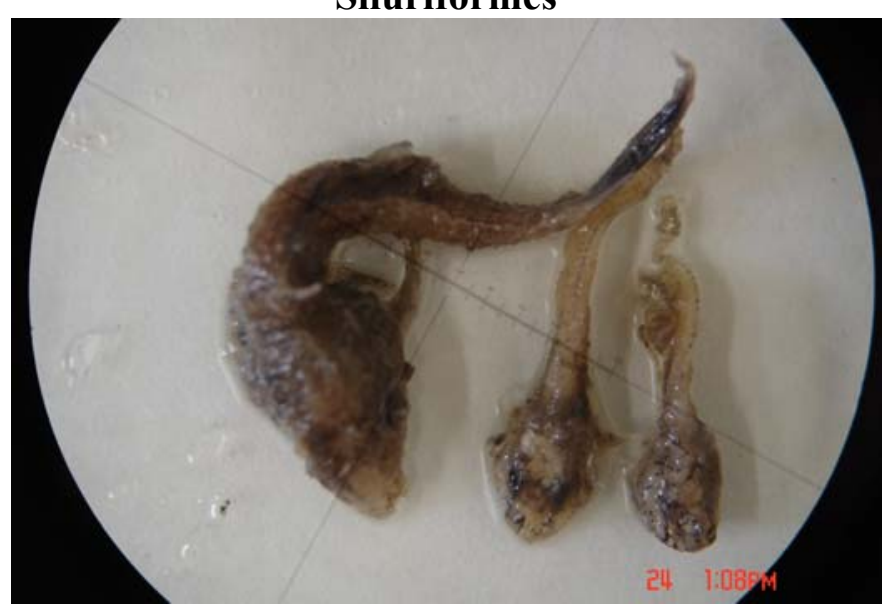

Peixes (não identificado)
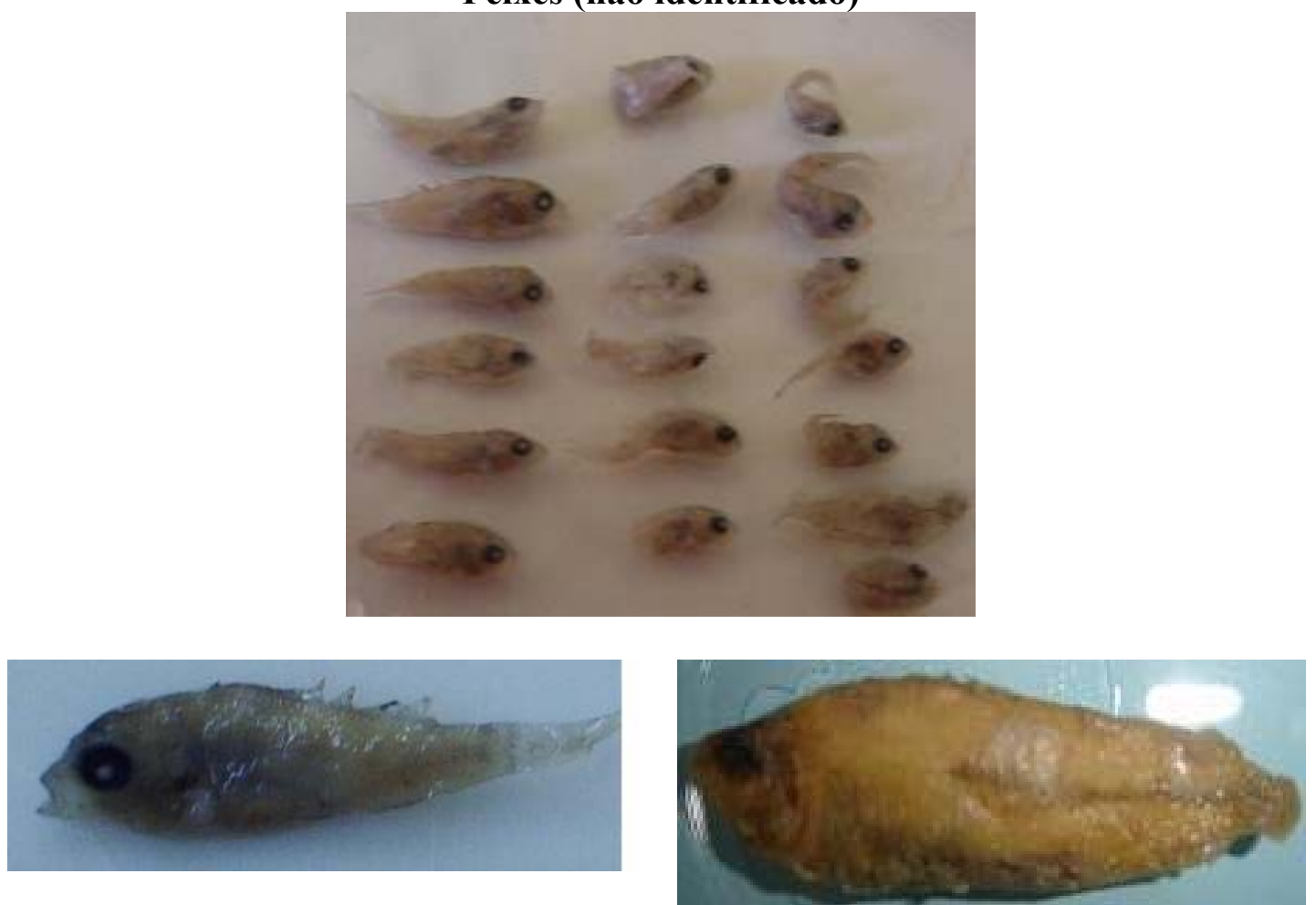


\section{ANEXO E - Fotos}

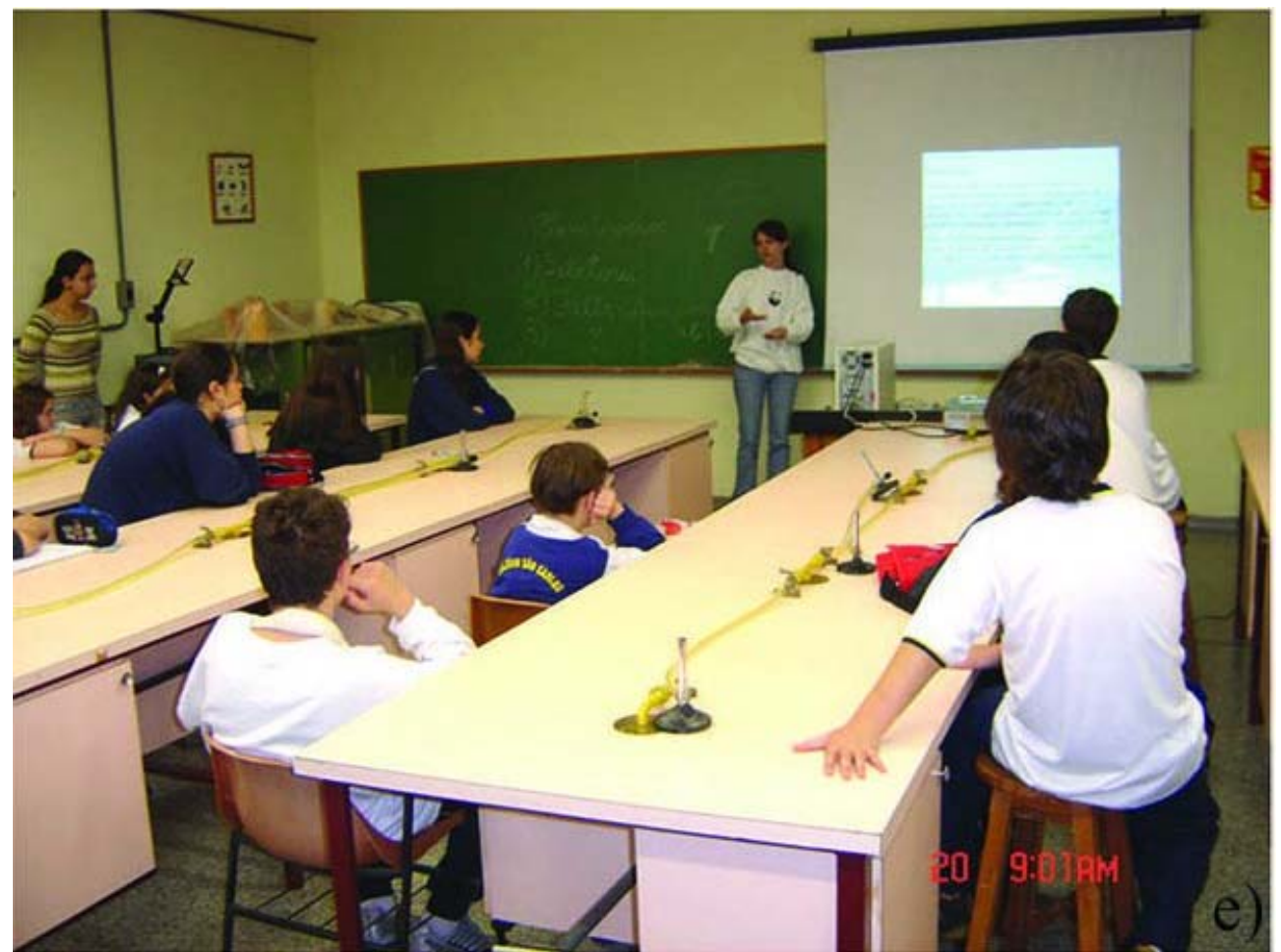

FIGURA A: aula para alunos do ensino fundamental sobre a introdução de peixes.

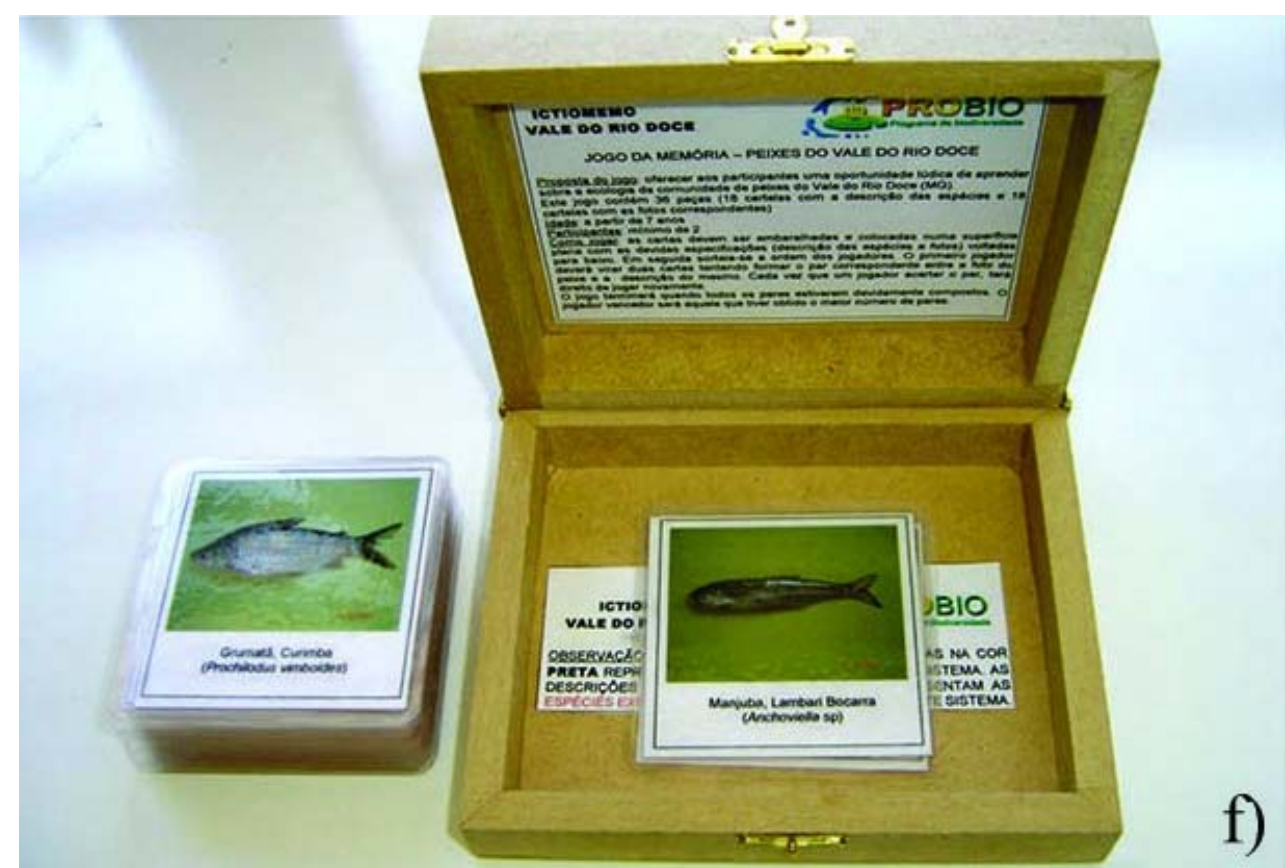

FIGURA B: jogo da memória "Ictiomemo" sobre as espécies de peixes nativas e invasoras, do sistema do médio e baixo rio Tietê, elaborado durante o projeto PROBIO 2. 


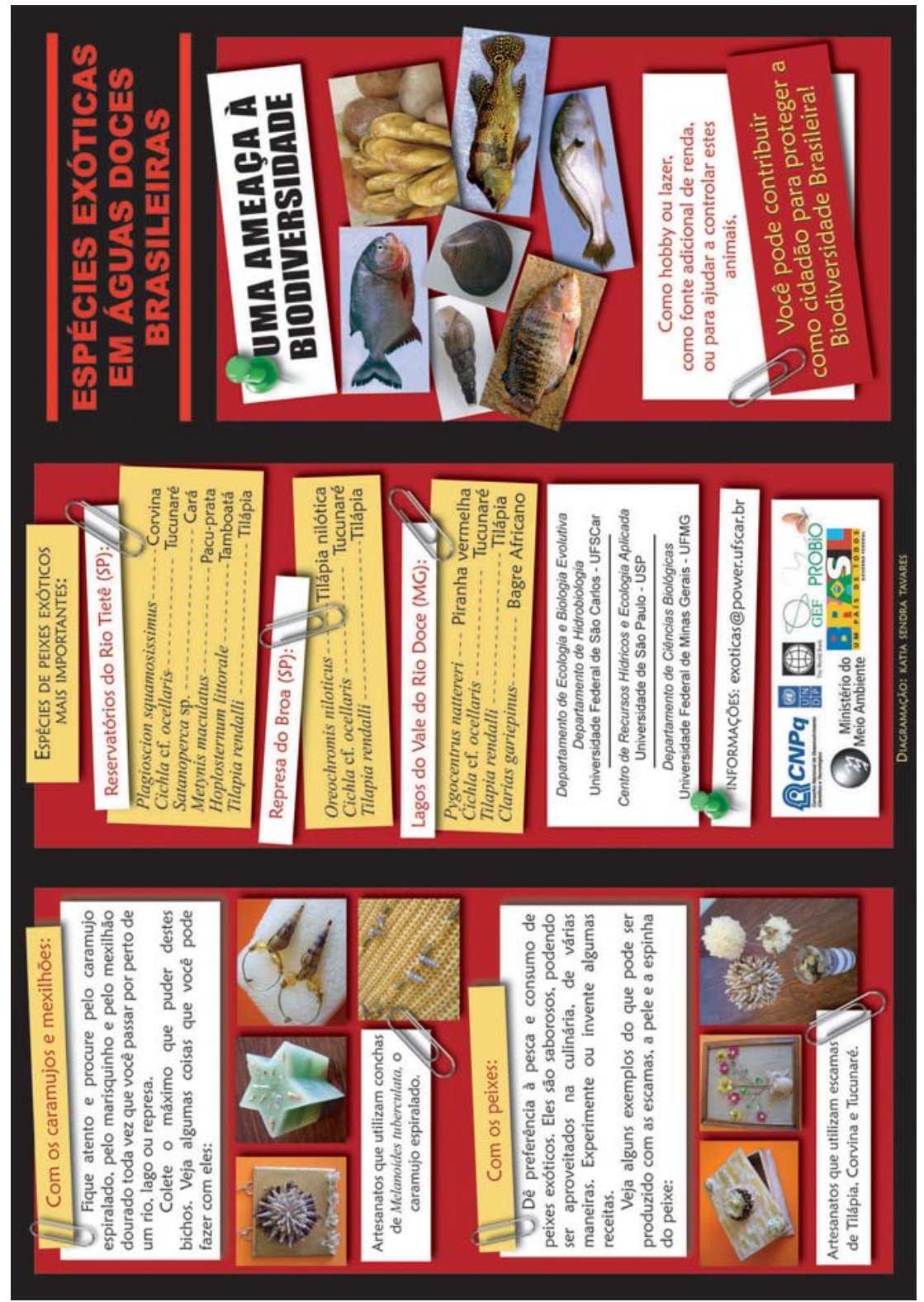

FIGURA C: Folder elaborado durante o projeto sobre as espécies de peixes e moluscos invasores (frente). 


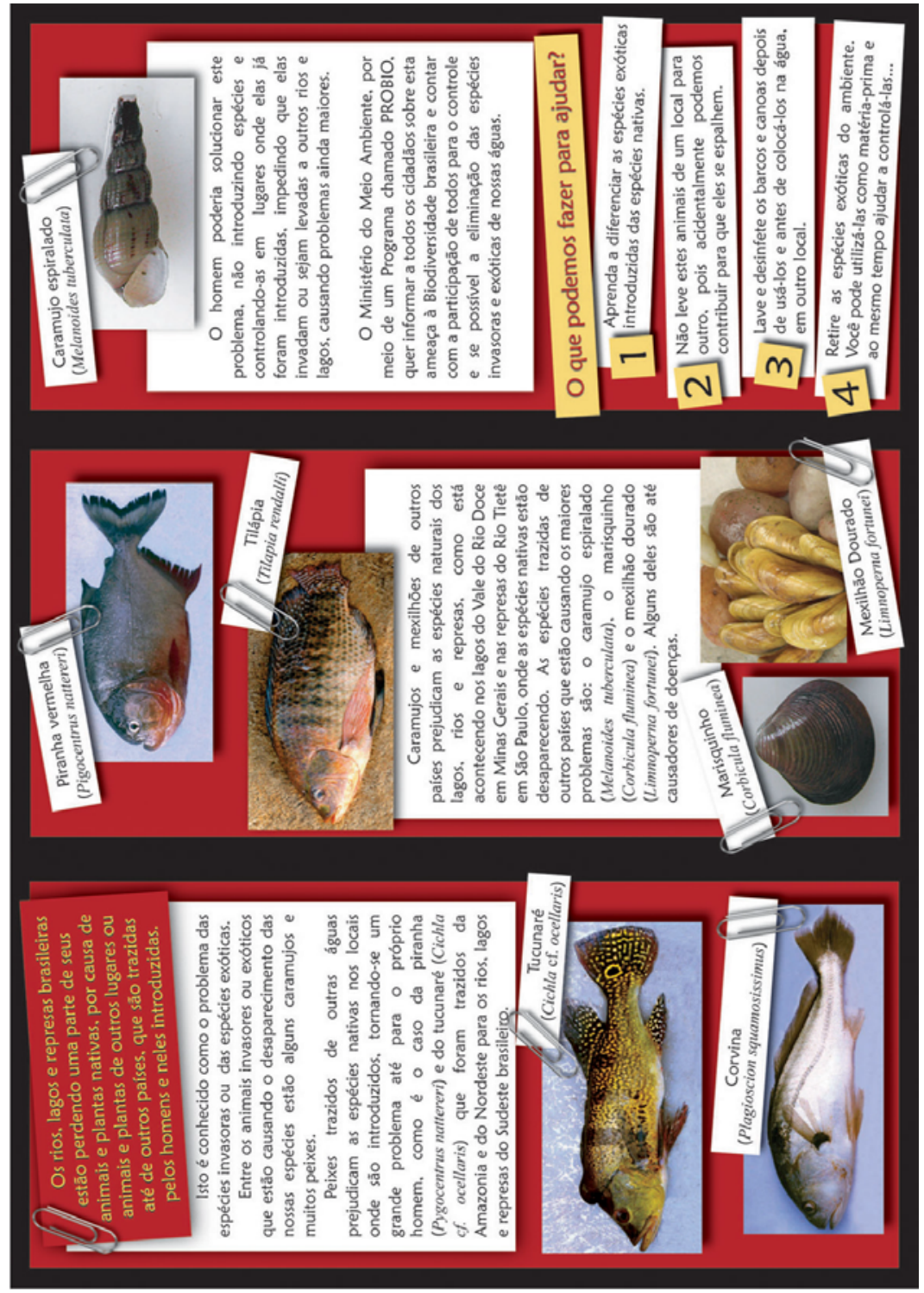

FIGURA D: Folder elaborado durante o projeto sobre as espécies de peixes e moluscos invasores (verso). 